Cochrane Database of Systematic Reviews

\title{
Constraint-induced movement therapy for upper extremities in people with stroke (Review)
}

Corbetta D, Sirtori V, Castellini G, Moja L, Gatti R

Corbetta D, Sirtori V, Castellini G, Moja L, Gatti R.

Constraint-induced movement therapy for upper extremities in people with stroke.

Cochrane Database of Systematic Reviews 2015, Issue 10. Art. No.: CD004433.

DOI: 10.1002/14651858.CD004433.pub3.

www.cochranelibrary.com 
TABLE OF CONTENTS

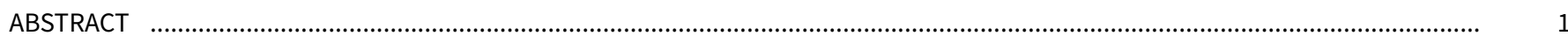

PLAIN LANGUAGE SUMMARY

SUMMARY OF FINDINGS

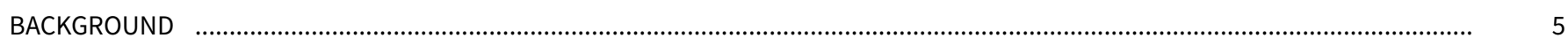

OBJECTIVES

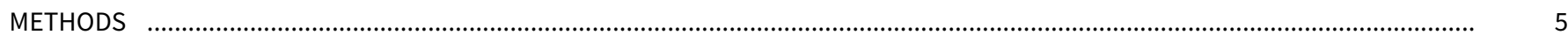

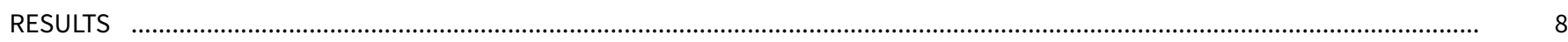

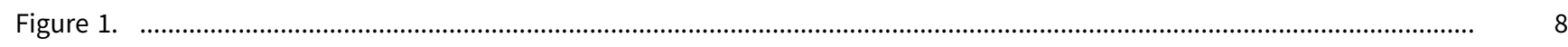

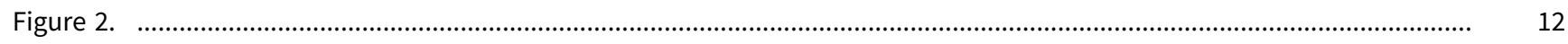

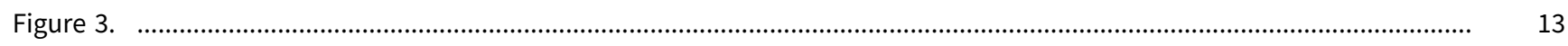

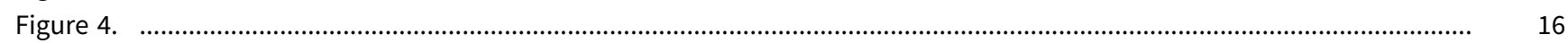

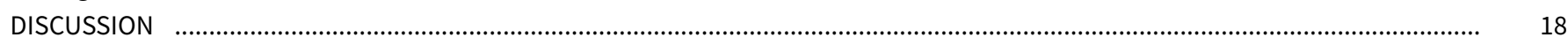

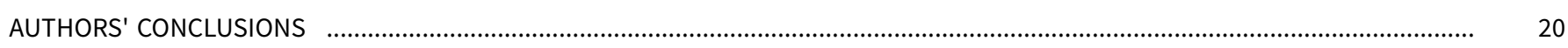

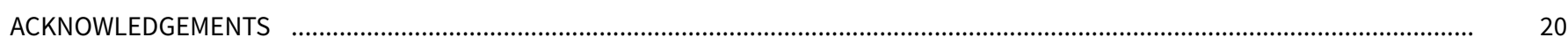

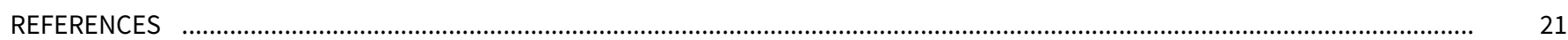

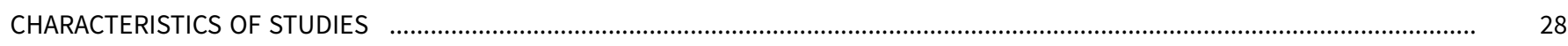

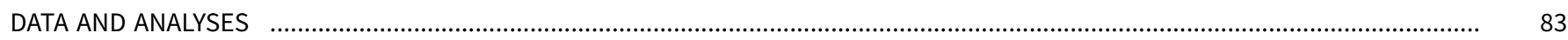

Analysis 1.1. Comparison 1 Constraint versus control: primary outcome, Outcome 1 Disability postintervention. $\quad$.................... 83

Analysis 1.2. Comparison 1 Constraint versus control: primary outcome, Outcome 2 Disability: 3 to 6-month follow-up. ......... 84

Analysis 2.1. Comparison 2 Constraint versus control: subgroup analysis on primary outcome, Outcome 1 Amount of task 84 practice.

Analysis 2.2. Comparison 2 Constraint versus control: subgroup analysis on primary outcome, Outcome 2 Anatomical region restraint.

Analysis 2.3. Comparison 2 Constraint versus control: subgroup analysis on primary outcome, Outcome 3 Time since stroke. .. Analysis 3.1. Comparison 3 Constraint versus control: secondary outcomes, Outcome 1 Arm Motor Function. ........................ Analysis 3.2. Comparison 3 Constraint versus control: secondary outcomes, Outcome 2 Perceived Arm Motor Function (Quality of Use).

Analysis 3.3. Comparison 3 Constraint versus control: secondary outcomes, Outcome 3 Perceived Arm Motor Function (Amount of Use).

Analysis 3.4. Comparison 3 Constraint versus control: secondary outcomes, Outcome 4 Arm Motor Impairment. ...................... 90

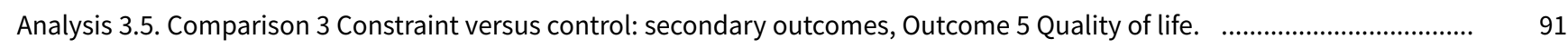

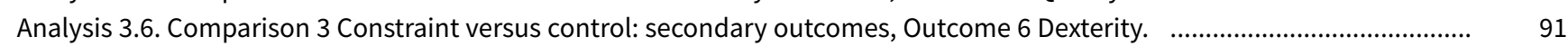
ADDITIONAL TABLES

APPENDICES

FEEDBACK

WHAT'S NEW

HISTORY

CONTRIBUTIONS OF AUTHORS 
[Intervention Review]

\section{Constraint-induced movement therapy for upper extremities in people with stroke}

Davide Corbetta $^{1}$, Valeria Sirtori ${ }^{1}$, Greta Castellini ${ }^{2}$, Lorenzo Moja2,3, Roberto Gatti ${ }^{4}$

1Unit of Functional Recovery, San Raffaele Hospital, Milan, Italy. 2Unit of Clinical Epidemiology, IRCCS Galeazzi Orthopaedic Institute, Milan, Italy. ${ }^{3}$ Department of Biomedical Sciences for Health, University of Milan, Milan, Italy. ${ }^{4}$ School of Physiotherapy, University VitaSalute San Raffaele, Milan, Italy

Contact: Valeria Sirtori, Unit of Functional Recovery, San Raffaele Hospital, Via Olgettina, 48, Milan, 20132, Italy. sirtori.valeria@hsr.it.

Editorial group: Cochrane Stroke Group.

Publication status and date: Edited (no change to conclusions), comment added to review, published in Issue 9, 2017.

Citation: Corbetta D, Sirtori V, Castellini G, Moja L, Gatti R. Constraint-induced movement therapy for upper extremities in people with stroke. Cochrane Database of Systematic Reviews 2015, Issue 10. Art. No.: CD004433. DOI: 10.1002/14651858.CD004433.pub3.

Copyright @ 2017 The Cochrane Collaboration. Published by John Wiley \& Sons, Ltd.

\section{A B S T R A C T}

\section{Background}

In people who have had a stroke, upper limb paresis affects many activities of daily life. Reducing disability is therefore a major aim of rehabilitative interventions. Despite preserving or recovering movement ability after stroke, sometimes people do not fully realise this ability in their everyday activities. Constraint-induced movement therapy (CIMT) is an approach to stroke rehabilitation that involves the forced use and massed practice of the affected arm by restraining the unaffected arm. This has been proposed as a useful tool for recovering abilities in everyday activities.

\section{Objectives}

To assess the efficacy of CIMT, modified CIMT (mCIMT), or forced use (FU) for arm management in people with hemiparesis after stroke.

\section{Search methods}

We searched the Cochrane Stroke Group trials register (last searched June 2015), the Cochrane Central Register of Controlled Trials (CENTRAL; The Cochrane Library Issue 1, 2015), MEDLINE (1966 to January 2015), EMBASE (1980 to January 2015), CINAHL (1982 to January 2015), and the Physiotherapy Evidence Database (PEDro; January 2015).

\section{Selection criteria}

Randomised control trials (RCTs) and quasi-RCTs comparing CIMT, mCIMT or FU with other rehabilitative techniques, or none.

\section{Data collection and analysis}

One author identified trials from the results of the electronic searches according to the inclusion and exclusion criteria, three review authors independently assessed methodological quality and risk of bias, and extracted data. The primary outcome was disability.

\section{Main results}

We included 42 studies involving 1453 participants. The trials included participants who had some residual motor power of the paretic arm, the potential for further motor recovery and with limited pain or spasticity, but tended to use the limb little, if at all. The majority of studies were underpowered (median number of included participants was 29) and we cannot rule out small-trial bias. Eleven trials (344 participants) assessed disability immediately after the intervention, indicating a non-significant standard mean difference (SMD) 0.24 (95\% confidence interval ( $\mathrm{Cl})-0.05$ to 0.52 ) favouring $\mathrm{CIMT}$ compared with conventional treatment. For the most frequently reported outcome, arm motor function (28 studies involving 858 participants), the SMD was 0.34 ( $95 \% \mathrm{Cl} 0.12$ to 0.55 ) showing a significant effect ( $P$ value 
0.004) in favour of CIMT. Three studies involving 125 participants explored disability after a few months of follow-up and found no significant difference, SMD $-0.20(95 \% \mathrm{Cl}-0.57$ to 0.16$)$ in favour of conventional treatment.

\section{Authors' conclusions}

CIMT is a multi-faceted intervention where restriction of the less affected limb is accompanied by increased exercise tailored to the person's capacity. We found that CIMT was associated with limited improvements in motor impairment and motor function, but that these benefits did not convincingly reduce disability. This differs from the result of our previous meta-analysis where there was a suggestion that CIMT might be superior to traditional rehabilitation. Information about the long-term effects of CIMT is scarce. Further trials studying the relationship between participant characteristics and improved outcomes are required.

\section{PLAIN LANGUAGE SUMMARY}

\section{Constraint-induced movement therapy for upper limb (arm) recovery after stroke}

\section{Review question}

We wanted to assess the effects of constraint-induced movement therapy (CIMT) on ability to manage daily activities and on the recovery of movement in paralysed arms after a stroke.

\section{Background}

After a stroke, people can suffer from paralysis of an arm, and, even if some movement control remains, use it less than the unaffected arm. The paralysis makes arm movements, such as reaching, grasping, and manipulating objects difficult. In turn, this causes many difficulties in activities of daily life, such as bathing, dressing, eating and using the toilet. During CIMT the unaffected arm is restrained so it cannot be used, which means the affected arm has to be used instead. The unaffected arm and hand are prevented from moving with a glove or a special arm rest. CIMT is supposed to be a useful tool for recovering the ability to perform everyday activities.

\section{Study characteristics}

We, a team of Cochrane researchers, searched widely through the medical literature and identified 42 relevant studies involving 1453 participants. The evidence is current to January 2015. The participants in these studies had some control of their affected arm and were generally able to open their affected hand by extending the wrist and fingers. CIMT treatments varied between studies in terms of the time for which the participants' unaffected arm was constrained each day, and the amount of active exercise that the affected arm was required to do. CIMT was compared mainly to active physiotherapy treatments, and sometimes to no treatment.

\section{Key results}

The 42 studies assessed different aspects of recovery from stroke, and not all measured the same things. Eleven studies (with 344 participants) assessed the effect of CIMT on disability (the effective use of the arm in daily living) and found that the use of CIMT did not lead to improvement in ability to manage everyday activities such as bathing, dressing, eating, and toileting. Twenty-eight trials (with 858 participants) tested whether CIMT improved the ability to use the affected arm. CIMT appeared to be more effective at improving arm movement than active physiotherapy treatments or no treatment.

\section{Quality of the evidence}

The quality of the evidence for each outcome is limited due to small numbers of study participants and poor reporting of study details. We considered the quality of the evidence to be low for disability and very low for the ability to use the affected arm. 


\begin{tabular}{|c|c|c|c|c|c|}
\hline \multicolumn{6}{|c|}{$\begin{array}{l}\text { S UM M A RY O F FIN DING S } \\
\text { Summary of findings for the main comparison. }\end{array}$} \\
\hline \multicolumn{6}{|c|}{$\begin{array}{l}\text { Constraint-induced movement therapy (CIMT) or modified CIMT (MCIMT) or Forced Use (FU) compared with usual care or no treatment for the recovery of affected } \\
\text { upper limb in people with stroke }\end{array}$} \\
\hline \multicolumn{6}{|c|}{$\begin{array}{l}\text { Patient or population: people with stroke receiving upper limb rehabilitation } \\
\text { Settings: inpatient and outpatients } \\
\text { Intervention: CIMT or mCIMT or FU } \\
\text { Comparison: usual care or no treatment }\end{array}$} \\
\hline \multirow[t]{3}{*}{ Outcomes } & \multicolumn{2}{|c|}{ Illustrative comparative risks* $(95 \% \mathrm{Cl})$} & \multirow{3}{*}{$\begin{array}{l}\text { Relative effect } \\
(95 \% \mathrm{Cl})\end{array}$} & \multirow{3}{*}{$\begin{array}{l}\text { No of participants } \\
\text { (studies) }\end{array}$} & \multirow[t]{3}{*}{ Comments } \\
\hline & Assumed risk & Corresponding risk & & & \\
\hline & $\begin{array}{l}\text { Usual care or no } \\
\text { treatment }\end{array}$ & CIMT or mCIMT or FU & & & \\
\hline $\begin{array}{l}\text { Disability } \\
\text { different scales assessing disabil- } \\
\text { ity or dependence in activities of } \\
\text { daily living }\end{array}$ & & $\begin{array}{l}\text { The mean disability in the interven- } \\
\text { tion groups was } \\
\mathbf{0 . 2 4} \text { standard deviations higher } \\
\text { (-0.05 lower to } 0.52 \text { higher) }\end{array}$ & & $\begin{array}{l}344 \\
\text { (11 studies) }\end{array}$ & $\begin{array}{l}\text { A standard deviation of } \\
0.24 \text { represents a small } \\
\text { difference between the } \\
\text { groups } \\
\text { The estimated effect is } \\
\text { non significant because its } \\
95 \% \text { interval confidence } \\
\text { includes the null effect }\end{array}$ \\
\hline $\begin{array}{l}\text { Arm Motor Function } \\
\text { different scales assessing motor } \\
\text { ability and functioning of upper } \\
\text { extremity in functional tasks } \\
\text { Follow-up: at the end of treat- } \\
\text { ment }\end{array}$ & & $\begin{array}{l}\text { The mean arm motor function in the } \\
\text { intervention groups was } \\
\mathbf{0 . 3 4} \text { standard deviations higher } \\
\text { ( } 0.12 \text { to } 0.55 \text { higher) }\end{array}$ & & $\begin{array}{l}858 \\
\text { (28 studies) }\end{array}$ & $\begin{array}{l}\text { A standard deviation of } \\
0.34 \text { represents a small } \\
\text { difference between the } \\
\text { groups }\end{array}$ \\
\hline $\begin{array}{l}\text { Perceived Arm Motor Function } \\
\text { (Quality of Use) } \\
\text { Motor Activity Log scale. } \\
\text { Follow-up: at the end of treat- } \\
\text { ment }\end{array}$ & $\begin{array}{l}\text { The mean per- } \\
\text { ceived arm motor } \\
\text { function (quality of } \\
\text { use) ranged across } \\
\text { control groups } \\
\text { from } \mathbf{0 . 1 4} \text { to } \mathbf{1 . 4} \\
\text { points }\end{array}$ & $\begin{array}{l}\text { The mean perceived arm motor } \\
\text { function (quality of use) in the inter- } \\
\text { vention groups was } \\
\mathbf{0 . 6 8} \text { higher } \\
\text { ( } 0.47 \text { to } 0.88 \text { higher) }\end{array}$ & & $\begin{array}{l}891 \\
\text { (24 studies) }\end{array}$ & $\begin{array}{l}\text { The minimal clinically im- } \\
\text { portant difference for this } \\
\text { scale assessing the quali- } \\
\text { ty of use is } 1 \text { or } 1.1 \text { points } \\
\text { depending on the domi- } \\
\text { nance of the affected arm } \\
\text { (Lang 2008). }\end{array}$ \\
\hline
\end{tabular}




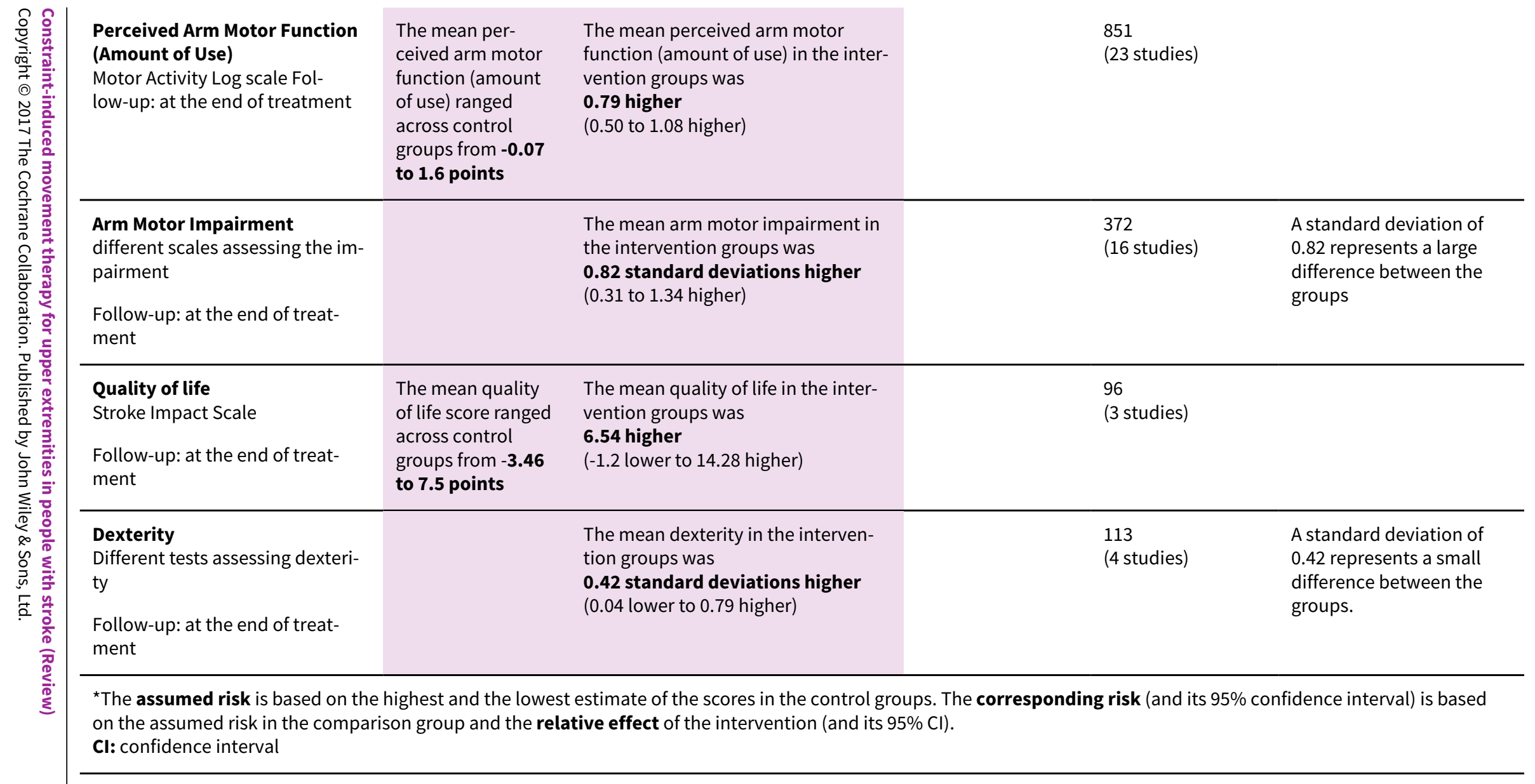




\section{B A C K G R O U N D}

\section{Description of the condition}

Stroke is a health concern worldwide and one of the main causes of disability (Albert 2012; WHO 2011). In Europe, stroke costs around EUR 64.1 billion, and in the United Kingdom around GBP 8.9 billion per annum is spent on community care and rehabilitation of people after stroke (Gustavsson 2010; Saka 2009). In fact, only $12 \%$ of people that experience a stroke are independent in basic activities of daily living (ADL) one week after stroke onset (Wade 1987); in the long-term, up to $74 \%$ of them have to rely on assistance for basic ADLs like feeding, self-care, and mobility (Miller 2010).

\section{Description of the intervention}

To restore independence to stroke survivors and reduce the cost of therapy and care, a number of approaches are now being investigated in an attempt to increase the effectiveness of stroke rehabilitation techniques for the recovery of the upper extremity (Pollock 2014). The management of upper extremity in people with stroke can involve a number of different treatments, which include: bilateral arm training (McCombe Waller 2008), biofeedback (Crow 1989; Moreland 1994; Rathkolb 1990; Sathian 2000), brain stimulation (Dayan 2013; Kagan 2012), electrical stimulation/ functional electrical stimulation (Pomeroy 2006), mental practice (Page 2005a; Page 2007a), mirror therapy (Michielsen 2010), robot assistance (Hesse 2003; Lum 2002; Masiero 2007; Mehrholz 2012), repetitive task training (French 2007), virtual reality (Laver 2011), and constraint-induced movement therapy (CIMT; Miltner 1999; Page 2001; Page 2002a; Taub 1993; Taub 1994; Taub 1999).

CIMT, as described by the first authors (Miltner 1999; Taub 1994; Taub 1999), is based on two fundamental principles.

- Forced use of the affected arm by restraining the unaffected arm, with a sling or a hand splint, during dedicated exercise sections or usual ADLs ( $90 \%$ of waking hours).

- Massed practice (several hours of exercise) of the affected arm through a shaping method, where shaping involves a commonly operant conditioning method in which a behavioural objective (in this case 'movement') is approached in small steps of progressively increasing difficulty. The participant is rewarded with enthusiastic approval for improvement, but never blamed or punished for failure.

The initial report of the use of CIMT proposed extensive and intensive training (six to eight hours per day; Miltner 1999; Taub 1994; Taub 1999); over the years, though, others have developed different forms of constraint therapy, reducing the training during the period of restraint (Page 2001; Page 2002a; Page 2002b), or concentrating only on the use of restraint (forced use), with no additional treatment of the affected arm (Burns 2007; Ploughman 2004).

\section{How the intervention might work}

The rationale for CIMT is based on the theory of 'learning nonuse' from experiments on monkeys. Researchers observed that after upper limb de-afferentation (interruption of nerves), monkeys did not use their affected limb even though their motor ability was nearly normal (Knapp 1963; Taub 1977; Taub 1980). This 'nonuse' was an acquired behaviour learned during the spinal shock period and, as a consequence of its origin, could be reversed by behavioural measures such as, for example, constraint of the sound limb. Thus the learned 'non-use' theory predicts that people after stroke have, in fact, greater movement ability than they show in their everyday tasks. If this is correct, constraint of the unaffected arm would be a useful tool for realising this ability in everyday activities (Sterr 2006).

\section{Why it is important to do this review}

Over recent years, the neuroplasticity and cortical reorganisation of the central nervous system (CNS) has been observed and described in trials with people after stroke undergoing CIMT (Kim 2004; Levy 2001; Liepert 2000; Liepert 2001; Lin 2010; Ro 2006; Schaechter 2002; Szaflarski 2006). The preliminary findings suggest that the functional improvements produced by CIMT are accompanied by plastic brain reorganisation associating noticeable brain changes with functional improvements related to CIMT. Our initial review published in 2008 identified 19 studies, now several new studies have been published and an update of our review was necessary in order to define better the effect of constraining therapies on stroke recovery.

\section{O B JECTIVES}

To assess the efficacy of CIMT, modified CIMT (mCIMT), or forced use (FU) for arm management in people with hemiparesis after stroke.

\section{METHODS}

\section{Criteria for considering studies for this review}

\section{Types of studies}

Randomised controlled trials (RCTs) and quasi-RCTs comparing CIMT or mCIMT or FU with other rehabilitative techniques (occupational therapy or physiotherapy), or none.

\section{Types of participants}

We examined trials of adults (aged over 18 years) with a clinical diagnosis of stroke, either ischaemic or haemorrhagic (World Health Organization (WHO) definition; Hatano 1976), with paresis of an arm.

\section{Types of interventions}

The studies included all used CIMT or mCIMT or FU for the treatment of the affected upper limb compared with other rehabilitative techniques (occupational therapy or physiotherapy) or none.

For the purpose of this review we used the following definitions (as described in Hoare 2007):

- CIMT: restraint of the unaffected upper limb, with more than three hours per day of therapy;

- mCIMT: restraint of the unaffected upper limb, with three hours or less per day of therapy;

- FU: restraint of the unaffected upper limb but no specific treatment of the affected upper limb.

We considered all interventions, irrespective of:

- number of hours of training per day;

- number of hours of restraint per day;

- duration of treatment; 
- type of exercise used in training sessions.

\section{Types of outcome measures}

If a study presented more than one measure for the same outcome category, we included the measure most frequently used across studies in the analysis.

\section{Primary outcomes}

\section{Disability}

Functional Independence Measure (FIM), Barthel Index (BI).

\section{Secondary outcomes}

\section{Arm motor function}

Wolf Motor Function Test (only score; WFMT), Arm Research Arm Test (ARAT), Arm Motor Ability Test (AMAT), Emory Function Test (EMF), Assessment of motor and process skills (AMPS)

\section{Perceived arm motor function}

Motor Activity Log (MAL): Amount of Use (AoU) and Quality of Use (QoU).

\section{Arm motor impairment}

Fugl Meyer Assessment (FMA), Chedoke McMaster Impairment Inventory (CMII), hand strength.

\section{Quality of life}

Stoke Impact Scale (SIS).

\section{Dexterity*}

Nine-Hole Peg Test (9HPT), Sixteen-Hole Peg Test (16HPT), Grooved Pegboard Test (GPT).

* a low score in scales assessing this item indicates a positive outcome and indicates a better performance.

\section{Search methods for identification of studies}

See the 'Specialized register' section in the Cochrane Stroke Group module. We searched for trials in all languages and arranged translation of relevant papers where necessary.

\section{Electronic searches}

We searched the Cochrane Stroke Group Trials Register (last searched June 2015), the Cochrane Central Register of Controlled Trials (CENTRAL; The Cochrane Library 2015, Issue 1; Appendix 1), MEDLINE Ovid (1966 to January 2015; Appendix 2), EMBASE Ovid (1980 to January 2015; Appendix 3), CINAHL Ebsco (1982 to January 2015; Appendix 4), AMED Ovid (1985 to January 2015; Appendix 5), and in January 2015 the Physiotherapy Evidence Database (PEDro; http://ptwww.cchs.usyd.edu.au/pedro/; Appendix 6).

In addition, we searched the following trials registries:

- National Institute of Health Clinical Trials Database (http:// www.clinicaltrials.gov; 1 June 2015);

- Stroke Trials Registry (www.strokecenter.org/trials/; 1 June 2015).

\section{Searching other resources}

We also searched the reference lists of relevant papers.

\section{Data collection and analysis}

\section{Selection of studies}

One review author (DC) read the titles of identified references and eliminated obviously irrelevant studies. We obtained abstracts for the remaining studies and then, on the basis of the inclusion criteria, two review authors (DC and VS) independently ranked these as 'relevant', 'irrelevant' or 'unsure'. We retrieved and reviewed the full text articles for those ranked as relevant and those ranked as unsure. We resolved disagreements by consensus, and consulted a third review author (RG) if disagreements persisted.

We have documented the reasons for the exclusion of studies in Characteristics of excluded studies. When studies published in nonEnglish languages appeared relevant, we retrieved the full text and asked a native speaker to translate it in order to ascertain whether the study met the inclusion criteria.

\section{Data extraction and management}

Four review authors (DC, VS, GC and RG) independently extracted data. We recorded all data on a standardised checklist, incorporating: methods (e.g. randomisation, blinding, completeness of follow-up, reliability and validity of scales), details of participants (e.g. age, sex, time since stroke, side affected), interventions, inclusion and exclusion criteria, and all assessed outcomes. We resolved disagreements by consensus. In some cases we contacted study authors by email for clarification. When not clearly reported or imputable, we extracted numeric data from graphs through the use of Engauge Software 5.1.

\section{Assessment of risk of bias in included studies}

We assessed the risk of bias in the included studies using the criteria in the Cochrane Handbook for Systematic Reviews of Interventions (Higgins 2011).

\section{Methods of randomisation}

We regarded a randomisation method as appropriate if it meant that each study participant had the same chance of receiving each intervention. We considered the following methods of allocation appropriate: using random number tables, a computer random number generator, coin tossing, or card shuffling.

\section{Allocation concealment (when the investigators cannot predict which treatment comes next)}

We scored this as:

- low risk of bias - when the method of allocation was clearly described (e.g. central randomisation, serially numbered opaque, sealed envelopes);

- unclear risk of bias - when the authors did not report any allocation concealment approach at all, or did not describe it clearly;

- high risk of bias - when the method of allocation was not concealed.

\section{Potential for selection bias after allocation}

We scored this as:

- low risk of bias - trials where an intention-to-treat analysis was possible and there were few losses to follow up; 
- unclear risk of bias - trials reporting exclusions (less than $10 \%$ exclusions);

- high risk of bias - no reporting of exclusions, or more than $10 \%$ exclusions, or wide differences in exclusions between groups.

\section{Blinding with reference only to the outcome assessor}

We scored this as:

- low risk of bias - blinded;

- unclear risk of bias - information not reported;

- high risk of bias - not blinded.

\section{Follow-up}

We scored this as:

- low risk of bias - if the numbers and reasons for dropouts and withdrawals in all intervention groups were described and if $90 \%$ or more of the randomised participants were included in the analysis, or if it was specified that there were no dropouts or withdrawals;

- unclear risk of bias - if the report gave the impression there were no dropouts or withdrawals, but it was not specifically stated;

- high risk of bias - if less than $90 \%$ of the randomised participants were included in the analysis or the number or reasons for dropouts and withdrawals were not described.

\section{Scales to measure outcomes}

Scales had to be supported by studies about their psychometric properties. We classified the scales as:

- low risk of bias - if studies support the reliability and validity of the scale;

- unclear risk of bias - if supporting data were not provided, or the scale has never been tested;

- high risk of bias - if there was evidence of insufficient reliability or validity.

\section{Measures of treatment effect}

Two review authors (DC and VS) independently classified outcome measures in terms of the domain assessed (disability, arm motor function, perceived arm motor function, arm motor impairment, quality of life and dexterity). When a study presented more than one outcome measure for the same domain, we used the measure most frequently utilised across studies for the analysis. We converted continuous data to mean difference (MD) and, if different scales were used, we first computed a standardised mean difference (SMD), and second, an overall MD and overall SMD.

\section{Dealing with missing data}

When standard deviations of the changes were not reported, we estimated them in the treatment and control groups from the variances, or through the use of Engauge Software 5.1 as needed for data analysis.

If data for the estimation of standard deviation of changes were unreported, we contacted study authors by email to request the information. If we did not receive a reply, we contacted the study authors again.

\section{Assessment of heterogeneity}

We did a statistical summary of treatment effects only if there was no major clinical heterogeneity in terms of participants' characteristics. We assessed the degree of heterogeneity among the trials by the $1^{2}$ statistic for each outcome. We judged an $1^{2}$ value greater than $50 \%$ to be indicative of substantial heterogeneity (Higgins 2011). We calculated overall estimates using the fixed-effect or random-effects model, depending on the 12 heterogeneity test results and on clinical heterogeneity related to the implementation of interventions and to the characteristics of the participants.

\section{Assessment of reporting biases}

We addressed publication bias by means of visual inspection of funnel plots for signs of asymmetry, and generated the funnel plots using Review Manager 5 (RevMan 2014). We explored publication bias on arm motor function instead of disability, as arm motor function was the most frequent outcome assessed by the included studies.

\section{Data synthesis}

We pooled outcomes measured with different instruments using SMD. In all analyses with the exception of the subgroup analyses, we used the random-effects model with $95 \% \mathrm{Cl}$ using Review Manager 5 in order to take into account the clinical heterogeneity among studies (RevMan 2014).

\section{Subgroup analysis and investigation of heterogeneity}

There were four possible post-hoc subgroup analyses (Table 1).

- 'Dosage of task practice': on the basis of the cut-off of three hours, which is the difference between CIMT and mCIMT (see 'Types of interventions'), we calculated the dosage of exercise by multiplying the number of weeks by the number of sessions per week by the session duration in hours. We divided trials into those providing more than 30 hours of training, and those providing 30 hours of training or less.

- Anatomical region restraint: we divided studies in to those constraining the unaffected arm only at the hand by a mitt, and those constraining both hand and arm by a sling and mitt.

- Restraint effect: we included only the studies where the only independent variable between groups was restraint (e.g. where constraint was not accompanied by additional exercise, or the number of hours and type of treatment in the control and constraint groups were the same).

- Time since stroke: we used mean time since stroke at recruitment to classify trials into three categories: zero to three months, three months to nine months, and over nine months.

To investigate differences between subgroups, we used the approach for a significance test described by Deeks 2001. This method is implemented in the Review Manager software for fixedeffect analyses based on the inverse-variance method (RevMan 2014).

\section{Sensitivity analysis}

We conducted sensitivity analyses for the primary outcome to explore the effects of the methodological quality of the included studies on overall effect. 


\section{RESULTS}

\section{Description of studies}

See Characteristics of included studies, Characteristics of excluded studies.

\section{Results of the search}

The database searches identified 5863 records, while the searches of the trial registers identified nine records of ongoing, completed or terminated studies.

\section{Figure 1. Study flow diagram.}

\begin{tabular}{|l|}
19 trials from the previous \\
version of this review \\
published in 2009
\end{tabular}

Records identified through database searching $n=5863$ (in the update)

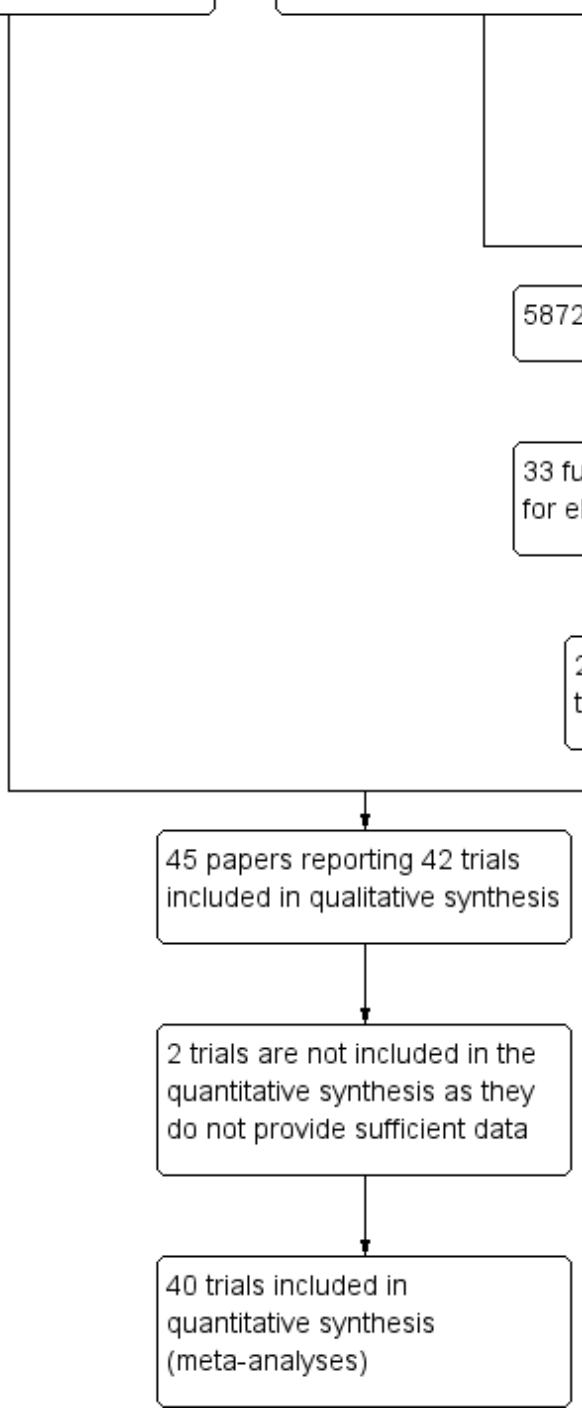

\section{Included studies}

A total of 42 published RCTs met the inclusion criteria (Alberts 2004; Atteya 2004; Azab 2009; Boake 2007; Bergheim 2010; Brogårdh 2009; Brunner 2012; Dahl 2008; Dromerick 2000; Dromerick 2009; Hammer 2009; Hayner 2010; Huseyinsinoglu 2012; Khan 2011; Kim
On the basis of information presented in titles and abstracts, we identified 33 studies as potentially relevant and we obtained the full text papers. Seven papers did not meet at least one of our inclusion criteria: firstly, most studies compared different forms of CIMT, and secondly, they reported data from trials already included in the review.

We included 24 papers that reported 23 trials, and added these to the 19 trials identified in the previous version of this review to give a total of 42 included trials (Figure 1 ).

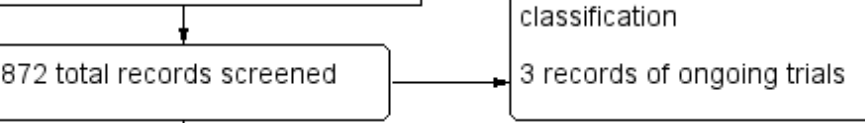


In 13 studies, participants were randomised to three interventions:

- mCIMT, traditional rehabilitation (training without restriction of the sound limb), and no treatment (Atteya 2004; Page 2001; Page 2002b ; Page 2004; Page 2008);

- CIMT at low dose versus CIMT at high dose versus control (Dromerick 2009);

- mCIMT versus conventional therapy versus therapeutic climbing (Khan 2011);

- mCIMT versus bilateral arm training (BAT) versus control (Lin 2009a);

- mCIMT versus modified bilateral arm training with rhythmic auditory cueing (BATRAC) versus dose-matched conventional treatment Van Delden 2013);

- CIMT plus mirror therapy versus CIMT versus control (Yoon 2014);

- mCIMT versus conventional treatment versus intensive conventional treatment (Wang 2011);

- mCIMT versus BAT versus control (Wu 2011);

- mCIMT plus trunk restraint versus mCIMT versus control (Wu 2012a).

In order to reduce the heterogeneity among studies and to preserve the equipoise principle, we considered only the data from arms comparing CIMT or mCIMT of FU with traditional rehabilitation (Edwards 1998). For Dromerick 2009 we combined the two experimental groups working at two different regimens into a single group performing $\mathrm{mCIMT}$; in Wang 2011 we considered the intensive conventional group to be the control group.

For more details, see the Characteristics of included studies table.

The studies were conducted in the USA (14 studies), Asia (14 studies) and Europe (14 studies).

Nine were identified as pilot RCTs (Alberts 2004; Brogårdh 2009; Dromerick 2000; Hammer 2009; Khan 2011; Myint 2008; Page 2002b; Page 2005b; Ploughman 2004), although it is not clear whether 'pilot' referred to examination of new CIMT characteristics, to the feasibility of the study, or to the small sample and lack of sample size calculation. Nineteen studies were multicentre.

\section{Participants}

A total of 1453 participants were enrolled in the 42 trials. There were more men $(n=934 ; 64 \%)$ than women. The mean age ranged from 37 years to 87 years (Page 2004; Wu 2007c, respectively), with the majority between 55 and 70 years. Time since stroke was zero to three months for 13 trials (Azab 2009; Bergheim 2010; Boake 2007; Brogårdh 2009; Brunner 2012; Dromerick 2000; Dromerick 2009; Myint 2008; Page 2005b; Ploughman 2004; Singh 2013; Treger 2012; Yoon 2014); three to nine months for six trials (Alberts 2004; Atteya 2004; Hammer 2009; Page 2001; Page 2002b; Wolf 2006), and more than nine months for five trials (Lin 2007; Page 2004; Page 2008; Taub 1993; Wittenberg 2003). Eight studies reported time since stroke onset vaguely: in the next days (Khan 2011), more than 1.5 months (Krawczyk 2012), more than two months (Tariah 2010), more than three months (Lin 2010), more than six months (Hayner 2010; Lin 2009a; Wu 2011), and more than one year (Kim 2008). One trial considered participants in which stroke onset varied between 0 to six months (Wang 2011), three trials between one to 37 months (Wu 2007a; Wu 2007b; Wu 2007c), one between one to six months (Van Delden 2013), two between three to 24 months (Huseyinsinoglu 2012; Smania 2012), one study between six to 59 months (Wu 2012a), one trial considered people in which the stroke onset varied between one to 92 months (Dahl 2008), and one between one and 10 years (Suputtitada 2004).

Thirty-six studies with a total of 1298 participants described the type of stroke: 15 studies included only people with ischaemic stroke (Alberts 2004; Bergheim 2010; Dromerick 2000; Hammer 2009; Hayner 2010; Krawczyk 2012; Lin 2010; Page 2001; Page 2002b; Page 2004; Page 2005b; Page 2008; Tariah 2010; Taub 1993; Treger 2012), while the remaining 21 trials enrolled people with haemorrhagic and ischaemic stroke (Boake 2007; Brunner 2012; Dahl 2008; Dromerick 2009; Huseyinsinoglu 2012; Kim 2008; Lin 2007; Lin 2009a; Myint 2008; Ploughman 2004; Singh 2013; Smania 2012; Suputtitada 2004; Van Delden 2013; Wang 2011; Wolf 2006; Wu 2007b; Wu 2007c; Wu 2011; Wu 2012a; Yoon 2014).

Fifty-six per cent $(n=729)$ of the participants had an ischaemic stroke, the remaining $44 \%(n=569)$ had a haemorrhagic stroke.

Thirty-three studies, with a total of 1011 participants, reported the number of people with the right-side affected $(n=627 ; 62 \%$; Alberts 2004; Atteya 2004; Azab 2009; Boake 2007; Bergheim 2010; Brogårdh 2009; Brunner 2012; Dromerick 2000; Dromerick 2009; Hammer 2009; Khan 2011; Krawczyk 2012; Lin 2007; Lin 2009a; Lin 2010; Myint 2008; Page 2001; Page 2002b; Page 2004; Page 2005b; Page 2008; Ploughman 2004; Smania 2012; Suputtitada 2004; Tariah 2010; Taub 1993; Van Delden 2013; Wu 2007a; Wu 2007b; Wu 2007c; Wu 2011; Wu 2012a; Yoon 2014).

Nine studies, with a total of 524 participants, reported the number of people presenting with paresis of pre-stroke dominant side (n = 260; 50\%; Alberts 2004; Huseyinsinoglu 2012; Myint 2008; Taub 1993; Van Delden 2013; Wolf 2006; Wu 2007a; Wu 2007b; Wu 2007c).

The main inclusion criteria reported were as follows.

- Movement capacity of the upper arm:

- ability to extend actively the metacarpophalangeal and interphalangeal joints at least $10^{\circ}$, and the wrist $20^{\circ}$ (Alberts 2004; Atteya 2004; Bergheim 2010; Boake 2007; Dahl 2008; Hammer 2009; Huseyinsinoglu 2012; Lin 2010; Myint 2008; Page 2001; Page 2002b; Page 2004; Page 2005b; Page 2008; Taub 1993; Suputtitada 2004; Tariah 2010; Wang 2011; Wittenberg 2003; Wolf 2006; Wu 2007a);

- ability to extend actively the metacarpophalangeal and interphalangeal joints and the wrist at least $10^{\circ}$ (Singh 2013; Smania 2012);

- ability to extend the metacarpophalangeal and interphalangeal joints of two digits and the wrist $10^{\circ}$, plus $10^{\circ}$ of thumb abduction/extension (Alberts 2004; Brogårdh 2009; Brunner 2012; Smania 2012; Van Delden 2013; Wolf 2006; Yoon 2014);

- trace of movements of the hand and some fingers dexterity preserved (Azab 2009; Hayner 2010; Kim 2008);

- ability to lift a floppy disc off the table top and to release it afterwards (Krawczyk 2012);

- score 1 to 3 on the motor arm items of the National Institute of Health Stroke Scale (NIHSS; Boake 2007; Dromerick 2000); 
- stage 3 or above in the reach Brunnstrom for the proximal part of the upper extremity (Lin 2007; Lin 2009a; Wu 2007b; Wu 2007c; Wu 2012a);

- stage 2 to 6 on the Chedoke McMaster Impairment Inventory (CMII; Khan 2011; Ploughman 2004);

- score 0 to 2 on Modified Rankin Scale before the stroke (Dahl 2008).

- Absence of cognitive impairment:

- Mini Mental State Examination (MMSE) or modified MMSE more than 24 or 70 respectively (Alberts 2004; Atteya 2004; Brogårdh 2009; Brunner 2012; Dahl 2008; Dromerick 2009; Hammer 2009; Hayner 2010; Huseyinsinoglu 2012; Krawczyk 2012; Lin 2007; Lin 2009a; Lin 2010; Myint 2008; Page 2001; Page 2002b; Page 2004; Page 2005b; Page 2008; Ploughman 2004; Singh 2013; Smania 2012; Suputtitada 2004; Tariah 2010; Taub 1993; Van Delden 2013; Wang 2011; Wolf 2006; Wu 2007a; Wu 2007b; Wu 2007c; Wu 2011; Wu 2012a);

- no neglect or speech comprehension difficulties (Boake 2007; Brogårdh 2009; Dahl 2008; Hammer 2009; Huseyinsinoglu 2012; Kim 2008; Krawczyk 2012; Singh 2013; Suputtitada 2004; Taub 1993; Treger 2012; Van Delden 2013; Wang 2011; Yoon 2014);

- score $\leq 1$ on the consciousness, communication and neglect item of the NIHSS (Dromerick 2000).

- Non-use of the affected arm in the real world: score $<2.5$ on the MAL (Alberts 2004; Huseyinsinoglu 2012; Lin 2007; Lin 2009a; Page 2005b; Page 2008; Smania 2012; Tariah 2010; Wittenberg 2003; Wolf 2006; Wu 2007a; Wu 2007b; Wu 2011; Wu 2012a).

- No balance problems including walking (Alberts 2004; Brogårdh 2009; Hammer 2009; Hayner 2010; Huseyinsinoglu 2012; Kim 2008; Krawczyk 2012; Lin 2007; Lin 2009a; Myint 2008; Smania 2012; Suputtitada 2004; Tariah 2010; Taub 1993; Wang 2011; Wolf 2006; Wu 2007a; Wu 2007b; Wu 2011; Wu 2012a).

- No excessive pain in the affected arm: score $<4$ on the visual analogue scale (Alberts 2004; Atteya 2004; Huseyinsinoglu 2012; Khan 2011; Myint 2008; Page 2001; Page 2002b; Page 2004; Page 2005b; Page 2008; Singh 2013; Tariah 2010; Wang 2011; Wolf 2006).

- No excessive spasticity: score $\leq 2$ (in any joint) respectively on the Ashworth Scale or on the modified Ashworth Scale (Atteya 2004; Hammer 2009; Huseyinsinoglu 2012; Lin 2007; Page 2001; Page 2002b; Page 2004; Page 2005b; Page 2008; Singh 2013; Tariah 2010; Taub 1993; Wang 2011; Wu 2007a; Wu 2007c).

- No joint limitation of the affected arm (Alberts 2004; Boake 2007; Wolf 2006).

\section{Intervention}

Nine studies, with a total of 416 participants, focused on the efficacy of CIMT (Alberts 2004; Dahl 2008; Hayner 2010; Krawczyk 2012; Myint 2008; Taub 1993; Wang 2011; Wittenberg 2003; Wolf 2006), while 29 studies, with a total of 943 participants, focused on the efficacy of mCIMT (Atteya 2004; Azab 2009; Bergheim 2010; Boake 2007; Brunner 2012; Dromerick 2000; Dromerick 2009; Huseyinsinoglu 2012; Khan 2011; Lin 2007; Lin 2009a; Lin 2010; Page 2001; Page 2002b; Page 2004; Page 2005b; Page 2008; Singh 2013; Smania 2012; Suputtitada 2004; Tariah 2010; Treger 2012; Van Delden 2013; Wu 2007a; Wu 2007b; Wu 2007c; Wu 2011; Wu 2012a; Yoon 2014). Four studies, with 94 participants, investigated the efficacy of FU (Brogårdh 2009; Hammer 2009; Kim 2008; Ploughman 2004).

\section{Time of restraint:}

- During waking hours for one study (Wittenberg 2003);

- 90\% of waking hours for eleven studies (Alberts 2004; Boake 2007; Brogårdh 2009; Dahl 2008; Huseyinsinoglu 2012; Myint 2008; Singh 2013; Smania 2012; Taub 1993; Wang 2011; Wolf 2006);

- from six hours per day to $90 \%$ of waking hours for one study (Dromerick 2009);

- from six to seven hours per day for two studies (Azab 2009; Bergheim 2010);

- six hours per day for 14 studies (Dromerick 2000; Hammer 2009; Hayner 2010; Lin 2007; Lin 2009a; Lin 2010; Suputtitada 2004; Van Delden 2013; Wu 2007a; Wu 2007b; Wu 2007c; Wu 2011; Wu 2012a; Yoon 2014);

- five hours per day for eight studies (Atteya 2004; Kim 2008; Krawczyk 2012; Page 2001; Page 2002b; Page 2004; Page 2005b; Page 2008);

- four to five hours per day for one study (Khan 2011);

- four hours per day for two studies ( Brunner 2012; Treger 2012);

- two hours per day for one study (Tariah 2010);

- a mean effective restraint time of 2.7 hours per day was reported by one study (Ploughman 2004).

Time of exercise with the affected arm:

- between 30 and 45 hours/week in seven studies (Alberts 2004; Dahl 2008; Hayner 2010; Suputtitada 2004; Taub 1993; Wittenberg 2003; Wolf 2006);

- between 10 and 25 hours/week in 20 studies (Boake 2007; Brunner 2012; Dromerick 2000; Dromerick 2009; Huseyinsinoglu 2012; Khan 2011; Krawczyk 2012; Lin 2007; Lin 2009a; Lin 2010; Myint 2008; Singh 2013; Smania 2012; Tariah 2010; Wang 2011; Wu 2007a; Wu 2007b; Wu 2007c; Wu 2011; Yoon 2014);

- five hours/week or less in 11 studies (Atteya 2004; Azab 2009; Bergheim 2010; Page 2001; Page 2002b; Page 2004; Page 2005b; Page 2008; Ploughman 2004; Treger 2012; Van Delden 2013).

Treatment duration:

- two weeks in 19 studies (Alberts 2004; Bergheim 2010; Boake 2007; Brogårdh 2009; Dahl 2008; Dromerick 2000; Dromerick 2009; Hammer 2009; Hayner 2010; Huseyinsinoglu 2012; Myint 2008; Singh 2013; Smania 2012; Suputtitada 2004; Taub 1993; Treger 2012; Wittenberg 2003; Wolf 2006; Yoon 2014);

- three weeks for nine studies (Krawczyk 2012; Lin 2007; Lin 2009a; Lin 2010; Wu 2007a; Wu 2007b; Wu 2007c; Wu 2011; Wu 2012a);

- four weeks for three studies (Azab 2009; Brunner 2012; Wang 2011);

- six weeks for one study (Van Delden 2013);

- eight weeks for two studies (Kim 2008; Tariah 2010);

- 10 weeks for six studies (Atteya 2004; Page 2001; Page 2002b; Page 2004; Page 2005b; Page 2008).

One study did not report the treatment duration (Khan 2011).

Types of exercise: 
- all studies used functional or ADL tasks: in 19 studies this was done through shaping techniques (Alberts 2004; Bergheim 2010; Brunner 2012; Boake 2007; Dromerick 2009; Hayner 2010; Huseyinsinoglu 2012; Kim 2008; Lin 2010; Myint 2008; Page 2002b; Page 2004; Page 2005b; Page 2008; Smania 2012; Tariah 2010; Van Delden 2013; Wolf 2006; Wu 2007a);

- two studies included proprioceptive neuromuscular facilitation (PNF; Atteya 2004; Page 2001);

- one study used conventional treatment for upper extremity, which involved the facilitation of proximal motor control progressing to skilled-task training, without shaping therapy (Ploughman 2004).

Anatomical region restraint:

- both hand and arm in 12 studies (Atteya 2004; Hammer 2009; Myint 2008; Page 2001; Page 2002b; Page 2004; Page 2008; Ploughman 2004; Taub 1993; Wang 2011; Wittenberg 2003; Yoon 2014);

- only the hand in the remaining 30 studies.

\section{Intervention delivery}

In all studies the interventions were delivered and supervised by trained physiotherapists or occupational therapists, and each participant assigned to an intervention group participated in individual therapy sessions, except in Dahl 2008 and Suputtitada 2004 where the participants exercised in groups of four. The wearing of the constraint was checked by questioning the participants every two weeks about satisfaction with the protocol (Atteya 2004), keeping a log of the hours of restraint per day (Azab 2009; Brogårdh 2009; Brunner 2012; Hammer 2009; Lin 2009a; Myint 2008; Page 2002a; Page 2004; Page 2005b; Ploughman 2004; Singh 2013; Smania 2012; Tariah 2010; Treger 2012; Wang 2011; Wu 2011; Wu 2012a), and through a physical sensor and timer placed in the mitt and by a home diary (Wolf 2006). Supervision of the constraint was not described in the other studies.

Twenty-four studies included outpatients (Alberts 2004; Atteya 2004; Azab 2009; Hayner 2010; Huseyinsinoglu 2012; Kim 2008; Lin 2007; Lin 2009a; Lin 2010; Myint 2008; Page 2001; Page 2002b; Page 2004; Page 2005b; Page 2008; Smania 2012; Suputtitada 2004; Tariah 2010; Taub 1993; Wang 2011; Wolf 2006; Wu 2007b; Wu 2011; Wu 2012a), 11 studies included only inpatients (Bergheim 2010; Brogårdh 2009; Dahl 2008; Dromerick 2000; Dromerick 2009; Khan 2011; Krawczyk 2012; Singh 2013; Treger 2012; Wittenberg 2003; Yoon 2014), six studies included both inpatients and outpatients (Boake 2007; Brunner 2012; Hammer 2009; Ploughman 2004; Wu 2007a; Wu 2007c), and one study did not specify (Van Delden 2013).

\section{Outcomes}

All studies considered pre-treatment and post-treatment outcome measures. Seventeen studies had longer follow-up:

- one month (Van Delden 2013);

- one and three months (Hammer 2009);

- three months (Bergheim 2010; Boake 2007; Brogårdh 2009; Dromerick 2009; Smania 2012);

- four months (Tariah 2010);

- six months (Azab 2009; Dahl 2008; Hayner 2010; Khan 2011; Wittenberg 2003);
- 12 months (Krawczyk 2012; Myint 2008);

- at four, eight and 12 months (Wolf 2006);

- up to three years (Taub 1993).

The 42 included trials considered similar outcome categories. We attributed measures used in the studies to each outcome category as detailed below and in Table 2 .

\section{Primary outcomes}

- Disability:

- Functional Independence Measure (FIM): nine studies (Dahl 2008; Dromerick 2009; Huseyinsinoglu 2012; Lin 2007; Lin 2009a; Ploughman 2004; Treger 2012; Wu 2007a; Wu 2007c);

- Barthel Index (BI): three studies (Azab 2009; Myint 2008; Yoon 2014).

\section{Secondary outcomes}

- Arm motor function:

- Action Research Arm Test (ARAT): 14 studies (Atteya 2004; Brunner 2012; Dromerick 2000; Dromerick 2009; Hammer 2009; Myint 2008; Page 2001; Page 2002b; Page 2004; Page 2005b; Page 2008; Ploughman 2004; Van Delden 2013; Wu 2012a);

- Wolf Motor Function Test (WMFT): 14 studies (Alberts 2004; Atteya 2004; Dahl 2008; Hayner 2010; Huseyinsinoglu 2012; Khan 2011; Singh 2013; Smania 2012; Tariah 2010; Wittenberg 2003; Wang 2011; Wolf 2006; Wu 2011; Yoon 2014);

- Emory Motor Function test (EMF): one study (Taub 1993);

- Manual Function Test (MFT): two studies (Kim 2008; Treger 2012);

- The Rivermead Motor Assessment Arm scale: one study (Krawczyk 2012);

- Motor Assessment Scale: one study (Brogårdh 2009).

- Perceived motor function, amount of use and quality of use:

- Motor Activity Log (MAL): 29 studies (Atteya 2004; Boake 2007; Brogårdh 2009; Dahl 2008; Hammer 2009; Huseyinsinoglu 2012; Khan 2011; Kim 2008; Krawczyk 2012; Lin 2007; Lin 2009a; Lin 2010; Myint 2008; Page 2001; Page 2002b; Page 2004; Page 2005b; Page 2008; Smania 2012; Tariah 2010; Taub 1993; Van Delden 2013; Wittenberg 2003; Wolf 2006; Wu 2007a; Wu 2007b; Wu 2007c; Wu 2011; Wu 2012a).

- Arm motor impairment:

- Fugl-Meyer Assessment (FMA): 17 studies (Alberts 2004; Atteya 2004; Boake 2007; Hammer 2009; Lin 2009a; Lin 2010; Page 2001; Page 2002b; Page 2004; Page 2005b; Page 2008; Singh 2013; Tariah 2010; Van Delden 2013; Wu 2007b; Wu 2007c; Yoon 2014);

- Chedoke McMaster Impairment Inventory (CMII): three studies (Ploughman 2004; Tariah 2010; Van Delden 2013);

- Birgitta Lind Marks Assessment Motor (BLMA): one study (Krawczyk 2012);

- Jamar hand dynamometer: one study (Ploughman 2004);

- maximal grip strength with a force transducer: three studies (Alberts 2004; Van Delden 2013; Yoon 2014);

- shoulder and elbow isometric force: one study (Khan 2011).

- Dexterity:

- Grooved Pegboard Test (GPT): one study (Boake 2007); 
- Nine-Hole Peg Test (NHPT): four studies (Brunner 2012; Myint 2008; Van Delden 2013; Yoon 2014);

- Sixteen-Hole Peg Test: one study (Hammer 2009);

- Box and block test: one study (Yoon 2014);

- Perdue Pegboard Test: one study (Kim 2008).

- Quality of life:

- Stroke Impact Scale (SIS): seven studies (Dahl 2008; Dromerick 2009; Lin 2009a; Van Delden 2013; Wolf 2006; Wu 2007c; Wu 2012a).

\section{Excluded studies}

We excluded 12 studies after reading the full text as they did not meet our inclusion criteria. We have provided all the reasons for these exclusions in Characteristics of excluded studies.

\section{Risk of bias in included studies}

Refer to Figure 2 or Figure 3 and Characteristics of included studies. If required, we contacted the corresponding author of the relevant studies for further information.

\section{Figure 2. Risk of bias graph: review authors' judgements about each risk of bias item presented as percentages} across all included studies.

\section{Random sequence generation (selection bias)}

Allocation concealment (selection bias)

Blinding (performance bias and detection bias)

Incomplete outcome data addressed? (Post-treatment)
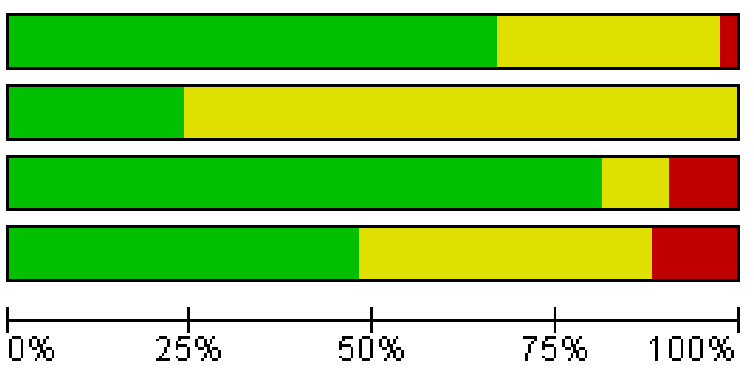
Figure 3. Risk of bias summary: review authors' judgements about each risk of bias item for each included study.

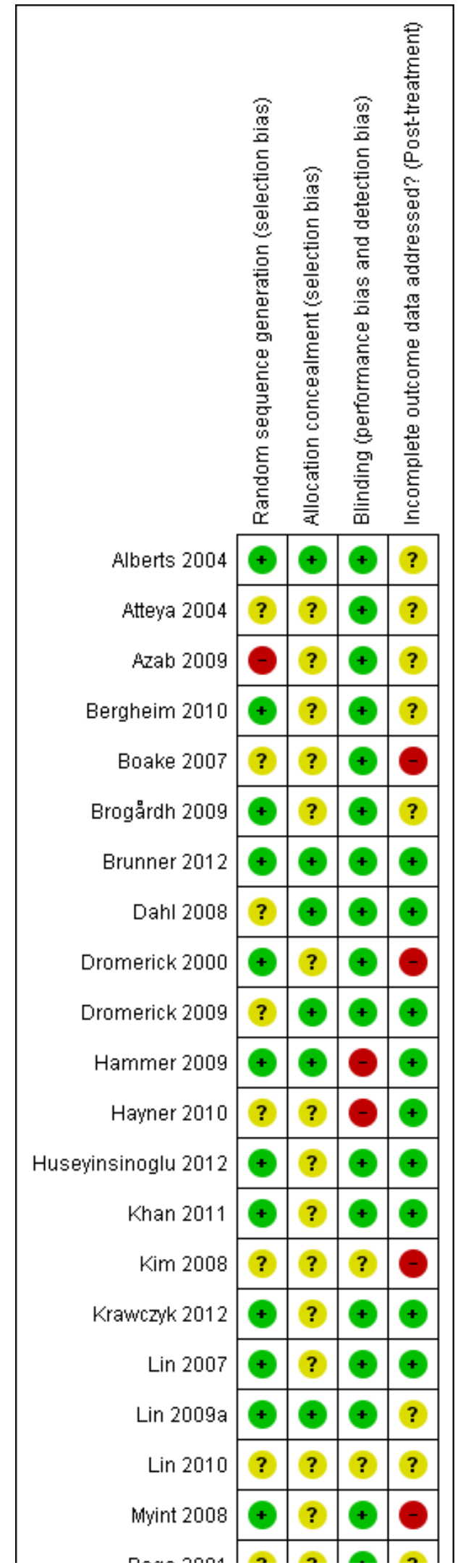


Figure 3. (Continued)

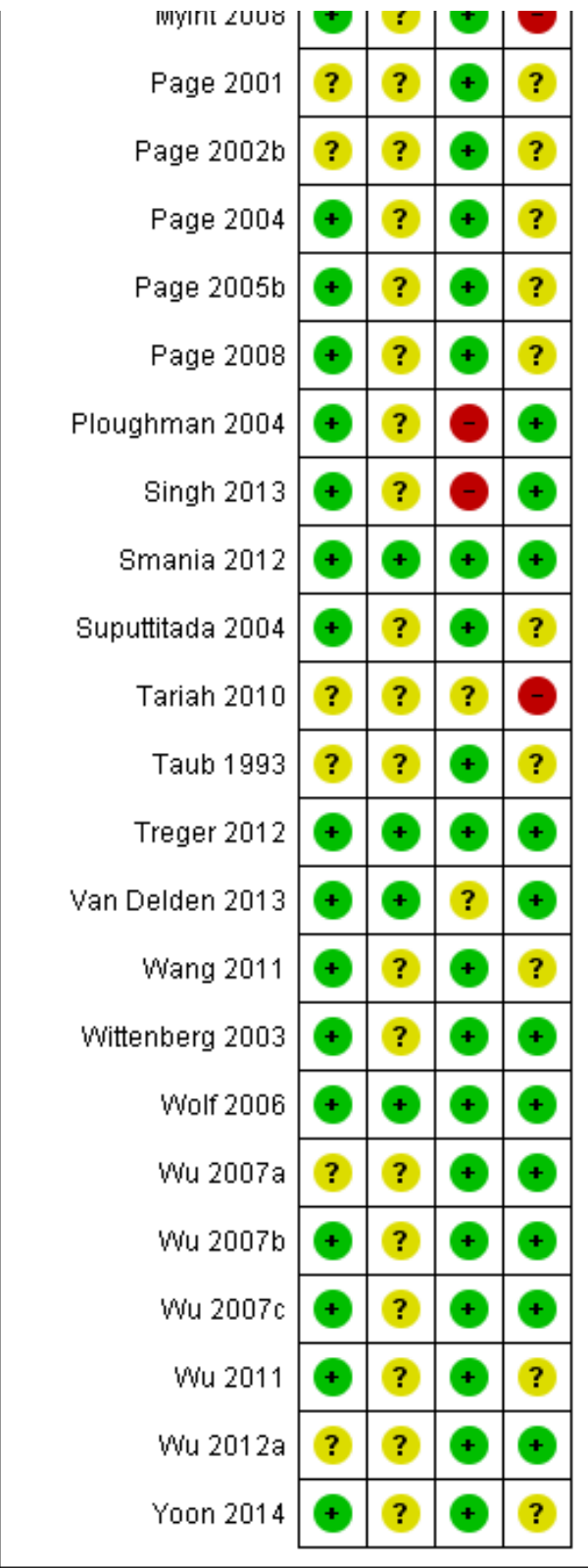

\section{Allocation}

\section{Randomisation}

The sequence of randomisation was described and appropriate in 27 studies (Alberts 2004; Bergheim 2010; Brogårdh 2009; Brunner 2012; Dromerick 2000; Hammer 2009; Huseyinsinoglu 2012; Khan 2011; Krawczyk 2012; Lin 2007; Lin 2009a; Page 2004; Page 2005b; Page 2008; Ploughman 2004; Singh 2013; Smania 2012; Suputtitada 2004; Treger 2012; Van Delden 2013; Wang 2011; Wittenberg 2003; Wolf 2006; Wu 2007b; Wu 2007c; Wu 2011; Yoon 2014). Lin 2007 used a randomisation stratified by side of stroke; Alberts 2004 and Wolf 2006 balanced the randomisation with respect to gender, premorbid handedness, side of stroke and level of function; Boake 2007 stratified by age and NIHSS score, and Dromerick 2009 balanced for age, total NIHSS score, pretest ARAT and days from stroke onset. Prestratification was applied to the participants based on whether they had received botulinum A injection in Huseyinsinoglu 2012. Van Delden 2013 stratified the participants according to whether they had higher functional ability or lower functional ability of the arm. In Hayner 2010 study participants were stratified into more and less affected.

We considered one study at high risk of bias because only a keyword of the article referred to randomisation (Azab 2009). We considered other studies at unclear risk of bias mainly because they provided insufficient data.

\section{Allocation concealment}

Allocation concealment was described and appropriate in 10 studies (Alberts 2004; Brunner 2012; Dahl 2008; Hammer 2009; Khan 2011; Lin 2009a; Smania 2012; Treger 2012; Van Delden 2013; Wolf 2006); the remaining studies did not report sufficient information. 


\section{Blinding}

Outcome assessors were blinded in 34 studies. In Hammer 2009, Hayner 2010, Ploughman 2004 and Singh 2013 the assessor was not blinded, and blinding was not described in the remaining four studies (Kim 2008; Lin 2010; Tariah 2010; Van Delden 2013).

\section{Incomplete outcome data}

Sixteen studies provided complete information about participants who withdrew and their reasons (Boake 2007; Brunner 2012; Hammer 2009; Hayner 2010; Huseyinsinoglu 2012; Khan 2011; Kim 2008; Krawczyk 2012; Lin 2007; Myint 2008; Ploughman 2004; Singh 2013; Smania 2012; Treger 2012; Van Delden 2013; Wolf 2006); four studies provided numbers of withdrawals but not reasons (Azab 2009; Dromerick 2000; Dromerick 2009; Tariah 2010); 16 studies presented unclear information about withdrawals: none of these clearly stated that there were no dropouts (Alberts 2004; Atteya 2004; Brogårdh 2009; Lin 2009a; Lin 2010; Page 2001; Page 2002b; Page 2004; Page 2005b; Page 2008; Suputtitada 2004; Tariah 2010; Taub 1993; Wang 2011; Wu 2011; Yoon 2014 ). In one study one participant was excluded from the analyses post-hoc because he had received botulinum toxin type $A$ in the more affected limb less than three months before the study (Page 2004).

The remaining six studies had no drop-outs.

By post-treatment follow-up nine studies had lost less than $10 \%$ of participants (Brogårdh 2009; Brunner 2012; Dromerick 2009; Hayner 2010; Huseyinsinoglu 2012; Khan 2011; Lin 2007; Van Delden 2013; Wolf 2006); six studies had lost between $10 \%$ and $20 \%$ of participants (Dromerick 2000; Hammer 2009; Krawczyk 2012; Myint 2008; Ploughman 2004; Smania 2012); and two studies had lost more than $20 \%$ of participants (Boake 2007; Kim 2008).

At long-term follow-up, Myint 2008 and Hammer 2009 had lost less than $10 \%$ of participants, while Azab 2009, Boake 2007, Brogårdh 2009, Krawczyk 2012, and Wolf 2006 had lost between 10\% and 20\% of participants.

Three studies performed intention-to-treat analyses (Alberts 2004; Smania 2012; Wolf 2006). Twenty-five studies that did not have apparent withdrawals performed analyses on all included participants (Atteya 2004; Azab 2009; Bergheim 2010; Brogårdh 2009; Brunner 2012; Dromerick 2009; Dahl 2008; Krawczyk 2012; Lin 2009a; Lin 2010; Page 2001; Page 2002b; Page 2005b; Page 2008; Singh 2013; Suputtitada 2004; Treger 2012; Wang 2011; Wittenberg 2003; Wu 2007a; Wu 2007b; Wu 2007c; Wu 2011;
Wu 2012a; Yoon 2014). One study mixed intention-to-treat and per-protocol analyses (Boake 2007). The others performed perprotocol analyses (Dromerick 2000; Hammer 2009; Hayner 2010; Huseyinsinoglu 2012; Khan 2011; Kim 2008; Lin 2007; Myint 2008; Page 2004; Ploughman 2004;Taub 1993; Tariah 2010; Van Delden 2013).

\section{Validity of scales}

All scales used in the studies for primary and secondary outcomes were supported by references to their psychometric properties, and were considered able to quantify performance in individuals after stroke with motor characteristics similar to the people enrolled in the included studies. The study on clinimetric properties of the MAL scale reports relatively stable internal consistency in a population of chronic stroke patients, a correlation with ARAT score at baseline (Spearman's rho was 0.63 for AoU and QoU), but considerable doubts remain about the longitudinal construct validity of the instrument, and the study does not recommend its use as a primary outcome measure in trials (Van der Lee 2004).

\section{Other potential sources of bias}

Six trials based their sample size on prior statistical power calculations (Brogårdh 2009; Brunner 2012; Smania 2012; Treger 2012; Van Delden 2013; Wolf 2006). Most studies were very small; the median sample size was 29 randomised participants (interquartile range 16 to 44). Small sample sizes are related to type 2 errors (Altman 1990; Hotopf 1997; Hotopf 1999), so if the median number of participants randomised is 29 , then the complete analysis will only include around 15 participants per group.

\section{Publication bias and small study effects}

Visual inspection of the funnel plot indicated that pooled data might have been influenced by publication bias (Figure 4). Slight asymmetry of the plot is possible, with few studies characterised by extreme statistically significant results, largely favouring CIMT. It is also possible that others studies are 'missing' from the opposite area, which is in favour of the control. Another possible reason for slight asymmetry could be related to the large number of small trials we identified. Their methodological components for random sequence generation, allocation concealment and double blinding might have been inadequate. The reporting of most studies was largely unsatisfactory, preventing us from making full judgements of methods. These potential methodological shortcomings can be associated with exaggerated estimates of benefits of treatment. 
Figure 4. Funnel plot of comparison: 3 Constraint versus control: secondary outcomes, outcome: 3.1 Arm Motor Function.

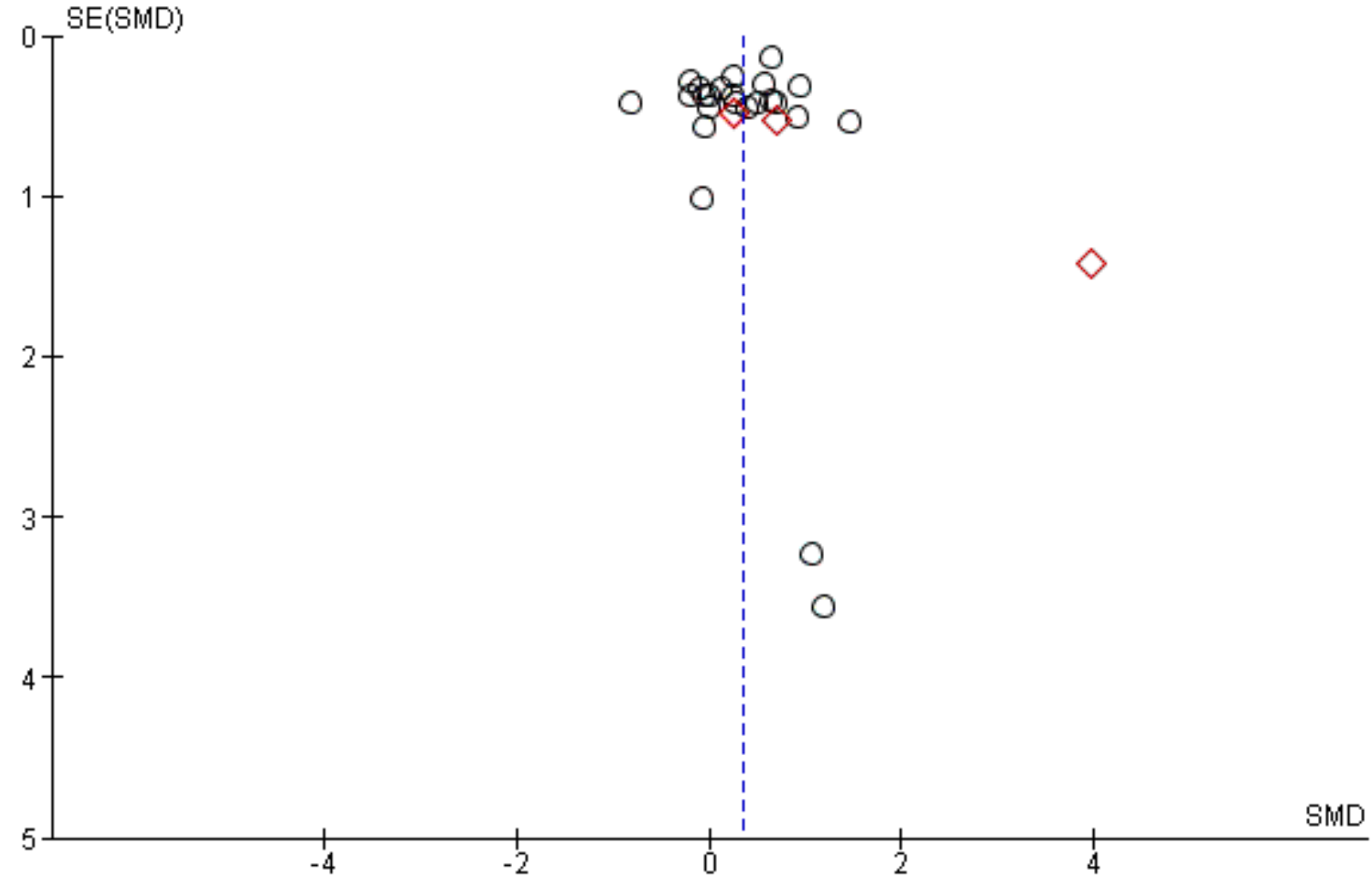

Subgroups

Constraint therapy versus usual care

Constraint therapy versus no treatment

\section{Studies awaiting assessment}

Six studies are awaiting assessment because information that is currently available about them is insufficient to determine whether they would be eligible for inclusion in this review. Five studies are labelled as 'completed' or 'terminated' on ClinicalTrials.gov (Barzel 2015; Boe 2014; Dos Santos 2012; Olivier 2012; Uswatte 2014), and one has been published as a poster (Jansa 2007).

Three studies are ongoing and recruiting (Gautier 2015; Padovani Do Santos 2015; Pereira 2015).

\section{Effects of interventions}

See: Summary of findings for the main comparison

We conducted meta-analyses when at least two studies provided sufficient data. We included trials that compared the intervention versus no treatment, or no active treatment, in a specific subgroup to show how the estimated overall effect was based on information provided by these studies (Alberts 2004; Kim 2008; Taub 1993; Wittenberg 2003). In consideration of the clinical heterogeneity among studies, which related to variability in the interventions included and in the patient case-mix, we considered it appropriate to perform random-effects metaanalyses to incorporate heterogeneity, except within subgroup analyses.
Fourteen trials monitored the presence of adverse events or medical complications leading to dropouts (Boake 2007; Brunner 2012; Dahl 2008; Dromerick 2000; Dromerick 2009; Hammer 2009; Khan 2011; Kim 2008; Krawczyk 2012; Myint 2008; Page 2008; Ploughman 2004; Smania 2012; Wolf 2006). Six of these studies monitored and reported on adverse events (Boake 2007; Dahl 2008; Dromerick 2000; Page 2008; Ploughman 2004; Wolf 2006), and four stated that none occurred (Boake 2007; Dahl 2008; Page 2008; Ploughman 2004). Rates of adverse events among these studies appeared not to differ between CIMT and the comparison groups, and CIMT appeared to have no adverse effects.

\section{Primary outcomes}

\section{Comparison 1.1: Disability post-intervention}

Twelve studies with 411 participants measured disability immediately after the experimental and control interventions (Azab 2009; Dahl 2008; Dromerick 2009; Huseyinsinoglu 2012; Lin 2007; Lin 2009a; Myint 2008; Ploughman 2004; Treger 2012; Wu 2007a; Wu 2007c; Yoon 2014). Data were available for 344 participants (84\%) from 11 studies. The impact of CIMT on disability indicated a nonsignificant effect (SMD 0.24, 95\% Cl -0.05 to 0.52; Analysis 1.1).

Sixty-nine participants contributing to this meta-analysis were recruited from studies with more than a $10 \%$ loss to follow-up. 


\section{Comparison 1.2: Disability at three- and six-month follow-up}

Three studies recruiting 125 participants measured disability at three months (Dromerick 2009; Myint 2008), or at six months after treatment (Dahl 2008). The impact of CIMT on disability indicated a non-significant effect (SMD $-0.21,95 \% \mathrm{Cl}-0.57$ to 0.16 , Analysis 1.2).

\section{Subgroup analysis: Disability}

We carried out analyses for the following three subgroups considering data availability.

- 'Dosage of task practice': we grouped trials according to whether they provided 30 or more hours of exercise, or up to 30 hours of exercise.

- Anatomical region restraint: we grouped trials according to whether both arm and hand were restrained, or only the hand.

- Time since stroke: we grouped trials according to whether they recruited within three months, three to nine months, or more than nine months post stroke.

\section{Comparison 2.1: Amount of task practice}

Three studies with 91 participants reported over 30 hours of exercise (Dahl 2008; Myint 2008; Yoon 2014); eight studies with 253 participants reported 30 hours or less of exercise (Dromerick 2009; Huseyinsinoglu 2012; Lin 2007; Lin 2009a; Ploughman 2004; Treger 2012; Wu 2007a; Wu 2007c). Longer exercise for upper limb function showed no statistically significant effect size (SMD 0.25, 95\% CI-0.18 to 0.67 ); shorter exercise had a non-significant effect size (SMD 0.18 , $95 \% \mathrm{Cl}-0.07$ to 0.44 ; Analysis 2.1 ). The difference between the two groups of trials was not significant ( $P$ value 0.8 ).

\section{Comparison 2.2: Anatomical region restraint}

Two studies with 61 participants reported both arm and hand restriction (Myint 2008; Yoon 2014); nine studies including 283 participants reported only hand restriction (Dahl 2008; Dromerick 2009; Huseyinsinoglu 2012; Lin 2007; Lin 2009a; Ploughman 2004; Treger 2012; Wu 2007a; Wu 2007c). The restriction of both arm and hand for upper limb function showed a non-statistically significant effect size (SMD $0.35,95 \% \mathrm{Cl}-0.17$ to 0.87 ); restriction of the hand only was non-statistically significant (SMD $0.17,95 \% \mathrm{Cl}-0.08$ to 0.41 ; Analysis 2.2). The difference between the effect estimates for the two groups of trials was not significant (P value 0.53 ).

\section{Comparison 2.3: Time since stroke}

Five studies with 164 participants measured disability on people with stroke at zero to three months (Myint 2008; Ploughman 2004; Treger 2012; Yoon 2014); five studies with 176 participants measured it at more than nine months (Dahl 2008; Huseyinsinoglu 2012; Lin 2007; Lin 2009a; Wu 2007a).

No studies measured disability on people with subacute stroke at three to nine months. We did not include four studies in this subgroup analysis because of the wide range of chronicity of participants (Dahl 2008; Huseyinsinoglu 2012; Lin 2009a; Wu 2007c). People with acute and chronic stroke showed no statistically significant effect size: for zero to three months (SMD 0.07, 95\% Cl -0.26 to 0.39 ) or more than nine months (SMD $0.49 \mathrm{Cl}-0.02$ to 1.00 ; Analysis 2.3). The difference between the effect estimates for the two groups of trials was not significant ( $P$ value 0.17 ). We did not find heterogeneity among studies $\left(I^{2}=47.2 \%\right)$.
The comparison for the restraint effect could not be performed because of insufficient data.

\section{Secondary outcomes}

\section{Comparison 3.1: Arm motor function}

Thirty-four studies with 988 participants measured arm motor function (Alberts 2004; Atteya 2004; Bergheim 2010; Brogårdh 2009; Brunner 2012; Dahl 2008; Dromerick 2000; Dromerick 2009; Hammer 2009; Hayner 2010; Huseyinsinoglu 2012; Khan 2011; Kim 2008; Krawczyk 2012; Myint 2008; Page 2001; Page 2002b; Page 2004; Page 2005b; Page 2008; Ploughman 2004; Singh 2013; Smania 2012; Tariah 2010; Taub 1993; Treger 2012; Van Delden 2013; Suputtitada 2004; Wang 2011; Wittenberg 2003; Wolf 2006; Wu 2011; Wu 2012a; Yoon 2014). Data were available for 858 participants (87\%). The impact of CIMT on upper limb function indicated a significant effect size (SMD $0.34,95 \% \mathrm{Cl} 0.12$ to 0.55 ; Analysis 3.1). We found moderate heterogeneity among studies ( $12=47 \%)$.

\section{Comparison 3.2: Perceived arm motor function (quality of use (QoU))}

Twenty-nine studies with 1086 participants measured perceived arm motor function QoU (Atteya 2004; Boake 2007; Brogårdh 2009; Brunner 2012; Dahl 2008; Hammer 2009; Huseyinsinoglu 2012; Khan 2011; Kim 2008; Krawczyk 2012; Lin 2007; Lin 2009a; Lin 2010; Myint 2008; Page 2001; Page 2002b; Page 2004; Page 2005b; Page 2008; Smania 2012; Tariah 2010; Taub 1993; Van Delden 2013; Wolf 2006; Wu 2007a; Wu 2007b; Wu 2007c; Wu 2011; Wu 2012a); data were available for 891 participants $(82 \%)$. The impact of CIMT on perceived upper limb function QoU indicated a large and significant effect (MD $0.68,95 \% \mathrm{Cl} 0.47$ to 0.88 ; Analysis 3.2). We found considerable heterogeneity among studies $\left(1^{2}=74 \%\right)$.

\section{Comparison 3.3: Perceived arm motor function (amount of use (AoU))}

Twenty-eight studies with 1046 participants measured perceived arm motor function (AoU; Atteya 2004; Boake 2007; Brogårdh 2009; Brunner 2012; Dahl 2008; Hammer 2009; Huseyinsinoglu 2012; Khan 2011; Kim 2008; Lin 2007; Lin 2009a; Lin 2010; Myint 2008; Page 2001; Page 2002b; Page 2004; Page 2005b; Page 2008; Smania 2012; Tariah 2010; Van Delden 2013; Wittenberg 2003; Wolf 2006; Wu 2007a; Wu 2007b; Wu 2007c; Wu 2011; Wu 2012a); data were available for 851 participants (81\%). The impact of CIMT on perceived upper limb function AoU indicated a large and significant effect (MD $0.79,95 \% \mathrm{Cl} 0.50$ to 1.08; Analysis 3.3). We found considerable heterogeneity among studies $\left(1^{2}=87 \%\right)$.

\section{Comparison 3.4: Arm motor impairment}

Eighteen studies with 451 participants measured arm motor impairment (Alberts 2004; Atteya 2004; Boake 2007; Hammer 2009; Lin 2009a; Lin 2010; Page 2001; Page 2002b; Page 2004; Page 2005b; Page 2008; Ploughman 2004; Singh 2013; Tariah 2010; Van Delden 2013; Wu 2007b; Wu 2007c; Yoon 2014); data were available for 372 participants (82\%). The impact of CIMT on upper limb impairment indicated a significant effect (SMD 0.82, 95\% Cl 0.31 to 1.34; Analysis 3.4). We found considerable heterogeneity among studies $\left(1^{2}=\right.$ $77 \%)$. 


\section{Comparison 3.5: Quality of life}

Eight studies with 537 participants measured quality of life (Dahl 2008; Dromerick 2009; Lin 2009a; Van Delden 2013; Wolf 2006; Wu 2007b; Wu 2007c; Wu 2012a); data were available for 96 participants $(18 \%)$. The impact of CIMT on quality of life indicated a nonsignificant effect (MD 6.54, $95 \% \mathrm{Cl}-1.2$ to 14.28 ; Analysis 3.5). We found no statistical heterogeneity $\left(\mathrm{I}^{2}=0 \%\right)$.

\section{Comparison 3.6: Dexterity}

Seven studies with 229 participants included a measure of dexterity (Boake 2007; Brunner 2012; Hammer 2009; Kim 2008; Myint 2008; Van Delden 2013; Yoon 2014); data were available for 113 participants (49\%). The impact of CIMT on upper limb dexterity indicated a significant effect (SMD 0.42, 95\% Cl 0.04 to 0.79 ; Analysis 3.6). We found no statistical heterogeneity $\left(1^{2}=0 \%\right)$.

\section{DISCUSSION}

\section{Summary of main results}

This work updates the previous Cochrane review published in 2008 on the efficacy of CIMT, mCIMT and FU. The review now includes 42 trials with 1453 participants. All studies enrolled people who had compromised, but residual, ability of upper arm and hand, participants were able to extend the wrist and the metacarpophalangeal joints at least $10^{\circ}$ and $20^{\circ}$ respectively, or presented a Brunnstrom stage $>3$ and with limited pain or spasticity. Moreover, people with cognitive impairment were excluded.

Results of this review show a superiority of CIMT in comparison with other rehabilitation approaches on the recovery from motor impairment and motor function (secondary outcomes) but not in disability (primary outcome).

\section{Effect of CIMT on disability}

Eleven trials with 344 participants measured disability and we included their results in the analysis.

The impact of CIMT on disability indicates a non-significant effect if compared with active rehabilitation approaches (SMD 0.24, 95\% Cl -0.05 to 0.52 ). Also, at the longest follow-up, no superiority of CIMT is documented and subgroup analyses do not show interactions between disability and amount of task practice, anatomical region restraint or time since stroke. The main active rehabilitation approaches used by the control groups consisted of occupational therapy and techniques of adaptation to motor impairment (Dahl 2008; Dromerick 2009; Lin 2009a; Myint 2008), functional task practice (Lin 2007; Ploughman 2004; Treger 2012; Wu 2007a; Wu 2007c), Bobath principles (Huseyinsinoglu 2012), and unspecified conventional rehabilitation (Yoon 2014). The treatment duration was well balanced among studies except in that of Huseyinsinoglu 2012, in which CIMT treatment lasted three times as long as the treatment performed by the control group, and in the Yoon 2014 study, in which there was a similar four-fold imbalance between the groups.

In summary, these studies showed that the use of constraining approaches (CIMT, mCIMT and FU) compared with a similar dose of rehabilitation targeting the practice of functional tasks did not result in a demonstrable improvement in disability.

\section{Secondary outcomes}

Twenty-eight studies with a total of 848 participants measured arm motor function and we included them in the analysis. CIMT was always compared with active rehabilitation approaches, and showed a limited effect in improving arm motor function.

The majority of trials used a mCIMT, eight studies used CIMT (Dahl 2008; Hayner 2010; Khan 2011; Myint 2008; Taub 1993; Wittenberg 2003; Wolf 2006; Yoon 2014), and only three studies used FU (Hammer 2009; Kim 2008; Ploughman 2004). Comparison groups performed the same dose of treatment with the exception of five studies in which the control groups' dose was lower (Dromerick 2009; Taub 1993; Wittenberg 2003; Wolf 2006; Yoon 2014), one study in which the dose was smaller in the treatment group (Huseyinsinoglu 2012), and two studies in which it was not clearly specified (Dahl 2008; Kim 2008).

Twenty-three and 24 of the included studies with a total of 851 and 891 participants, respectively, measured the perceived arm motor function (AoU and QoU, respectively) and we included them in the analysis. In three studies the control groups did not perform treatments (Kim 2008, Taub 1993, Wittenberg 2003). The estimated effect of CIMT led to a significant and clinically relevant improvement in the perceived arm motor function of the paretic arm (Lang 2008).

Sixteen of the included studies with a total of 372 participants measured arm motor impairment and we included them in the analysis. In one study the control group did not perform treatments (Kim 2008). The estimated effect of CIMT was considered to be large in modifying the arm motor impairment of the affected arm.

Four of the included studies with a total of 113 participants measured dexterity and we included them in the analysis. The estimated effect of CIMT led to a significant small effect in improving upper limb dexterity.

CIMT does not appear to have a better effect than other rehabilitation approaches in improving quality of life; this was measured in three studies.

It is worth noting the considerable heterogeneity of the studies included in the review, regarding the way in which CIMT was applied and the characteristics of the control treatments. Considering this heterogeneity, and some differences among the outcome measures used by the authors, the results of these analyses should be interpreted with caution.

When reported, rates of adverse events among included studies do not appear to differ between CIMT and the comparison groups, and CIMT appears to have no adverse effects.

Sixteen studies declared dropout levels of $4 \%$ to $23 \%$, including losses for non-medical reasons, with the exception of one study in which four of the 13 participants in the experimental group did not complete the programme due to difficulties in performing the ADLS (Kim 2008).

\section{Overall completeness and applicability of evidence}

In 2009 this review concluded that "the impact of CIMT on disability indicated a modest significant benefit". With the increase in the number of included studies, the effect of CIMT on disability 
decreased and became non-significant (SMD $0.24,95 \% \mathrm{Cl}-0.05$ to 0.52; Analysis 1.1). We classified the magnitude of effect sizes as proposed by Juni 2006 . The effect size of 0.24 standard deviation units obtained for disability is considered small. It corresponds to an overlap in the distribution of participants allocated in the experimental or control interventions of about $85 \%$ of cases, indicating that only $15 \%$ of people would benefit from CIMT treatment after stroke. Also, the sample sizes of the 42 included studies were generally small.

It has been argued that only individuals presenting with mild to moderate paresis of the upper limb (Nijland 2010; Smania 2007), as well as those who are more motivated, would be eligible for CIMT treatment (Wissink 2014). Actually, from reports of included trials there is a clear difficulty in finding eligible participants. Sixtyone per cent for Lin 2010, and 93\% for Smania 2012, of people assessed for eligibility were excluded because they did not fit the inclusion criteria. Moreover, about $20 \%$ of eligible people refused to participate in the study. This means that only a small number of the people who were screened were included in these eligible trials. Moreover, the presence of movement requested as part of the inclusion criteria could have allowed for selection of those people with less severe stroke. Transcranial magnetic stimulation and diffusion tensor imaging studies show that voluntary wrist and finger extension are associated with the integrity of the corticospinal tract system (Butler 2007; Stinear 2007; Stinear 2010). Consequently, the characteristics of people to include in these trials raise questions about the application of this intervention in a wide range of stroke survivors.

The included studies were heterogeneous in participant and intervention characteristics for both CIMT and the control group. However, none of the subgroup analyses performed in this review (dose of treatment, time since stroke, anatomical region restraint) revealed a group of better responders. Although no evidence exists that the dose of CIMT influences the results, it does not imply that it is not important. Consequently, it is not possible to exclude the possibility that the high dose of CIMT reported in the Yoon 2014 study introduced heterogeneity in the analysis, thus providing overestimation of the effect of CIMT on disability. Finally, the results of this meta-analysis do not show that the first weeks after stroke onset are the most important for the application of CIMT, as studies on neuroplasticity might suggest (Sunderland 2005).

Improvements introduced by CIMT are mainly based on learning to optimise the use of end-effectors through compensatory strategies. The effects documented in this meta-analysis involve motor impairment and motor function without a translation in disability. This could be considered as surprising, as the rationale for CIMT is based on decreasing the learned non-use phenomenon, however, it could be due to the characteristics of the measures of disability.

The number of RCTs and the data that inform this review have increased over the past few years. However, the included studies were generally poor in terms of relevance of findings and quality of reporting. Only 11 out of 42 studies (with 344 participants) reported data on the most relevant clinical outcome - disability comparing CIMT with an active control intervention. Reporting was often incomplete, which made some studies uninformative.

The applicability of cumulative evidence characterised by a large number of small trials of uncertain quality challenges definitive conclusions about the role of CIMT; however, the findings of this review suggest that CIMT does not show relevant benefits for the outcomes that may matter most to people after their stroke.

\section{Quality of the evidence}

Three-quarters of the included trials can be considered to be at unclear risk of bias (see Risk of bias in included studies) for at least one key bias area. In fact, key methodological information was often not reported for sequence generation, allocation concealment, blinding, and missing data. Blinding of study personnel, particularly outcome assessors, was reported in the majority of studies.

Many trials were likely to be underpowered, likely to approach analyses on a per protocol basis, and had a strong inclination to perform multiple testing on function scales.

Recent meta-reporting studies showed promising improvements in the reporting of rehabilitation trials (Abdul Latif 2011; Villamar 2013), and reviews (DiSilvestro 2015; Gianola 2013). In the cohort of trials that have evaluated the effectiveness of CIMT, there were a few recent trials that adopted robust methods and accurate reporting of clinical and methodological aspects (Brunner 2012; Smania 2012; Treger 2012; Wolf 2006). These trials represent the next generation in terms of methodological issues, and a major step forward in research to understand fully the benefit and safety of rehabilitation techniques in comparative studies.

\section{Potential biases in the review process}

We chose disability as the primary outcome, although it was considered by a minority of eligible studies ( 11 studies with a total of 344 participants), whereas arm motor function was used as the primary outcome in the majority of included studies ( 28 studies with 858 participants).

Although the analysis showed the largest effect of CIMT on perceived arm motor function, caution is needed in interpreting this result, because of the lack of consistency in the MAL scale, as described in the Risk of bias in included studies section. Its clinimetric properties need further investigation in order to define its use in longitudinal studies.

Most trials were small, with some trials enrolling only six or 10 participants. This is unacceptable, given the high incidence of stroke and the opportunity to recruit a large sample. Our sample of trials may therefore have been influenced by publication bias, which tends to exaggerate the effect of treatment. The randomisation methods were described only in about half of the included trials. It is not possible to determine if some studies excluded participants after randomisation, or whether blinding was not adequately maintained. These weaknesses could be expected to lead to bias in favour of a treatment effect. The reporting of the data was poor; for example, many trials only reported that there were no significant differences between the intervention and the control groups. This lack of proper reporting could also be expected to lead to bias in favour of a treatment effect. It should also be noted that many authors of trials have a cultural and professional interest in disseminating positive results about the rehabilitative techniques they propose.

Finally, only one author of the review scanned the titles obtained from electronic databases searching in order to exclude irrelevant studies and this could have introduced bias. 


\section{AUTHORS' CONCLUSIONS}

\section{Implications for practice}

Compared with traditional rehabilitation, constraint-induced movement therapy (CIMT) is associated with limited improvements in motor impairment and motor function, but these benefits do not convincingly reduce disability. These results differ from our previous meta-analysis, which suggested a possible improvement in disability with CIMT. The recent studies included in this review did not confirm these findings, and data about the long-term effects of CIMT are limited.

CIMT can be considered a multifaceted intervention where the restriction of the less affected limb is accompanied by an increase in the amount and quality of exercise for the affected limb. The impact on arm impairment and motor function may not be due solely to the constraint, but also to the type and amount of exercise. However, this review could not identify which of these factors is more important.

The selection of participants for the included studies focused on people with stroke who had at least some active extension of the wrist and fingers, with limited pain or spasticity, plus good compliance with rehabilitation treatment. It appears that the review results apply most appropriately to this patient group. Many studies were underpowered with a high risk of small trial bias and publication bias. It is not clear if the apparent benefits on motor impairment and motor function can be translated into improvements in activities of daily living. Moreover, it is not possible to comment on the long-term effects of CIMT.

\section{Implications for research}

It is likely that additional randomised controlled trials (RCTs) investigating CIMT as a rehabilitation technique would be worthwhile if they:

- involve a control group under active treatment, since CIMT involves a certain amount of exercise;
- consider disability or arm motor function as the primary outcomes;

- include a validated quality of life measure as one of the outcomes; and

- determine and report the sample size and power analysis transparently.

CIMT trials do not make it clear which people might most benefit from this treatment. Participants in the RCTs were those with at least some active extension of wrist and fingers and with limited pain or spasticity. Researchers involved in future studies should analyse the correlation between participant characteristics and outcome improvements in order to identify responders to CIMT. Clinicians who aspire to offer their patients a tailored programme of CIMT need to examine individual characteristics carefully to identify potential factors that are likely to increase the limited chance of success of CIMT.

\section{ACKN OWLEDGEMENTS}

We renew our acknowledgements for all those people who helped in developing the protocol and the first version of this systematic review: we would like to thank Hazel Fraser for constant help and assistance, Brenda Thomas for help developing the search strategy, and the Cochrane Stroke Group Editorial Team.

Thanks to all the editors and reviewers that worked to improve the quality of this review: Peter Langhorne, Alex Pollock, Valentina Assi, Ruth Barclay, Brenda Thomas, and Kedar K Mate.

Thanks to Elizabeth Royle for her valuable copy-edit comments, to Francesca Nicastro for English language support, to Prof Winstein for her availability and support.

Thanks also to Profs Alberts, Atteya, Azab, Bergheim, Boake, Brogardh, Brunner, Dahl, Dromerick, Hammer, Hayner, Huseyinsinoglu, Khan, Kim, Krawczyk, Lin, Myint, Page, Ploughman, Singh, Smania, Suputtittada, Tariah, Taub, Treger, Van Delden, Wang, Wittenberg, Wolf, Wu, and Yoon for their availability and collaboration, and especially for their work and efforts to provide better care for people who have experienced a stroke. 


\section{R E F E R E N C E S}

\section{References to studies included in this review}

Alberts 2004 \{published data only\}

Alberts JL, Butler AJ, Wolf SL. The effects of constraintinduced therapy on precision grip: a preliminary study. Neurorehabilitation Neural Repair 2004;18(4):250-8. [MEDLINE: 15537995]

\section{Atteya 2004 \{published data only\}}

Atteya AAA. Effects of modified constraint induced movement therapy on upper limb function in subacute stroke patients. Neurosciences 2004;9(1):24-9.

\section{Azab 2009 \{published data only\}}

Azab M, Al-Jarrah M, Nazzal M, Maayah M, Abu Sammour M, Jamous M. Effectiveness of constraint-induced movement therapy (CIMT) as home-based therapy on Barthel Index in patients with chronic stroke. Topics in Stroke Rehabilitation 2009;16(3):207-11.

\section{Bergheim 2010 \{published data only\}}

Bergheim A. Modified constraint induced movement therapy versus traditional physiotherapy for cerebral infarction: a pilot study [Modifisert constraint-induced movement therapy versus tradisjonell fysioterapietter hjerneinfarkt: en pilot studie]. Fysioterapeuten 2010;2(10):16-22.

\section{Boake 2007 \{published data only\}}

Boake C, Noser EA, Ro T, Baraniuk S, Gaber M, Johnson R, et al. Constraint-induced movement therapy during early stroke rehabilitation. Neurorehabilitation and Neural Repair 2007;21(1):14-24.

\section{Brogårdh 2009 \{published data only\}}

Brogårdh C, Vestling M, Sjölund BH. Shortened constraintinduced movement therapy in subacute stroke - no effect of using a restraint: a randomized controlled study with independent observers. Journal of Rehabilitation Medicine 2009;41:231-6.

\section{Brunner 2012 \{published data only\}}

Brunner IC, Skouen JS, Strand LI. Is modified constraint-induced movement therapy more effective than bimanual training in improving arm motor function in the subacute phase post stroke? A randomized controlled trial. Clinical Rehabilitation 2012;26(12):1078-86.

\section{Dahl 2008 \{published data only\}}

Dahl AE, Askim T, Stock R, Langørgen E, Lydersen S, Indredavik B. Short- and long-term outcome of constraintinduced movement therapy after stroke: a randomized controlled feasibility trial. Clinical Rehabilitation 2008;22(5):436-47. [PUBMED: 18441040 ]

\section{Dromerick 2000 \{published data only\}}

Dromerick AW, Edwards DF, Hahn M, Dromerick AW, Edwards DF, Hahn M. Does the application of constraint-induced movement therapy during acute rehabilitation reduce arm impairment after ischemic stroke?. Stroke 2000;31(12):2984-8. [MEDLINE: 11108760]

\section{Dromerick 2009 \{published data only\}}

Dromerick AW, Lang CE, Birkenmeier RL, Wagner JM, Miller JP, Videen TO, et al. Very early constraint-induced movement during stroke rehabilitation (VECTORS): a single-center RCT. Neurology 2009;73:195-201.

\section{Hammer 2009 \{published and unpublished data\}}

* Hammer AM, Lindmark B. Effects of forced use on arm function in the subacute phase after stroke: a randomized, clinical pilot study. Physical Therapy 2009;89(6):526-39.

Hammer AM, Lindmark B. Is forced use of the paretic upper limb beneficial? A randomized pilot study during subacute poststroke recovery. Clinical Rehabilitation 2009;23(5):424-33.

Hayner 2010 \{published data only\}

Hayner K, Gibson G, Giles GM. Comparison of constraintinduced movement therapy and bilateral treatment of equal intensity in people with chronic upper-extremity dysfunction after cerebrovascular accident. American Journal of Occupational Therapy 2010;64:528-39.

Huseyinsinoglu 2012 \{published data only\}

Huseyinsinoglu BE, Ozdincler AR, Krespi Y. Bobath Concept versus constraint-induced movement therapy to improve arm functional recovery in stroke patients: a randomized controlled trial. Clinical Rehabilitation 2012;26(8):705-15.

Khan 2011 \{published data only\}

Khan CM, Oesch PR, Gamper UN, Kool JP, Beer S. Potential effectiveness of three different treatment approaches to improve minimal to moderate arm and hand function after stroke - a pilot randomized clinical trial. Clinical Rehabilitation 2011;25(11):1032-41.

Kim 2008 \{published data only\}

Kim DG, Cho YW, Hong JH, Song JC, Chung HA, Bai D, et al. Effect of constraint-induced movement therapy with modified opposition restriction orthosis in chronic hemiparetic patients with stroke. NeuroRehabilitation 2008;23:239-44.

Krawczyk 2012 \{published data only\}

Krawczyk M, Sidaway M, Radwan 'ska A, Zaborska J, Ujma R, Członkowska A. Effects of sling and voluntary constraint during constraint-induced movement therapy for the arm after stroke: a randomized, prospective, single-centre, blinded observer rated study. Clinical Rehabilitation 2012;26(11):990-8.

Lin 2007 \{published and unpublished data\}

Lin KC, Wu CY, Wei TH, Lee CY, Liu JS. Effects of modified constraint-induced movement therapy on reach-to-grasp movements and functional performance after chronic stroke: a randomized controlled study. Clinical Rehabilitation 2007;21:1075-86. 
Lin 2009a \{published data only\}

* Lin K, Chang Y, Wu C, Chen Y. Effects of constraint-induced therapy versus bilateral arm training on motor performance, daily functions, and quality of life in stroke survivors. Neurorehabilitation and Neural Repair 2009;23(5):441-8.

Wu C, Hsieh Y, Lin K, Chuang L, Chang Y, Liu H, et al. Brain reorganization after bilateral arm training and distributed constraint-induced therapy in stroke patients: a preliminary functional magnetic resonance imaging study. Chang Gung Medical Journal 2010;33(6):628-38.

\section{Lin 2010 \{published data only\}}

Lin K, Chung H, Wu C, Liu H, Hsieh Y, Chen I, et al. Constraintinduced therapy versus control intervention in patients with stroke: a functional magnetic resonance imaging study. American Journal of Physical Medicine and Rehabilitation 2010;89(3):177-85.

\section{Myint 2008 \{published data only\}}

Myint JMWW, Yuen GFC, Yu TKK, Kng CPL, Wong AMY, Chow KKC, et al. A study of constraint-induced movement therapy in subacute stroke patients in Hong Kong. Clinical Rehabilitation 2008;22:112-24.

\section{Page 2001 \{published data only\}}

Page SJ, Sisto SA, Levine P, Johnston MV, Hughes M, Ge SJ, et al. Modified constraint induced therapy: a randomized feasibility and efficacy study. Journal of Rehabilitation Research and Development 2001;38(5):583-90. [MEDLINE: 11732835]

\section{Page 2002b \{published data only\}}

Page SJ, Sisto S, Johnston MV, Levine P. Modified constraintinduced therapy after subacute stroke: a preliminary study. Neurorehabilitation and Neural Repair 2002;16(3):290-5. [MEDLINE: 12234091]

\section{Page 2004 \{published data only\}}

Page SJ, Sisto S, Levine P, McGrath RE. Efficacy of modified constraint-induced movement therapy in chronic stroke: a single-blinded randomized controlled trial. Archives of Physical Medicine and Rehabilitation 2004;85(1):14-8. [MEDLINE: 14970962]

\section{Page 2005b \{published data only\}}

Page SJ, Levine P, Leonard AC. Modified constraint-induced therapy in acute stroke: a randomized controlled pilot study. Neurorehabilitation and Neural Repair 2005;19(1):27-32. [MEDLINE: 15673841]

\section{Page 2008 \{published data only\}}

Page SJ, Levine P, Leonard A, Szaflarski JP, Kissela BM. Modified constraint-induced therapy in chronic stroke: results of a single-blinded randomized controlled trial. Physical Therapy 2008;88(3):333-40

\section{Ploughman 2004 \{published and unpublished data\}}

Ploughman M, Corbett D. Can forced-use therapy be clinically applied after stroke? An exploratory randomized controlled trial. Archives of Physical Medicine and Rehabilitation 2004;85(9):1417-23. [MEDLINE: 15375810]
Singh 2013 \{published data only\}

Singh P, Pradhan B. Study to assess the effectiveness of modified constraint-induced movement therapy in stroke subjects: a randomized controlled trial. Annals of Indian Academy of Neurology 2013;16(2):180-4.

\section{Smania 2012 \{published data only\}}

Smania N, Gandolfi M, Paolucci S, Iosa M, lanes P, Recchia S, et al. Reduced-intensity modified constraint-induced movement therapy versus conventional therapy for upper extremity rehabilitation after stroke: a multicenter trial. Neurorehabilitation and Neural Repair 2012;26(9):1035-45.

Suputtitada 2004 \{published data only\}

Suputtitada A, Suwanwela NC, Tumvitee S. Effectiveness of constraint-induced movement therapy in chronic stroke patients. Journal of the Medical Association of Thailand 2004;87(12):1482-90. [MEDLINE: 15822545]

Tariah 2010 \{published data only\}

Tariah HA, Almalty A, Sbeih Z, Al-Oraibi S. Constraint induced movement therapy for stroke survivors in Jordon: a home-based model. International Journal of Therapy and Rehabilitation 2010;17(12):638-46.

Taub 1993 \{published and unpublished data\} Taub E, Miller NE, Novack TA, Cook EW 3rd, Fleming WC, Nepomuceno CS, et al. Technique to improve chronic motor deficit after stroke. Archive of Physical Medicine and Rehabilitation 1993;74:347-54. [MEDLINE: 8466415]

Treger 2012 \{published data only\}

Treger I, Aidinof L, Lehrer H, Kalichman L. Modified constraintinduced movement therapy improved upper limb function in subacute poststroke patients: a small-scale clinical trial. Topics in Stroke Rehabilitation 2012;19(4):287-93.

\section{Van Delden 2013 \{published data only\}}

Van Delden AEQ, Peper CE, Nienhuys KN, Zijp NI, Beek PJ, Kwakkel G. Unilateral versus bilateral upper limb training after stroke. the Upper Limb Training After Stroke clinical trial. Stroke 2013;44:2613-6.

\section{Wang 2011 \{published data only\}}

Wang Q, Zhao J, Zhu Q, Li J, Meng P. Comparison of conventional therapy, intensive therapy and modified constraint-induced movement therapy to improve upper extremity function after stroke. Journal of Rehabilitation Medicine 2011;43:619-25.

\section{Wittenberg 2003 \{published and unpublished data\}}

Wittenberg GF, Chen R, Ishii K, Bushara KO, Eckloff S, Croarkin $\mathrm{E}$, et al. Constraint-induced therapy in stroke: magnetic-stimulation motor maps and cerebral activation. Neurorehabilitation and Neural Repair 2003;17(1):48-57. [MEDLINE: 12645445]

Wolf 2006 \{unpublished data only\}

* Wolf SL, Winstein CJ, Miller JP, Taub E, Uswatte G, Morris D, et al. Effect of constraint-induced movement therapy on upper 
extremity function 3 to 9 months after stroke: the EXCITE randomized clinical trial. JAMA 2006;296(17):2095-104.

Wolf SL, Winstein CJ, Miller JP, Thompson PA, Taub E, Uswatte $\mathrm{G}$, et al. Retention of upper limb function in stroke survivors who have received constraint-induced movement therapy: the EXCITE randomised trial. Lancet Neurology 2008;7:33-40.

\section{Wu 2007a \{published and unpublished data\}}

Wu CY, Lin KC, Chen HC, Chen IH, Hong WH. Effects of modified constraint-induced movement therapy on movement kinematics and daily function in patients with stroke: a kinematic study of motor control mechanisms. Neurorehabilitation and Neural Repair 2007;21(5):460-6. [MEDLINE: 17601803]

\section{Wu 2007b \{published and unpublished data\}}

Wu CY, Chen CL, Tang SF, Lin KC, Huang YY. Kinematic and clinical analyses of upper-extremity movements after constraint-induced movement therapy in patients with stroke: a randomized controlled trial. Archives of Physical Medicine and Rehabilitation 2007;88:964-70.

\section{Wu 2007c \{published and unpublished data}

Wu CY, Chen CL, Tsai WC, Lin KC, Chou SH. A randomized controlled trial of modified constraint-induced movement therapy for elderly stroke survivors: changes in motor impairment, daily functioning and quality of life. Archives of Physical Medicine and Rehabilitation 2007;88:273-8.

\section{Wu 2011 \{published data only\}}

Wu C, Chuang L, Lin K, Chen H, Tsay P. Randomized trial of distributed constraint-induced therapy versus bilateral arm training for the rehabilitation of upper-limb motor control and function after stroke. Neurorehabilitation and Neural Repair 2011;25(2):130-9.

\section{Wu 2012a \{published data only\}}

Wu C, Chen Y, Lin K, Chao C, Chen Y. Constraint-induced therapy with trunk restraint for improving functional outcomes and trunk-arm control after stroke: a randomized controlled trial. Physical Therapy 2012;92(4):483-92.

Yoon 2014 \{published data only\}

Yoon JA, Koo BI, Shin MJ, Shin YB, Ko H, Shin Y. Effect of constraint-induced movement therapy and mirror therapy for patients with subacute stroke. Annals of Rehabilitation Medicine 2014;38(4):458-66

\section{References to studies excluded from this review}

\section{Brogårdh 2006 \{published data only\}}

Brogardh C, Flansbjer U. What is the long-term benefit of constraint-induced movement therapy? A four-year follow-up. Clinical Rehabilitation 2009;23:418-23.

* Brogårdh C, Sjölund BH. Constraint-induced movement therapy in patients with stroke: a pilot study on effects of small group training and of extended mitt use. Clinical Rehabilitation 2006;20(3):218-27. [MEDLINE: 16634340]

\section{Fuzaro 2012 \{published data only\}}

Fuzaro AC, Guerreiro CT, Galetti FC, Jucá RBVM, de Araujo JE. Modified constraint-induced movement therapy and modified forced-use therapy for stroke patients are both effective to promote balance and gait improvements. Revista Brasileira de Fisioterapia 2012;16(2):157-65.

Gautier 2008 \{published data only\}

Gauthier LV, Taub E, Perkins C, Ortmann M, Mark VW, Uswatte G. Remodeling the brain: plastic structural brain changes produced by different motor therapies after stroke. Stroke 2008;39(5):1520-5.

Lin 2008 \{published data only\}

Lin KC, Wu CY, Liu JS. A randomized controlled trial of constraint-induced movement therapy after stroke. Acta Neurochirurgica. Supplement 2008;101:61-4.

\section{Lin 2009b \{published data only\}}

Lin K, Wu C, Liu J, Chen Y, Hsu C. Constraint-induced therapy versus dose-matched control intervention to improve motor ability, basic/extended daily functions, and quality of life in stroke. Neurorehabilitation and Neural Repair 2009;23(2):160-5.

\section{Sawaki 2014 \{published data only\}}

Sawaki L, Butler AJ, Leng X, Wassenaar PA, Mohammad YM, Blanton S, Sathian K, Nichols-Larsen DS, Wolf SL, Good DC, Wittenberg GF. Differential patterns of cortical reorganization following constraint-induced movement therapy during early and late period after stroke: A preliminary study. NeuroRehabilitation 2014;35(3):415-26.

\section{Tan 2012 \{published data only\}}

Tan C, Tretriluxana J, Pitsch E, Runnarong N, Winstein CJ. Anticipatory planning of functional reach-to-grasp: a pilot study. Neurorehabilitation and Neural Repair 2012;26(8):957-67.

\section{Van der Lee 1999 \{published data only\}}

van der Lee JH, Wagenaar RC, Lankhorst GJ, Vogelaar TW, Deville WL, Bouter LM. Forced use of the upper extremity in chronic stroke patients: results from a single-blind randomized clinical trial. Stroke 1999;30(11):2369-75. [MEDLINE: 10548673]

\section{Wu 2012b $\{$ published data only\}}

Wu C, Chen Y, Chen H, Lin K, Yeh I. Pilot trial of distributed constraint-induced therapy with trunk restraint to improve poststroke reach to grasp and trunk kinematics. Neurorehabilitation and Neural Repair 2012;26(3):247-55.

\section{References to studies awaiting assessment}

\section{Barzel 2015 \{published data only\}}

Barzel A, Ketels G, Tetzlaff B, Krüger H, Haevernick K, Daubmann $A$, et al. Enhancing activities of daily living of chronic stroke patients in primary health care by modified constraintinduced movement therapy (HOMECIMT): study protocol for a cluster randomized controlled trial. Trials 2013;14:334. 
Boe 2014 \{unpublished data only\}

Boe S. Atlantic Canada Modified Constraint Induced Movement Therapy Trial. ClinicalTrials.gov (accessed 1 June 2015). [NCT01283620]

\section{Dos Santos 2012 \{unpublished data only\}}

dos Santos LB. Impact of the restriction of the non paretic upper limb in rehabilitation of patients post-stroke: randomized clinical trial. ClinicalTrials.gov (accessed 1 June 2015). [NCT01623973]

\section{Jansa 2007 \{unpublished data only\}}

Jansa J, Puh U, Angleitner K, Sicherl Z, Mesec A. Functional evaluation of constraint-induced movement therapy (CIMT) in acute stroke. European Journal of Neurology 2007; Vol. 14, issue 1 Suppl:152-3.

\section{Olivier 2012 \{unpublished data only\}}

Olivier S. Effects of a modified constraint induced therapy intervention in stroke patients: a multicenter, randomized controlled trial. ClinicalTrials.gov (accessed 1 June 2015). [NCT00839670]

\section{Uswatte 2014 \{unpublished data only\}}

Uswatte G. Constraint-induced therapy modified for rehabilitating arm function in stroke survivors $\mathrm{w} /$ plegic hands. ClinicalTrials.gov (accessed 1 June 2015). [NCT00366210]

\section{References to ongoing studies}

\section{Gautier 2015 \{unpublished data only\}}

Gautier L. Examining how motor rehabilitation promotes brain reorganization following stroke, an MRI study. ClinicalTrials.gov (accessed 1 June 2015). [NCT01725919]

\section{Padovani Do Santos 2015 \{published data only\}}

Padovani dos Santos T. Checking a security protocol of modified forced use therapy and efficacy reducing the constriction of the movement time in 12 hours. ClinicalTrials.gov (accessed 1 June 2015).

\section{Pereira 2015 \{unpublished data only\}}

Pereira ND, Camargo PR, Furtado CH. Effects of constraintinduced therapy for the scapular kinematics and related to the quality of movement in patients with severe chronic hemiparesis. ClinicalTrials.gov (accessed 1 June 2015). [NCT02373436]

\section{Additional references}

\section{Abdul Latif 2011}

Abdul Latif L, Daud Amadera JE, Pimentel D, Pimentel T, Fregni F. Sample size calculation in physical medicine and rehabilitation: a systematic review of reporting, characteristics, and results in randomized controlled trials. Archives of Physical Medicine and Rehabilitation 2011;92(2):306-15.

\section{Albert 2012}

Albert SJ, Kesselring J. Neurorehabilitation of stroke. Journal of Neurology 2012;259(1):817-32.

\section{Altman 1990}

Altman DG, Dore CJ. Randomisation and baseline comparisons in clinical trials. Lancet 1990;335:149-53.

\section{Burns 2007}

Burns A, Burridge J, Pickering R. Does the use of a constraint mitten to encourage use of the hemiplegic upper limb improve arm function in adults with subacute stroke?. Clinical Rehabilitation 2007;21(10):895-904. [MEDLINE: 17981848]

\section{Butler 2007}

Butler A, Wolf S. Putting the brain on the map: use of transcranial magnetic stimulation to assess and induce cortical plasticity of upper-extremity movement. Physical Therapy 2007;87:719-36.

\section{Crow 1989}

Crow JL, Lincoln NB, Nouri FM, De Weerdt W. The effectiveness of EMG biofeedback in the treatment of arm function after stroke. International Disability Studies 1989;11(4):155-60. [MEDLINE: 90375404]

\section{Dayan 2013}

Dayan E, Censor N, Buch ER, Sandrini M, Cohen LG. Noninvasive brain stimulation: from physiology to network dynamics and back. Nature Neuroscience 2013;16(7):838-44.

\section{Deeks 2001}

Deeks JJ, Altman DG, Bradburn MJ. Statistical methods for examining heterogeneity and combining results from several studies in meta-analysis. In: Egger M, Davey Smith G, Altman DG editor(s). Systematic Reviews in Health Care: Meta-analysis in Context. 2nd Edition. London: BMJ Publication Group, 2001.

\section{DiSilvestro 2015}

DiSilvestro KJ, Tjoumakaris FP, Maltenfort MG, Spindler KP, Freedman KB. Systematic reviews in sports medicine. American Journal of Sports Medicine 2015 Apr 21 [Epub ahead of print]. [PUBMED: 25899433]

\section{Edwards 1998}

Edwards SJL, Lilford RJ, Braunholtz DA, Jackson JC, Hewison J, Thornton J. Ethical issues in the design and conduct of randomized controlled trials. Health Technology Assessments 1998;2:1-130.

\section{Engauge Software 5.1 [Computer program]}

http://digitizer.sourceforge.net/. Engauge Digitizer. http:// digitizer.sourceforge.net/, 2011.

\section{French 2007}

French B, Thomas LH, Leathley MJ, Sutton CJ, McAdam J, Forster A, et al. Repetitive task training for improving functional ability after stroke. Cochrane Database of Systematic Reviews 2007, Issue 4. [DOI: 10.1002/14651858.CD006073.pub2]

\section{Gianola 2013}

Gianola S, Gasparini M, Agostini M, Castellini G, Corbetta D, Gozzer P, et al. Survey of the reporting characteristics of systematic reviews in rehabilitation. Physical Therapy 2013;93(11):1456-66. 


\section{Gustavsson 2010}

Gustavsson A, Svensson M, Jacobi F, Allgulander C, Alonso J, Beghi E. Cost of disorders of the brain in Europe 2010. European Neuropsychopharmacology 2011;21:718-79.

\section{Hatano 1976}

Hatano S. Experience from a multicenter stroke register: a preliminary report. Bulletin of the World Health Organization 1976;54:541-53.

\section{Hesse 2003}

Hesse S, Schulte-Tigges G, Konrad M, Bardeleben A, Werner C. Robot-assisted arm trainer for the passive and active practice of bilateral forearm and wrist movements in hemiparetic subjects. Archives of Physical Medicine and Rehabilitation 2003;84(6):915-20. [MEDLINE: 12808550]

\section{Higgins 2011}

Higgins JPT, Green S (editors). Cochrane Handbook for Systematic Reviews of Interventions Version 5.1.0 [updated March 2011]. The Cochrane Collaboration, 2011. Available from www.cochrane-handbook.org.

\section{Hoare 2007}

Hoare BJ, Wasiak J, Imms C, Carey L. Constraint -induced movement therapy in the treatment of the upper limb in children with hemiplegic cerebral palsy. Cochrane Database of Systematic Reviews 2007, Issue 2. [DOI: 10.1002/14651858.CD004149.pub2]

\section{Hotopf 1997}

Hotopf M, Lewis G, Normand C. Putting trials on trial - the costs and consequences of small trials in depression: a systematic review of methodology. Journal of Epidemiology and Community Health 1997;51(4):354-8. [MEDLINE: 9328538]

\section{Hotopf 1999}

Hotopf M, Churchill R, Lewis G. Pragmatic randomised controlled trials in psychiatry. British Journal of Psychiatry 1999;175:217-23.

\section{Juni 2006}

Juni P, Reichenbach S, Dieppe P. Osteoarthritis: rational approach to treating the individual. Best Practice and Research. Clinical Rheumatology 2006;20(4):721-40.

\section{Kagan 2012}

Kagan A, Korner-Bitensky N. Virtual reality - upper extremity. Stroke Engine Intervention. Montreal: McGill University. Available at: http://www.strokengine.ca/intervention/virtualreality-upper-extremity/ 2009 (accessed 30 May 2015).

\section{Kim 2004}

Kim YH, Park JW, Ko MH, Jang SH, Lee PK. Plastic changes of motor network after constraint-induced movement therapy. Yonsei Medical Journal 2004;45(2):241-6. [MEDLINE: 15118995]

\section{Knapp 1963}

Knapp HD, Taub E, Berman AJ. Movements in monkeys with deafferented forelimbs. Experimental Neurology 1963;7:305-15. [MEDLINE: 14033714]

\section{Lang 2008}

Lang CE, Edwards DF, Birkenmeier RL, Dromerick AW. Estimating minimal clinically important differences of upperextremity measures early after stroke. Archives of Physical Medicine and Rehabilitation 2008;89(9):1693-700.

\section{Laver 2011}

Laver KE, George S, Thomas S, Deutsch JE, Crotty M. Virtual reality for stroke rehabilitation. Cochrane Database of Systematic Reviews 2011, Issue 9. [DOI: 10.1002/14651858.CD008349.pub2]

\section{Levy 2001}

Levy CE, Nichols DS, Schmalbrock PM, Keller P, Chakeres DW. Functional MRI evidence of cortical reorganization in upperlimb stroke hemiplegia treated with constraint-induced movement therapy. American Journal of Physical Medicine and Rehabilitation 2001;80(1):4-12. [MEDLINE: 21019896]

\section{Liepert 2000}

Liepert J, Bauder H, Wolfgang HR, Miltner WH, Taub E, Weiller C. Treatment-induced cortical reorganization after stroke in humans. Stroke 2000;31(6):1210-6. [MEDLINE: 10835434]

\section{Liepert 2001}

Liepert J, Uhnde I, Graf S, Leidner O, Weiller C. Motor cortex plasticity during forced-use therapy in stroke patients: a preliminary study. Journal of Neurology 2001;248(4):315-21. [MEDLINE: 21268483]

\section{Lum 2002}

Lum PS, Burgar CG, Shor PC, Majmundar M, Van der Loos M. Robot-assisted movement training compared with conventional therapy techniques for the rehabilitation of upper-limb motor function after stroke. Archives of Physical Medicine and Rehabilitation 2002;83(7):952-9. [MEDLINE: 12098155]

\section{Masiero 2007}

Masiero S, Celia A, Rosati G, Armani M. Robotic-assisted rehabilitation of the upper limb after acute stroke. Archives of Physical Medicine and Rehabilitation 2007;88(2):142-9. [MEDLINE: 17270510]

\section{McCombe Waller 2008}

McCombe Waller S, Whitall J. Bilateral arm training: why and who benefits?. NeuroRehabiltiation 2008;23:29-41.

\section{Mehrholz 2012}

Mehrholz J, Platz T, Kugler J, Pohl M. Electromechanical and robot-assisted arm training for improving generic activities of daily living, arm function, and arm muscle strength after stroke. Cochrane Database of Systematic Reviews 2012, Issue 6. [DOI: 10.1002/14651858.CD006876.pub3]

\section{Michielsen 2010}

Michielsen ME, Selles RW, van der Geest JN, EckhardtM, Yavuzer G, Stam HJ, et al. Motor recovery and cortical reorganization after mirror therapy in chronic stroke patients. Neurorehabilitation and Neural Repair 2011;25(3):223-33. 


\section{Miller 2010}

Miller E, Murray L, Richards L, Zorowitz R, Bakas T. Comprehensive overview of nursing and interdisciplinary rehabilitation care of the stroke patient: a scientific statement from the American Heart Association. Stroke 2010;41:2402-48.

\section{Miltner 1999}

Miltner WH, Bauder H, Sommer M, Dettmers C, Taub E. Effects of constraint-induced movement therapy on patients with chronic motor deficits after stroke: a replication. Stroke 1999;30(3):586-92. [MEDLINE: 10066856]

\section{Moreland 1994}

Moreland J, Thomson MA. Efficacy of electromyographic biofeedback compared with conventional physical therapy for upper-extremity function in patients following stroke: a research overview and meta-analysis. Physical Therapy 1994;74(6):534-47. [MEDLINE: 94255537]

\section{Nijland 2010}

Nijland $\mathrm{RH}$, van Wegen EE, Harmeling-van der Wel BC, Kwakkel G, EPOS Investigators. Presence of finger extension and shoulder abduction within 72 hours after stroke predicts functional recovery: early prediction of functional outcome after stroke: the EPOS cohort study. Stroke 2010;41(4):745-50.

\section{Page 2002a}

Page SJ, Sisto S, Johnston MV, Levine P, Hughes M. Modified constraint-induced therapy in subacute stroke: a case report. Archive of Physical Medicine and Rehabilitation 2002;82(3):286-90. [MEDLINE: 11833037]

\section{Page 2005a}

Page SJ, Levine P, Leonard AC. Effects of mental practice on affected limb use and function in chronic stroke. Archives of Physical Medicine and Rehabilitation 2005;86(3):399-402. [MEDLINE: 15759218]

\section{Page 2007a}

Page SJ, Levine P, Leonard A. Mental practice in chronic stroke: results of a randomized, placebo-controlled trial. Stroke 2007;38(4):1293-7. [MEDLINE: 17332444]

\section{Pollock 2014}

Pollock A, Farmer SE, Brady MC, Langhorne P, Mead GE, Mehrholz J, et al. Interventions for improving upper limb function after stroke. Cochrane Database of Systematic Reviews 2014, Issue 11. [DOI: 10.1002/14651858.CD010820.pub2]

\section{Pomeroy 2006}

Pomeroy VM, King L, Pollock A, Baily-Hallam A, Langhorne P. Electrostimulation for promoting recovery of movement of functional ability after stroke. Cochrane Database of Systematic Reviews 2006, Issue 2. [DOI: 10.1002/14651858.CD003241.pub2]

\section{Rathkolb 1990}

Rathkolb O, Baykoushev S, Baykousheva V. Myobiofeedback in motor reeducation of wrist and fingers after hemispherical stroke. Electromyography and Clinical Neurophysiology 1990;30(2):89-92. [MEDLINE: 90183897]

\section{RevMan 2014 [Computer program]}

The Nordic Cochrane Centre, The Cochrane Collaboration. Review Manager (RevMan). Version 5.3. Copenhagen: The Nordic Cochrane Centre, The Cochrane Collaboration, 2014.

\section{Ro 2006}

Ro T, Noser E, Boake C, Johnson R, Gaber M, Speroni A, et al. Functional reorganization and recovery after constraint-induced movement therapy in subacute stroke: case reports. Neurocase 2006;12(1):50-60. [MEDLINE: 16517515]

\section{Saka 2009}

Saka Ö, Mcguire A, Wolfe C. Cost of stroke in the United Kingdom. Age and Ageing 2009;38:27-32.

\section{Sathian 2000}

Sathian K, Greenspan Al, Wolf SL. Doing it with mirrors: a case study of a novel approach to neurorehabilitation. Neurorehabilitation and Neural Repair 2000;14(1):73-6. [MEDLINE: 21121801]

\section{Schaechter 2002}

Schaechter JD, Kraft E, Hilliard TS, Dijkhuizen RM, Benner T, Finklestein SP, et al. Motor recovery and cortical reorganization after constraint-induced movement therapy in stroke patients: a preliminary study. Neurorehabilitation and Neural Repair 2002;16(4):326-38. [MEDLINE: 22348420]

\section{Sirtori 2003}

Sirtori V, Gatti R, Corbetta D. Constraint induced movement therapy for upper extremities in stroke patients. Cochrane Database of Systematic Reviews 2003, Issue 4. [DOI: 10.1002/14651858.CD004433]

\section{Smania 2007}

Smania N, Paolucci S, Tinazzi M, Borghero A, Manganotti P, Fiaschi A, et al. Active finger extension: a simple movement predicting recovery of arm function in patients with acute stroke. Stroke 2007;38(3):1088-90.

\section{Sterr 2006}

Sterr A, Szameitat A, Shen S, Freivogel S. Application of the CIT concept in the clinical environment: hurdles, practicalities, and clinical benefits. Cognitive and Behavioral Neurology 2006;19(1):48-54. [MEDLINE: 16633019]

\section{Stinear 2007}

Stinear C, Barber P, Smale P, Coxon J, Fleming M, Byblow W. Functional potential in chronic stroke patients depends on corticospinal tract integrity. Brain 2007;130:170-80.

\section{Stinear 2010}

Stinear C. Prediction of recovery of motor function after stroke. Lancet Neurology 2010;9:1228-32.

\section{Sunderland 2005}

Sunderland A, Tuke A. Neuroplasticity, learning and recovery after stroke: a critical evaluation of constraint-induced therapy. Neuropsychological Rehabilitation 2005;15(2):81-96. [MEDLINE: 16353503] 


\section{Szaflarski 2006}

Szaflarski JP, Page SJ, Kissela BM, Lee JH, Levine P, Strakowski SM. Cortical reorganization following modified constraint-induced movement therapy: a study of 4 patients with chronic stroke. Archives of Physical Medicine and Rehabilitation 2006;87(8):1052-8. [MEDLINE: 16876549]

\section{Taub 1977}

Taub E, Heitmann RD, Barro G. Alertness, level of activity, and purposive movement following somatosensory deafferentation in monkeys. Annals of the New York Academy of Sciences 1977;290:348-65. [MEDLINE: 96722]

\section{Taub 1980}

Taub E, Harger M, Grier HC, Hodos W. Some anatomical observations following chronic dorsal rhizotomy in monkeys. Neuroscience 1980;5(2):389-401. [MEDLINE: 6769070]

\section{Taub 1994}

Taub E, Crago JE, Burgio LD, Groomes TE, Cook EW, DeLuca SC, et al. An operant approach to rehabilitation medicine: overcoming learned nonuse by shaping. Journal of the Experimental Analysis of Behavior 1994;61(2):281-93. [MEDLINE: 94223269]

\section{Taub 1999}

Taub E, Uswatte G, Pidikiti R. Constraint-induced movement therapy: a new family of techniques with broad application to physical rehabilitation - a clinical review. Journal of Rehabilitation Research and Development 1999;36(3):237-51. [MEDLINE: 10659807]

\section{Van der Lee 2004}

Van der Lee JH, Beckerman H, Knol DL, de Vet HCW, Bouter LM. Clinimetric properties of the Motor Activity Log for the assessment of arm use in hemiparetic patients. Stroke 2004;35:1410-4.

\section{Villamar 2013}

Villamar MF, Contreras VS, Kuntz RE, Fregni F. The reporting of blinding in physical medicine and rehabilitation randomized controlled trials: a systematic review. Journal of Rehabilitation Medicine 2013;45(1):6-13.

\section{Wade 1987}

Wade D, Hewer R. Functional abilities after stroke: measurement, natural history and prognosis. Journal of Neurology, Neurosurgery, and Psychiatry 1987;50:177-82.

\section{WHO 2011}

World Health Organization. The atlas of heart disease and stroke. http://www.who.int/cardiovascular_diseases/en/cvd_ atlas_15_burden_stroke.pdf?ua=1 (accessed on 1 June 2015).

\section{Wissink 2014}

Wissink KS, Spruit-van Eijk M, Buijck BI, Koopmans RT, Zuidema SU. Stroke rehabilitation in nursing homes: intensity of and motivation for physiotherapy. Tijdschrift voor Gerontologie en Geriatrie 2014;45(3):144-53. [PUBMED: 24801121]

\section{References to other published versions of this review}

\section{Bjorklund 2006}

Bjorklund A, Fecht A. The effectiveness of constraint-induced therapy as a stroke intervention: a meta-analysis. Occupational Therapy in Health Care 2006;20(2):31-49.

\section{Bonaiuti 2007}

Bonaiuti D, Rebasti L, Sioli P. The constraint induced movement therapy: a systematic review of randomised controlled trials on the adult stroke patients. Europa Medicophysica 2007;43(2):139-46. [MEDLINE: 17525700]

\section{Corbetta 2010}

Corbetta D, Sirtori V, Moja L, Gatti R. Constraint-induced movement therapy in stroke patients: systematic review and meta-analysis. European Journal of Physical and Rehabilitation Medicine 2010;46:537-44.

\section{French 2008}

French B, Leathley M, Sutton C, McAdam J, Thomas L, Forster A, et al. A systematic review of repetitive functional task practice with modelling of resource use, costs and effectiveness. Health Technology Assessment 2008;12(30):1-4.

\section{Hakkennes 2005}

Hakkennes S, Keating JL. Constraint-induced movement therapy following stroke: a systematic review of randomised controlled trials. Australian Journal of Physiotherapy 2005;51(4):221-31. [MEDLINE: 16321129]

\section{Kwakkel 2015}

Kwakkel G, Veerbeek JM, van Wegen EE, Wolf SL. Constraintinduced movement therapy after stroke. Lancet Neurology 2015;14(2):224-34. [PUBMED: 25772900]

\section{Mark 2006}

Mark VW, Taub E, Morris DM. Neuroplasticity and constraintinduced movement therapy. Europa Medicophysica 2006;42:269-84.

\section{McIntyre 2012}

McIntyre A, Viana R, Janzen S, Mehta S, Pereira S, Teasell R. Systematic review and meta-analysis of constraint-induced movement therapy in the hemiparetic upper extremity more than six months post stroke. Topics in Stroke Rehabilitation 2012;19(6):499-513.

\section{Nijland 2011}

Nijland R, Kwakkel G, Bakers J, van Wegen E. Constraint-induced movement therapy for the upper paretic limb in acute or subacute stroke: a systematic review. International Journal of Stroke 2011;6:425-33.

\section{Pelton 2012}

Pelton T, van Vliet P, Hollands K. Interventions for improving coordination of reach to grasp following stroke: a systematic review. International Journal of Evidence-based Healthcare 2012;10:89-102. 


\section{Peurala 2011}

Peurala Sh, Kantanen MP, Sjögren T, Paltamaa J, Karhula M, Heinonen A. Effectiveness of constraint-induced movement therapy on activity and participation after stroke: a systematic review and meta-analysis of randomized controlled trials. 2011 26;3:209-23.

\section{Shi 2011}

Shi YX, Tian JH, Yang KH, Zhao Y. Modified constraint-induced movement therapy versus traditional rehabilitation in patients with upper-extremity dysfunction after stroke: a systematic review and meta-analysis. Archives of Physical Medicine and Rehabilitation 2011;92:972-82.

\section{Sirtori 2009}

Sirtori V, Corbetta D, Moja L, Gatti R. Constraint-induced movement therapy for upper extremities in stroke patients.
Cochrane Database of Systematic Reviews 2009, Issue 4. [DOI: 10.1002/14651858.CD004433]

\section{Stevenson 2012}

Stevenson T, Thalman L, Christie H, Poluha W. Constraintinduced movement therapy compared to dose-matched interventions for upper-limb dysfunction in adult survivors of stroke: a systematic review with meta-analysis. Physiotherapy Canada 2012;64(4):397-413.

\section{Thrane 2014}

Thrane G, Friborg O, Anke A, Indredavik B. A meta-analysis of constraint-induced movement therapy after stroke. Journal of Rehabilitation Medicine 2014;46(9):833-42.

* Indicates the major publication for the study

\section{CHARACTERISTICS OF STUDIES}

Characteristics of included studies [ordered by study ID]

Alberts 2004

$\begin{array}{ll}\text { Methods } & \text { Randomisation automated and balanced with respect to sex, premorbid handedness, side of stroke } \\ \text { and level of function } & \text { Blinded outcome assessor } \\ \text { No information about withdrawals } \\ \text { Multicentre, outpatients }\end{array}$

Participants USA

Recruited from 247 facilities spanning the 7 participating sites participating in a multi-site trial

10 participants: 5 intervention, 5 control

Inclusion criteria: cerebrovascular accident between 3 and 9 months, $10^{\circ}$ of active extension to the metacarpophalangeal and interphalangeal joints and $20^{\circ}$ at wrist, minimum passive range of motion of $90^{\circ}$ for shoulder flexion and abduction

Exclusion criteria: score of $<24$ on the MMSE, physician-determined major medical problems that would interfere with participation

Mean age (SD): intervention group: 65 (8.2) years, control group: 63.4 (15.5) years $\%$ women: intervention group $60 \%$, control group: $40 \%$

Stroke details: only ischaemic, $20 \%$ with right hemiparesis in each group

Time since stroke, mean (SD): intervention group 6.4 (1.1) months, control group 5.6 (1.5) months

CIMT versus no treatment

CIMT: shaping or adaptive task practice and repetitive task practice techniques

Amount of restraint: $90 \%$ of waking hours per day

Anatomical region restraint: hand

Session duration: 6 hours per day, 5 days per week for 2 weeks

\begin{tabular}{ll}
\hline Outcomes & Measures pre/post treatment \\
& - Arm motor function: WMFT \\
- Arm motor impairment: FMA, grip/force
\end{tabular}


Alberts 2004 (Continued)

Notes

\section{Risk of bias}

\begin{tabular}{lll}
\hline Bias & Authors' judgement & Support for judgement \\
\hline $\begin{array}{l}\text { Random sequence genera- } \\
\text { tion (selection bias) }\end{array}$ & Low risk & $\begin{array}{l}\text { Sequence generation by random automated generator } \\
\text { Quote: "Ten patients were randomly assigned to 1 of 2 groups" }\end{array}$ \\
\hline $\begin{array}{l}\text { Allocation concealment } \\
\text { (selection bias) }\end{array}$ & Low risk & Central allocation \\
\hline $\begin{array}{l}\text { Blinding (performance } \\
\text { bias and detection bias) } \\
\text { All outcomes }\end{array}$ & Low risk & $\begin{array}{l}\text { Quote: "An evaluator blinded to group assignment performed pre- and post- } \\
\text { WMFT and FMA assessments" }\end{array}$ \\
\hline $\begin{array}{l}\text { Incomplete outcome da- } \\
\text { ta addressed? (Post-treat- } \\
\text { ment) }\end{array}$ & Unclear risk & The study provided no information about withdrawals \\
\hline
\end{tabular}

Atteya 2004

$\begin{array}{ll}\text { Methods } & \text { Randomisation details were not reported } \\ \text { Blinded outcome assessor } \\ \text { No information about withdrawals } \\ \text { Single centre, outpatients }\end{array}$

Participants Saudi Arabia

Recruited via the King Saud Univerity

6 participants: 2 intervention, 2 control, 2 no treatment

Inclusion criteria: cerebrovascular accident between 1 and 6 months; $10^{\circ}$ of active extension to the metacarpophalangeal and interphalangeal joints and $20^{\circ}$ at wrist

Exclusion criteria: significant cognitive impairment, haemorraghic lesion, significant spasticity, significant pain of the upper limb

Mean age (SD): intervention group: 55 (2.8) years, control group: 52 (4.2) years, no treatment group: 56 (15.5) years

\% women: intervention group 50\%, control group: 50\%, no treatment group: $50 \%$

Stroke details: only ischaemic, $50 \%$ with right hemiparesis in each group

Time since stroke, mean (SD): intervention group 5.6 (0.3) months, control group 3.95 (2.3) months, no intervention group 4.65 (1.2) months

CIMT: physical and occupational therapy focused on PNF with emphasis on ADL tasks, compensatory techniques with the unaffected side, 2 functional tasks of the WMFT with shaping techniques Amount of restraint: 5 waking hours per day

Anatomical region restraint: arm and hand

Control: physical and occupational therapy focused on PNF with emphasis on ADL tasks, compensatory techniques with the unaffected side 
Atteya 2004 (Continued)

Session duration: 1 hour per day, 3 days per week, 10 weeks for each treatment group

\begin{tabular}{ll}
\hline Outcomes & Measures pre/post treatment \\
& - Arm motor function: ARAT, WMFT2 \\
- Perceived arm motor function: MAL \\
- Arm motor impairment: FMA
\end{tabular}

Notes

\section{Risk of bias}

\begin{tabular}{lll}
\hline Bias & Authors' judgement & Support for judgement \\
\hline $\begin{array}{l}\text { Random sequence genera- } \\
\text { tion (selection bias) }\end{array}$ & Unclear risk & $\begin{array}{l}\text { Quote: "all subjects were randomly assigned ... with an equal probability" } \\
\text { Comment: insufficient information to make a judgment }\end{array}$ \\
\hline $\begin{array}{l}\text { Allocation concealment } \\
\text { (selection bias) }\end{array}$ & Unclear risk & No information provided \\
\hline $\begin{array}{l}\text { Blinding (performance } \\
\text { bias and detection bias) } \\
\text { All outcomes }\end{array}$ & Low risk & Blinding of outcome assessor \\
\hline $\begin{array}{l}\text { Incomplete outcome da- } \\
\text { ta addressed? (Post-treat- } \\
\text { ment) }\end{array}$ & Unclear risk & The study provided no information about withdrawals \\
\hline
\end{tabular}

Azab 2009

\begin{tabular}{ll}
\hline Methods & Randomisation details were not reported \\
Blinded outcome assessor & No withdrawals \\
& Single centre, outpatients \\
Jordan & Recruited from King Abudallah University Hospital \\
& 37 participants: 20 intervention, 17 control \\
Inclusion criteria: ability to voluntarily extend fingers and wrist slightly & Exclusion criteria: severe cognitive disabilities \\
& Mean age (SD): 56 (9.9) years for all participants \\
& $\%$ women: $24 \%$ of all participants \\
& Stroke details: only ischaemic, $57 \%$ with right hemiparesis \\
& Time since stroke, mean (SD): 2.75 ( 0.7 ) months for all participants
\end{tabular}


Azab 2009 (Continued)

mCIMT: active range of motion of bilateral upper extremities, stretching exercises, hand-eye co-ordination activities, ambulation, and strengthening exercises for bilateral upper extremities

Amount of restraint: 6 to 7 hours per day

Anatomical region restraint: hand

Control: active range of motion of bilateral upper extremities, stretching exercises, hand-eye co-ordination activities, ambulation, and strengthening exercises for bilateral upper extremities

Session duration: 4 hours per week (in 3 day/week) for 4 weeks for both groups

Outcomes Measures pre/post treatment and follow-up at 6 months

- ADL measure: BI

Notes

\title{
Risk of bias
}

\begin{tabular}{|c|c|c|}
\hline Bias & Authors' judgement & Support for judgement \\
\hline \multirow{2}{*}{$\begin{array}{l}\text { Random sequence genera- } \\
\text { tion (selection bias) }\end{array}$} & High risk & Information provided only in the abstract \\
\hline & & Quote: "Key words: Barthel Index, CIMT, stroke randomized control study" \\
\hline $\begin{array}{l}\text { Allocation concealment } \\
\text { (selection bias) }\end{array}$ & Unclear risk & No information provided \\
\hline $\begin{array}{l}\text { Blinding (performance } \\
\text { bias and detection bias) } \\
\text { All outcomes }\end{array}$ & Low risk & $\begin{array}{l}\text { Quote: "The occupational therapist and the two physical therapists were dou- } \\
\text { ble-blinded to the therapy and group assignment of the patients" }\end{array}$ \\
\hline $\begin{array}{l}\text { Incomplete outcome da- } \\
\text { ta addressed? (Post-treat- } \\
\text { ment) }\end{array}$ & Unclear risk & $\begin{array}{l}\text { Quote: "The BI was measured at the beginning of the rehabilitation program } \\
\text { and at the discharge from rehabilitation. The BI was also re-evaluated at } 6 \\
\text { months post discharge in } 18 \text { patients ( } 64 \% \text { of the initial experimental group)" }\end{array}$ \\
\hline
\end{tabular}

\section{Bergheim 2010}

\begin{tabular}{ll}
\hline Methods & Randomisation by computer \\
& Blinded outcome assessor \\
No withdrawals \\
Single centre, inpatients \\
\hline
\end{tabular}

\section{Participants}

\author{
Norway \\ Recruited from stroke unit and the neurological department of geriatric medicine of Ullevaal University \\ Hospital \\ 4 participants: 2 intervention, 2 control \\ Inclusion criteria: cerebrovascular accident between 14 and 21 days; $10^{\circ}$ of active extension in the fin- \\ ger and $20^{\circ}$ in the wrist; ability to walk indoors without the use of walking aids; sufficient cognitive \\ function
}


Exclusion criteria: cerebral haemorrhage, prior stroke, unstable medical status, second cerebral diseases that were difficult to differentiate from a stroke, and previous illness/injury that significantly impaired function in arms

Mean age (SD): intervention group: 70.5 (13.4) years, control group: 76.5 (4.9) years

$\%$ women: intervention group 50\%, control group: $50 \%$

Stroke details: only ischaemic, $0 \%$ with right hemiparesis with $0 \%$ paresis of the dominant side in treatment group, $50 \%$ with right hemiparesis with $50 \%$ paresis of the dominant side in control group

Time since stroke: $14-21$ days after stroke onset

\begin{tabular}{ll}
\hline Interventions & mCIMT versus control \\
mCIMT: functional activities through shaping approach \\
Amount of restraint: 6-7 hours per day \\
Anatomical region restraint: hand \\
Control: mono and bilateral activities \\
Session duration: 1 hour per day, 5 days/week, 2 weeks for both groups \\
\hline Measures pre/post treatment and follow-up at 3 months \\
- Arm motor function: BLMA, WMFT \\
- Everyday motor function: MAS
\end{tabular}

Notes

\section{Risk of bias}

\begin{tabular}{lll}
\hline Bias & Authors' judgement & Support for judgement \\
\hline $\begin{array}{l}\text { Random sequence genera- } \\
\text { tion (selection bias) }\end{array}$ & Low risk & Quote: "the randomisation was performed from a computer generated list" \\
\hline $\begin{array}{l}\text { Allocation concealment } \\
\text { (selection bias) }\end{array}$ & Unclear risk & $\begin{array}{l}\text { Quote: "Enrolled patients consented in writing and orally and were random- } \\
\text { ized by closed numbered envelopes participation respectively group mCIMT or } \\
\text { TF [traditional physiotherapy]" }\end{array}$ \\
\hline $\begin{array}{l}\text { Blinding (performance } \\
\text { bias and detection bias) }\end{array}$ & Low risk & $\begin{array}{l}\text { Quote: "The outcome was examined by a physiotherapist blinded to therapy } \\
\text { patients received" }\end{array}$ \\
\hline $\begin{array}{l}\text { Incomplete outcome da- } \\
\begin{array}{l}\text { ta addressed? (Post-treat- } \\
\text { ment) }\end{array}\end{array}$ & Unclear risk & No missing outcome data \\
\hline
\end{tabular}

Boake 2007

Methods Randomisation: stratified by age and NIHSS, other details were not reported

Blinded outcome assessor

Post-treatment withdrawals $22 \%$, follow-up withdrawals: $11 \%$

Single centre, inpatients and outpatients

$\begin{array}{ll}\text { Participants } & \text { USA } \\ & \text { Recruited from admissions to the University Hospital of Memorial Hermann }\end{array}$




\section{3 participants: 10 intervention, 13 control}

Inclusion criteria: cerebrovascular accident within 14 days; score 1 to 3 on the motor arm item of the NIHSS; $10^{\circ}$ of active movement in the thumb and 2 or more fingers of the affected hand.

Exclusion criteria: not reported

Mean age (SD): intervention group: 63.1 (14.3)years, control group: 58.9 (14) years $\%$ women: intervention group $30 \%$, control group: $38 \%$

Stroke details: ischaemic or haemorrhagic, $40 \%$ with right hemiparesis in treatment group, $54 \%$ with right hemiparesis in control group

Time since stroke, mean (range): intervention group 3.3 (3 to 4.1 ) months, control group 3.3 (3 to 4.3 ) months

\begin{tabular}{ll}
\hline Interventions & mCIMT versus control \\
mCIMT: functional tasks with shaping techniques \\
Amount of restraint: $90 \%$ of waking hours per day \\
Anatomical region restraint: hand \\
Control: ADL with either hand, improvement of strength, muscle tone and range of motion of the affect- \\
ed arm \\
Session duration: 3 hours per day, 6 days per week, 2 weeks for each group \\
\hline Measures pre/post treatment, follow up at 3 to 4 months \\
- Perceived arm motor function: MAL \\
- Dexterity: GPT \\
- Arm motor impairment: FMA2 \\
- Neurophysiological test: TMS
\end{tabular}

Notes

\section{Risk of bias}

\begin{tabular}{lll}
\hline Bias & Authors' judgement & Support for judgement \\
\hline $\begin{array}{l}\text { Random sequence genera- } \\
\text { tion (selection bias) }\end{array}$ & Unclear risk & $\begin{array}{l}\text { Quote: "patients underwent baseline testing and were randomly allocated to } \\
\text { either CIMT or traditional therapy" }\end{array}$ \\
\hline $\begin{array}{l}\text { Allocation concealment } \\
\text { (selection bias) }\end{array}$ & Unclear risk & No information provided \\
\hline $\begin{array}{l}\text { Blinding (performance } \\
\text { bias and detection bias) }\end{array}$ & Low risk & $\begin{array}{l}\text { Quote: "Outcome evaluations were performed by personnel from outside ... } \\
\text { who were blind to treatment assignment" }\end{array}$ \\
\hline $\begin{array}{l}\text { Incomplete outcome da- } \\
\text { ta addressed? (Post-treat- } \\
\text { ment) }\end{array}$ & High risk & $\begin{array}{l}1 / 10 \text { missing from intervention group (due to incomplete data), 4/13 missing } \\
\text { from control group (due incomplete data and injuries). Reasons for missing } \\
\text { data outcomes possibly related to the true effect, with imbalance across inter- } \\
\text { vention and control groups }\end{array}$ \\
\hline
\end{tabular}


Brogårdh 2009

\begin{tabular}{ll}
\hline Methods & Randomisation by computer \\
& Blinded outcome assessor \\
Follow-up withdrawals: $<5 \%$ \\
Single centre, inpatients \\
\hline
\end{tabular}

Participants

Sweden

Recruited from the Department of Rehabilitation at Lund University Hospital

24 participants: 12 intervention, 12 control

Inclusion criteria: stroke onset between 1 and 3 months; $10^{\circ}$ of active extension at wrist at least $10^{\circ}$ of active extension of 2 fingers and $10^{\circ}$ of active movement in the thumb

Exclusion criteria: deformity of the more affected arm due to previous injury, drug abuse, epilepsy, mental disorder and botulinum toxin injections for spasticity treatment

Mean age (SD): intervention group: 58.5 (6.3) years, control group: 56.7 (10.5) years

$\%$ women: intervention group $17 \%$, control group: $33 \%$

Stroke details: $58 \%$ with right hemiparesis with $75 \%$ paresis of the dominant side in treatment group, $75 \%$ with right hemiparesis with $83 \%$ paresis of the dominant side in control group

Time since stroke, mean (SD): intervention group 1.56 (0.53) months, control group 1.7 (0.7) months

mCIMT: task practise, fine motor practise, muscle strength training, muscle stretching, swimming pool training, general activity training. Activity of upper arm was delivered through shaping approach Amount of restraint: $90 \%$ of waking hours per day

Anatomical region restraint: hand

Control: task practise, fine motor practise, muscle strength training, muscle stretching, swimming pool training, general activity training. Activity of upper arm was delivered through shaping approach Session duration: 3 hours per day for 2 weeks for both groups

\begin{tabular}{ll}
\hline Outcomes & Measures pre/post treatment, follow-up \\
- Everyday arm motor function: MAS2 \\
- Hand Function: SHFT \\
- Perceived arm motor function: MAL
\end{tabular}

Notes

\section{Risk of bias}

Bias Authors' judgement Support for judgement

Random sequence genera- Low risk Quote: "Randomization was performed from a computer-generated list of contion (selection bias) Secutive random numbers"

\begin{tabular}{lll}
\hline $\begin{array}{l}\text { Allocation concealment } \\
\text { (selection bias) }\end{array}$ & Unclear risk & No information provided \\
\hline $\begin{array}{l}\text { Blinding (performance } \\
\text { bias and detection bias) } \\
\text { All outcomes }\end{array}$ & Low risk & Quote: "All patients were assessed by independent and blinded assessors" \\
\hline
\end{tabular}


Brogårdh 2009 (Continued)

Incomplete outcome da- Unclear risk 1 participant missed the three months follow-up ta addressed? (Post-treatment)

Brunner 2012

$\begin{array}{ll}\text { Methods } & \text { Randomisation by computer } \\ \text { Blinded outcome assessor } \\ \text { Post-treatment withdrawals 6\% } \\ \text { Multicentre, inpatients and outpatients }\end{array}$

\section{Participants}

\section{Norway}

Recruited from 2 hospitals in the City of Bergen

30 participants: 14 intervention, 16 control

Inclusion criteria: cerebrovascular accident between 2 and 16 weeks; ability to extend the affected wrist and fingers at least $10^{\circ}$

Exclusion criteria: additional neurological diseases, unstable medical conditions, musculoskeletal disorders affecting arm mobility and severe cognitive impairment

Mean age (SD): intervention group: 61 (10) years, control group: 64.8 (12.8) years

$\%$ women: intervention group $21 \%$, control group: $50 \%$

Stroke details: ischaemic or haemorrhagic; $43 \%$ with right hemiparesis in treatment group, $37 \%$ with right hemiparesis in control group

Time since stroke, mean (SD): intervention group 1.6 (1.3) months, control group 1.23 (0.8) months

mCIMT: task-related arm training, strength training, mobility training with shaping approach and self training focusing on unilateral activities

Amount of restraint: 4 hours per day

Anatomical region restraint: hand

Control: task-related arm training, strength training, mobility training with shaping approach and self training focusing on bilateral activities

Session duration: 4 hours a week with physiotherapist plus 2-3 hours everyday of self-training for 4 weeks for both groups

$\begin{array}{ll}\text { Outcomes } & \text { Measures pre/post treatment } \\ & \text { - Arm motor function: ARAT } \\ \text { - Dexterity: 9HPT }\end{array}$

Notes

\section{Risk of bias}


Brunner 2012 (Continued)

Random sequence genera- Low risk tion (selection bias)
Quote: "A randomized controlled trial was applied. A computerized random numbers generator was used for randomising the patients in blocks of four patients into a modified constraint-induced movement therapy or a bimanual training group"

\begin{tabular}{lll}
\hline $\begin{array}{l}\text { Allocation concealment } \\
\text { (selection bias) }\end{array}$ & Low risk & $\begin{array}{l}\text { Quote: "Opaque, sealed envelopes were prepared by a person not involved in } \\
\text { the study, classifying the patients into one of the two groups" }\end{array}$ \\
\hline $\begin{array}{l}\text { Blinding (performance } \\
\text { bias and detection bias) } \\
\begin{array}{l}\text { All outcomes } \\
\text { the }\end{array}\end{array}$ & Low risk & $\begin{array}{l}\text { Quote: "The randomizations led to a balanced allocation, and blinded raters } \\
\text { secured unbiased assessments" }\end{array}$ \\
\hline
\end{tabular}

$\begin{aligned} & \text { Incomplete outcome da- } \\ & \text { ta addressed? (Post-treat- }\end{aligned}$
$\begin{array}{ll}\text { ment) } & \text { Quote: "There was two drop-outs, one in each group, due to other medical } \\ \text { problems" }\end{array}$

\section{Dahl 2008}

$\begin{array}{ll}\text { Methods } & \text { Block randomisation, other details were not reported } \\ & \text { Blinded outcome assessor } \\ & \text { No withdrawals } \\ & \text { Single centre, inpatients }\end{array}$

Participants Norway

Recruited from the Stroke Unit at Trondheim University Hospital and by announcement at hospitals and rehabilitation institutions in the neighbouring countries

30 participants: 18 intervention, 12 control

Inclusion criteria: time from onset of stroke > two weeks; score 0 to 2 points before the stroke on the modified Ranking Scale; $10^{\circ}$ of active extension to the metacarpophalangeal and interphalangeal joints and $20^{\circ}$ at wrist

Exclusion criteria: presence of other neurological diseases, unstable cardiovascular disease, severe depression ( $>12$ points on Montgomery and Aasberg Depression Rating Scale), marked neglect (line bisection more than $2 \mathrm{~cm}$ over the midline), life expectancy $<6$ months, sequel from a previous stroke and clinically evaluated insufficient endurance to participate

Mean age (SD): intervention group: 62 (8) years, control group: 60 (12) years

$\%$ women: intervention group $11 \%$, control group: $42 \%$

Stroke details: ischaemic or haemorrhagic; $78 \%$ paresis of dominant side in treatment group, $58 \%$ paresis of the dominant side in control group

Time since stroke, mean (SD): intervention group 21 (18) months, control group 26 (27) months

Interventions

CIMT versus control

CIMT: personalised ADL task training of the paretic limb, training difficulty was updated with daily progress

Amount of restraint: $90 \%$ of waking hours per day

Anatomical region restraint: hand

Control: treatment given according to each patient's need, involving both upper and lower extremity with various occupational and physical therapy approaches 
Dahl 2008 (Continued)

Session duration: 6 hours per day in the CIMT group, unspecified duration for control group for 10 consecutive weekdays

\begin{tabular}{|c|c|c|}
\hline Outcomes & \multicolumn{2}{|c|}{$\begin{array}{l}\text { Measures pre/post treatment and follow-up at } 6 \text { months } \\
\text { - Motor function: WMFT } \\
\text { - Perceived arm motor function: MAL } \\
\text { - ADL measure: FIM2 } \\
\text { - Quality of life: SIS }\end{array}$} \\
\hline \multicolumn{3}{|l|}{ Notes } \\
\hline \multicolumn{3}{|l|}{ Risk of bias } \\
\hline Bias & Authors' judgement & Support for judgement \\
\hline $\begin{array}{l}\text { Random sequence genera- } \\
\text { tion (selection bias) }\end{array}$ & Unclear risk & $\begin{array}{l}\text { Quote: "Eligible patients were block-randomised into a CIMT group or a con- } \\
\text { trol group" }\end{array}$ \\
\hline $\begin{array}{l}\text { Allocation concealment } \\
\text { (selection bias) }\end{array}$ & Low risk & $\begin{array}{l}\text { Quote: "Sealed opaque envelopes were used for randomisation and the proce- } \\
\text { dure was carried out by an external office" }\end{array}$ \\
\hline $\begin{array}{l}\text { Blinding (performance } \\
\text { bias and detection bias) } \\
\text { All outcomes }\end{array}$ & Low risk & Quote: "Two independent and blinded assessors performed the assessments" \\
\hline $\begin{array}{l}\text { Incomplete outcome da- } \\
\text { ta addressed? (Post-treat- } \\
\text { ment) }\end{array}$ & Low risk & No missing data \\
\hline
\end{tabular}

\section{Dromerick 2000}

\begin{tabular}{ll} 
Methods & Randomisation by random number table, other details were not reported \\
& Blinded outcome assessor \\
& Post-treatment withdrawals: $13 \%$ \\
& Single centre, inpatients \\
\hline
\end{tabular}

Participants USA

Recruited from the acute stroke and brain injury rehabilitation service

20 participants: 11 intervention, 9 control

Inclusion criteria: admission to inpatient rehabilitation within 14 days of ischemics stroke; score 1 or 2 on the motor arm item of the NIHSS; preserved cognitive function

Exclusion criteria: no upper extremity injury or conditions that limited use before the stroke

Mean age (SD): intervention group: 61.5 (13.7) years, control group: 71.4 (5.3) years

$\%$ women: intervention group $25 \%$, control group: $63 \%$

Stroke details: only ischaemic; $75 \%$ with right hemiparesis in treatment group, $63 \%$ with right hemiparesis in control group

Time since stroke, mean (SD): 6 (2.6) days for both groups (range 4 to 14 days)

Interventions CIMT versus control


Dromerick 2000 (Continued)

CIMT: ADL and functional tasks with the affected limb

Amount of restraint: at least 6 hours per day

Anatomical region restraint: hand

Control: compensatory techniques for ADL, upper extremity strength, range of motion and traditional positioning

Session duration: 2 hours per day, 5 days per week, 2 weeks for both groups

\begin{tabular}{ll}
\hline Outcomes & Measures pre/post treatment \\
- Motor function: ARAT \\
Measures post-treatment only \\
- ADL measure: BI, FIM
\end{tabular}

Notes

\section{Risk of bias}

\begin{tabular}{|c|c|c|}
\hline Bias & Authors' judgement & Support for judgement \\
\hline $\begin{array}{l}\text { Random sequence genera- } \\
\text { tion (selection bias) }\end{array}$ & Low risk & $\begin{array}{l}\text { Quote: "Subjects were individually randomized into experimental or control } \\
\text { groups by using a table of random numbers" }\end{array}$ \\
\hline $\begin{array}{l}\text { Allocation concealment } \\
\text { (selection bias) }\end{array}$ & Unclear risk & No information provided \\
\hline $\begin{array}{l}\text { Blinding (performance } \\
\text { bias and detection bias) } \\
\text { All outcomes }\end{array}$ & Low risk & Quote: "All posttreatment assessments were performed by blinded testers" \\
\hline $\begin{array}{l}\text { Incomplete outcome da- } \\
\text { ta addressed? (Post-treat- } \\
\text { ment) }\end{array}$ & High risk & $3 / 23$ dropouts, reasons not reported \\
\hline
\end{tabular}

Dromerick 2009

$\begin{array}{ll}\text { Methods } & \begin{array}{l}\text { Randomisation balanced for age, total NIHSS score, ARAT score and days from stroke onset, other de- } \\ \text { tails were not reported } \\ \text { Blinded outcome assessor }\end{array} \\ & \begin{array}{l}\text { Follow-up withdrawals: }<4 \% \\ \text { Single centre, inpatients }\end{array}\end{array}$

Participants USA

Recruitment from acute stroke admissions at Barnes-Jewish Hospital in St Louis

52 participants: 35 intervention, 17 control

Inclusion criteria: cerebrovascular accident within 28 days; score $\geq 3$ on the upper arm item of the MAS, but no necessary movements in the hand

Exclusion criteria: inability to give informed consent; clinically significant fluctuations in mental status within 3 days of enrolment; not independent prior to stroke; hemispatial neglect; sensory loss; not expected to survive 1 year due to other illnesses 
Dromerick 2009 (Continued)

Mean age (SD): intervention group: 63.6 (14.38) years, control group: 64.7 (14.6) years

$\%$ women: intervention group 57\%, control group: $63 \%$

Stroke details: ischaemic or haemorrhagic; $51 \%$ with right hemiparesis with $45 \%$ paresis of the dominant side in treatment group, $52.9 \%$ with right hemiparesis with $44.2 \%$ paresis of the dominant side in control group

Time since stroke, mean (SD): intervention group 9.3 (4.6) days, control group 10.4 (5.7) days

Interventions

This trial had 3 arms: 2 of the intervention groups performed mCIMT; 1 of the mCIMT groups performed a low intensity treatment (Low MCIMT) and the other group performed a high intensity treatment (High mCIMT)

mCIMT (Low mCIMT versus High mCIMT) versus control

mCIMT: functional activities of basic ADL with shaping approach for both groups Amount of restraint: Low mCIMT 6 hours per day, High mCIMT $90 \%$ of waking hours

Anatomical region restraint: hand

Control: traditional occupational therapy, involving compensatory techniques for ADL range of motion, and strengthening and upper extremity bilateral training activities

Session duration: 2 hours per day for Low mCIMT, 3 hours per day for High mCIMT and 2 hours per day for control group for 5 days a week for 2 weeks

$\begin{array}{ll}\text { Outcomes } & \text { Measures pre/post treatment, follow-up at } 3 \text { mor } \\ \text { - Overall stroke severity: NIHSS } \\ \text { - Arm motor function: ARAT } \\ \text { - ADL measure: FIM } \\ \text { - Puality of life: SIS (only at post-treatment) } \\ \text { - Depression: Geriatric Depression-15 Scale }\end{array}$

Notes

\section{Risk of bias}

\begin{tabular}{lll}
\hline Bias & Authors' judgement & Support for judgement \\
\hline $\begin{array}{l}\text { Random sequence genera- } \\
\text { tion (selection bias) }\end{array}$ & Unclear risk & $\begin{array}{l}\text { Quote: "... we adaptively randomized the group balancing for age, total NIHSS } \\
\text { score, pretest ARAT and days from stroke onset" }\end{array}$ \\
\hline $\begin{array}{l}\text { Allocation concealment } \\
\text { (selection bias) }\end{array}$ & Low risk & Quote: "The study clinical team met weekly to assure adherence to protocols" \\
\hline $\begin{array}{l}\text { Blinding (performance } \\
\text { bias and detection bias) } \\
\text { All outcomes }\end{array}$ & Low risk & Quote: "Trained raters performed all blinded evaluations" \\
\hline $\begin{array}{l}\text { Incomplete outcome da- } \\
\text { ta addressed? (Post-treat- } \\
\text { ment) }\end{array}$ & Low risk & $\begin{array}{l}\text { Quote: "All but two participants were available for assessment at the 90-day } \\
\text { primary endpoint" }\end{array}$ \\
\hline
\end{tabular}

Methods Randomisation through marked ballots of paper


Hammer 2009 (Continued)

Unblinded outcome assessor

Post-treatment withdrawals 13\%

Single centre, inpatients and outpatients

\section{Participants}

Sweden

Recruited from the departments of rehabilitation medicine, geriatrics, and neurology at a university hospital in central Sweden

30 participants: 15 intervention, 15 control

Inclusion criteria:cerebrovascular accident between 1 and 6 months; $10^{\circ}$ of active extension in the finger and $20^{\circ}$ in the wrist

Exclusion criteria: no severe cognitive impairment (score of 20 points in the MMSE); ability to understand and follow instructions

Mean age (SD): intervention group: 66.3 (10.3) years, control group: 60.4 (11.1) years

$\%$ women: intervention group $7 \%$, control group: $40 \%$

Stroke details: $73 \%$ with right hemiparesis with $80 \%$ paresis of the dominant side in treatment group, $53 \%$ with right hemiparesis with $46 \%$ paresis of the dominant side in control group

Time since stroke, mean (SD): intervention group 2.6 (1.5) months, control group 2.3 (1.2) months

mCIMT: conventional rehabilitation consisting of task-oriented activities, facilitation of proximal and distal motor control and improvement of strength and endurance, skilled task training (moving objects, writing or typing) and daily tasks

Amount of restraint: 6 hours per day, 5 days a week

Anatomical region restraint: arm and hand

Control: conventional rehabilitation consisting of task-oriented activities, facilitation of proximal and distal motor control and improvement of strength and endurance, skilled task training (moving objects, writing or typing) and daily tasks

Session duration: 3 hours per day, 5 days per week, 2 weeks for both groups

- Arm motor function: ARAT

- Arm motor impairment: FMA, grip/force

- Spasticity: MASh

- Dexterity: 16HPT

- Everyday arm motor function: MAS

- Perceived arm motor function: MAL

Notes

\section{Risk of bias}

\begin{tabular}{lll}
\hline Bias & Authors' judgement & Support for judgement \\
\hline $\begin{array}{ll}\text { Random sequence genera- } \\
\text { tion (selection bias) }\end{array}$ & Low risk & $\begin{array}{l}\text { Quote: "a restricted block randomisation was used. Thirty pieces of paper had } \\
\text { been prepared with the letter E (experimental group ...) on } 15 \text { of them and the } \\
\text { letter K (conventional group ...) on the other 15. A block size of } 10 \text { was used (5 } \\
\text { "E" plus 5 "K")" }\end{array}$ \\
& &
\end{tabular}


Hammer 2009 (Continued)

Allocation concealment (selection bias)
Low risk

Quote: "The pieces of paper were folded twice, and the first block of 10 was placed in a metal box, while the rest were stored in 2 sealed envelopes with 1 block in each. For each participant in the study, the metal box was shaken, and an arbitrarily chosen staff member drew a piece of paper to determine the group allocation"

\begin{tabular}{lll}
$\begin{array}{l}\text { Blinding (performance } \\
\text { bias and detection bias) } \\
\text { All outcomes }\end{array}$ & High risk & Quote: "... the present study had ... lack of blinding" \\
\hline $\begin{array}{l}\text { Incomplete outcome da- } \\
\text { ta addressed? (Post-treat- } \\
\text { ment) }\end{array}$ & Low risk & $\begin{array}{l}\text { Quote: "There were a total of } 4 \text { dropouts during the study. Two participants in } \\
\text { the FU group discontinued the 2-week intervention period; one dropped out } \\
\text { on the first day of intervention because of refusal to continue, and the other } \\
\text { was discharged on day } 5 \text { of the intervention. The other } 2 \text { participants dropped } \\
\text { out before follow-up because of illness (forced-use group) and because of re- } \\
\text { fusal to continue (standard training group)" }\end{array}$ \\
\hline
\end{tabular}

Hayner 2010

$\begin{array}{ll}\text { Methods } & \text { Randomisation balanced for WMFT score, other details were not reported } \\ \text { Unblinded outcome assessor } \\ \text { Post-treatment withdrawals } 8 \% \\ \text { Single centre, outpatients }\end{array}$

Participants Canada

Recruited through information disseminated to participants in a free clinic at Samuel Merritt University, clinics in the vicinity, and a local CVA support group

12 participants: 6 intervention, 6 control

Inclusion criteria: cerebrovascular accident least 6 months; ability to place the affected hand on a table surface, trace movements in the hand and had sufficient endurance to participate in therapy 6 hours per day for 10 consecutive weekdays

Exclusion criteria: inability to refrain from smoking (because a smoking area was unavailable), inability to tolerate a regular diet (because making lunch was a part of the therapeutic design)

Mean age (SD): intervention group: 54 (11.62) years, control group: 559.5 (11.77) years

$\%$ women: intervention group $67 \%$, control group: $50 \%$

Stroke details: ischaemic

Time since stroke, mean (SD): intervention group 21.1 (13.8) months, control group 67 (30.4) months

$\begin{array}{ll}\text { Interventions } & \text { CIMT versus control } \\ \text { CIMT: functional activities with } 1 \text { hand } \\ \text { Amount of restraint: at least } 6 \text { hours per day } \\ \text { Anatomical region restraint: hand } \\ \text { Control: functional activities with } 2 \text { hands } \\ \text { Session duration: } 6 \text { hours per day for } 10 \text { consecutive weekdays for both groups } \\ \text { Outcomes } \\ \text { Measures pre/post treatment and follow-up at } 6 \text { months }\end{array}$


Hayner 2010 (Continued)

- Global function: COPM

\section{Notes}

\section{Risk of bias}

\begin{tabular}{|c|c|c|}
\hline Bias & Authors' judgement & Support for judgement \\
\hline $\begin{array}{l}\text { Random sequence genera- } \\
\text { tion (selection bias) }\end{array}$ & Unclear risk & $\begin{array}{l}\text { Quote: "Participants were stratified into more and less affected UE [upper ex- } \\
\text { tremity] groups as determined by the WMFT total score and then blindly ran- } \\
\text { domized into the CIMT or bilateral group" }\end{array}$ \\
\hline \multirow[t]{2}{*}{$\begin{array}{l}\text { Allocation concealment } \\
\text { (selection bias) }\end{array}$} & Unclear risk & $\begin{array}{l}\text { Quote: "Participants were ... blindly randomized into the CIMT or bilateral } \\
\text { group" }\end{array}$ \\
\hline & & $\begin{array}{l}\text { Quote: "To ensure that intervention was truly of the same intensity and to } \\
\text { avoid organizational confounds, all participants were treated simultaneously, } \\
\text { in the same location, and by the same therapists" }\end{array}$ \\
\hline $\begin{array}{l}\text { Blinding (performance } \\
\text { bias and detection bias) } \\
\text { All outcomes }\end{array}$ & High risk & Quote: "Raters were not blinded" \\
\hline $\begin{array}{l}\text { Incomplete outcome da- } \\
\text { ta addressed? (Post-treat- } \\
\text { ment) }\end{array}$ & Low risk & $\begin{array}{l}\text { Quote: "One participant, randomized to the CIMT group, injured his affected } \\
\text { UE at home before posttesting during a non-study-related activity and was } \\
\text { dropped from the study" }\end{array}$ \\
\hline
\end{tabular}

Huseyinsinoglu 2012

$\begin{array}{ll}\text { Methods } & \text { Randomisation by computer, stratified by people who received injections of botulinum toxin-A } \\ & \text { Blinded outcome assessor } \\ & \text { Post-treatment withdrawals: } 8 \% \\ \text { Single centre, outpatients }\end{array}$

Participants Turkey

Recruited from the outpatient clinic of the Stroke Unit of the Florence Nightingale Hospital

\section{4 participants: 13 intervention, 11 control}

Inclusion criteria: cerebrovascular accident between 3 and 24 months; $10^{\circ}$ of active extension to the metacarpophalangeal and interphalangeal joints and $20^{\circ}$ at wrist

Exclusion criteria: no serious cognitive disorders; no excessive pain that would interfere with the ability to participate in the treatment; no excessive spasticity in any joint of the affected arm

Mean age (SD): intervention group: 49.1 (13.7) years, control group: 48.2 (15.4) years

$\%$ women: intervention group $36 \%$, control group: $54 \%$

Stroke details: ischaemic or haemorrhagic; $64 \%$ paresis of dominant side in treatment group, $27 \%$ paresis of the dominant side in control group

Time since stroke, mean (SD): intervention group 10.6 (6.1) months, control group 13.1 (6.3) months

Interventions mCIMT versus control

mCIMT: behavioural techniques, shaping and task activities Amount of restraint: $90 \%$ of waking hours for 12 consecutive days 
Huseyinsinoglu 2012 (Continued)

\author{
Anatomical region restraint: hand
}

Control: control muscle, tone quality of movements, weight bearing and stability of trunk arm activity in functional situation following Bobath principles

Session duration: mCIMT: 3 hours per day for 10 consecutive days; control group: 1 hour per day for 10 consecutive days

\begin{tabular}{ll}
\hline Outcomes & Measures pre/post treatment \\
& - ADL measures: FIM \\
- Arm motor function: WMFT \\
- Perceived arm motor function: MAL 3 \\
- Arm performance after stroke: MESUPES
\end{tabular}

Notes

\title{
Risk of bias
}

\section{Bias}

Random sequence genera- Low risk tion (selection bias)

\section{Authors' judgement Support for judgement}

Quote: "Subjects ... were randomly assigned to either ... group by using a randomisation function of Microsoft Office Excel software. Blocked randomisation was used. Treatment and random number columns were created and each part of the treatment column was (pre-assigned as B and C subjects, respectively) given a random number between 0 and 1 by the Microsoft Excel software random number generator. The sort and filter menu was used to sort the random number row from smallest to largest so that treatment groups were randomly ordered. Pre-stratification was applied to the subjects based on whether they had received injections of botulinum toxin-A within past three months"

Allocation concealment Unclear risk Not reported

(selection bias)

Blinding (performance Low risk

bias and detection bias)

All outcomes

Quote: "Before and after the interventions, measurements were obtained by a rater blinded to the group assignment. The blinded rater was trained to administer these tests before the beginning of the study"

Incomplete outcome da- Low risk ta addressed? (Post-treatQuote: "Two dropped out of the constraint-induced movement therapy group during the intervention period; both were personal choice. 22 participants completed the two-week treatment"

Khan 2011

Methods Randomisation with stratification by age, time since stroke, arm/hand function

Blinded outcome assessor

Post-treatment withdrawals $4 \%$, follow-up withdrawals: $7 \%$

Single centre, inpatients

Participants

Switzerland

Recruitment from stroke patients referred for inpatient rehabilitation in the Neurorehabilitation Center Valens

42 participants: 13 intervention, 14 control, 15 therapeutic climbing 
Khan 2011 (Continued)

Inclusion criteria: people with acute, subacute and chronic stroke; minimal to moderate arm and hand function stage 2-6 on the Chedoke McMaster Impairment Inventory sub scale and hand control

Exclusion criteria: shoulder pain, other neurological disorders or other serious co-morbidities

Mean age (SD): intervention group: 60.4 (16.1) years, control group: 60.4 (14.8) years, therapeutic climbing 62.2 (13.5) years

$\%$ women: intervention group 23\%, control group: 50\%, therapeutic climbing 33\%

Stroke details: $61 \%$ with right hemiparesis with $61 \%$ paresis of the dominant side in treatment group, $43 \%$ with right hemiparesis with $50 \%$ paresis of the dominant side in control group, and $67 \%$ with right hemiparesis with $73 \%$ paresis of the dominant side in therapeutic climbing group

Time since stroke, mean (SD): intervention group 5.2 (10.9) months, control group 15.7 (40.4) days, therapeutic climbing 11 (21.3) months

Interventions

This trial had 3 arms: the intervention group performed CIMT; a comparison group performed therapeutic climbing (TC) and the control group

CIMT versus control versus TC

CIMT: task-oriented training

Amount of restraint: during the exercises

Anatomical region restraint: hand

Control: postural control, inhibition of synergistic movements, facilitation of economic movements, conventional therapy

TC: climbing-specific exercises performed at the climbing wall inside the clinic

Session duration:

CIMT: 5 hours of individual physiotherapy and occupational therapy per week plus 5 hours of group exercises and 5 hours of self training per week;

Control group: 7.5 hours of individual physiotherapy and occupational therapy plus 5 hours of group exercises per week;

TC: 3,5 hours of individual physiotherapy and occupational therapy plus 4 hours of TC per week plus 5 hours of group exercises per week.

Total duration of treatment was not reported

Outcomes Measures pre/post treatment and follow-up at 6 months:

- Arm motor function: WMFT

- Perceived arm motor function: MAL

- Shoulder pain: CMII (subscale for shoulder pain)

Notes

\section{Risk of bias}

\section{Bias}

Authors' judgement Support for judgement

Random sequence genera- Low risk tion (selection bias)
Quote: "An independent and blinded research assistant performed concealed randomization using a randomization schedule with blocks of three generated by the primary researcher" 
Khan 2011 (Continued)

Allocation concealment Unclear risk Quote: "An independent and blinded research assistant performed concealed (selection bias) randomization using a randomization schedule with blocks of three generated by the primary researcher"

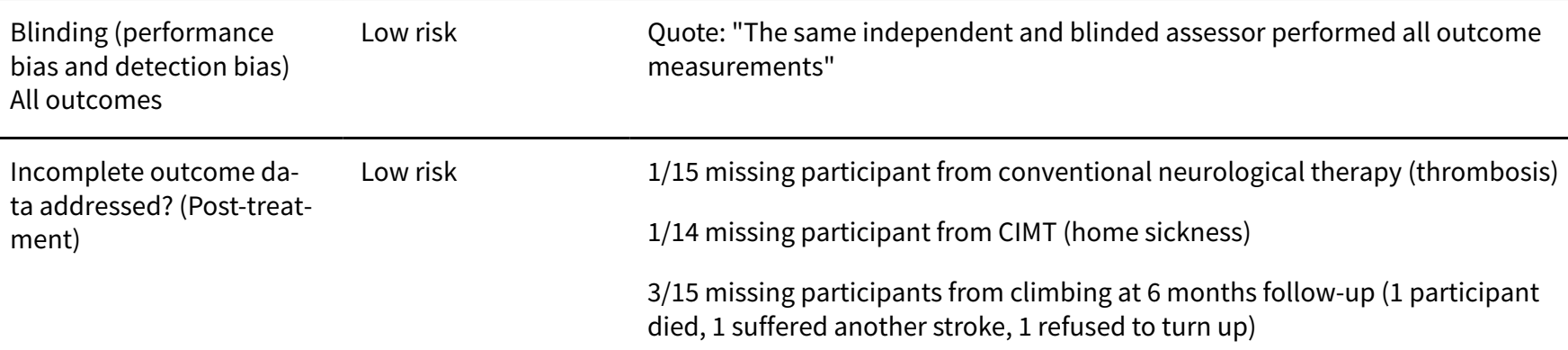

Kim 2008

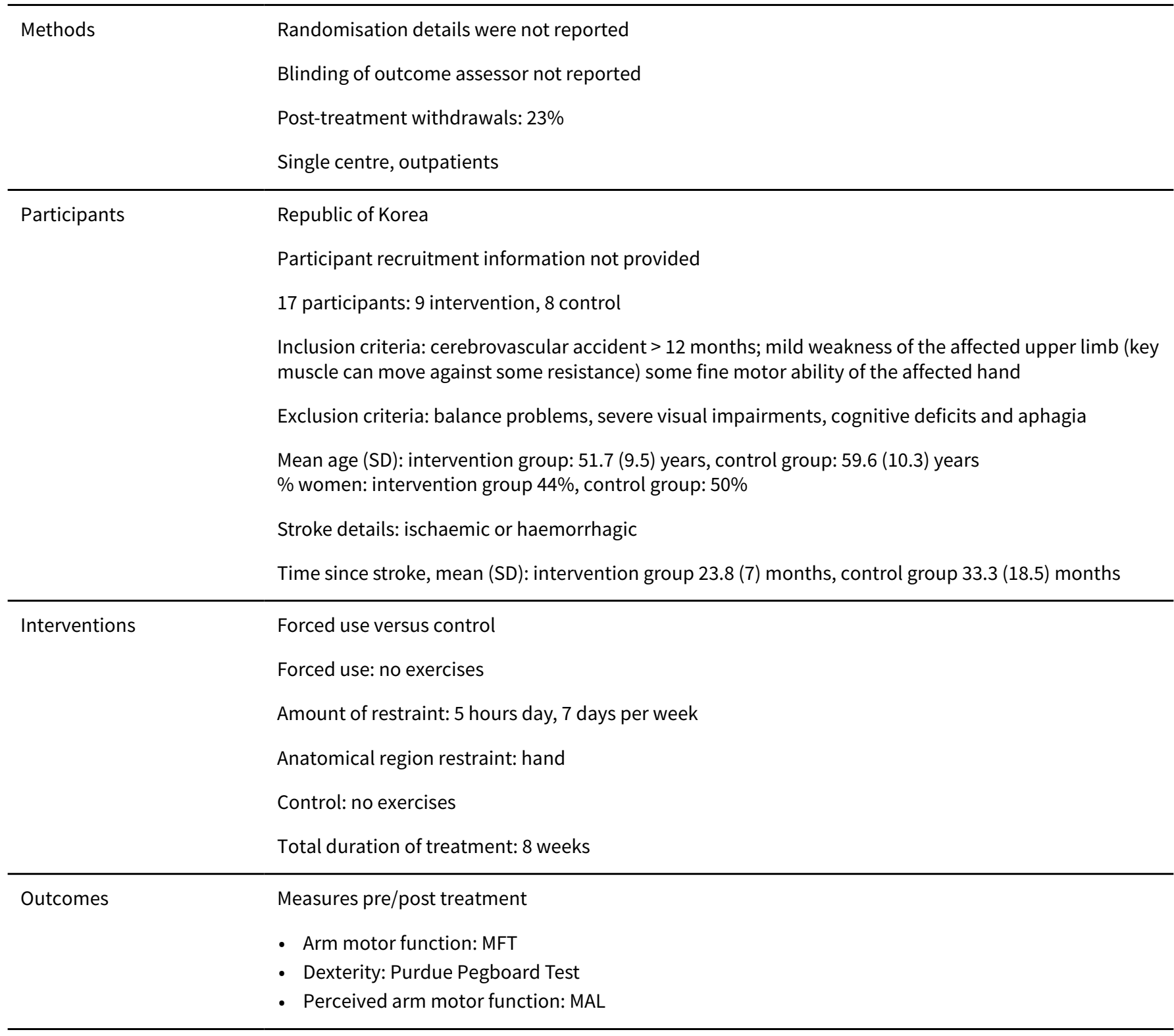


Kim 2008 (Continued)

Notes

\section{Risk of bias}

\begin{tabular}{lll}
\hline Bias & Authors' judgement & Support for judgement \\
\hline $\begin{array}{l}\text { Random sequence genera- } \\
\text { tion (selection bias) }\end{array}$ & Unclear risk & $\begin{array}{l}\text { Quote: "patients were randomly assigned to either the control group or the } \\
\text { CIMT group" }\end{array}$ \\
\hline $\begin{array}{l}\text { Allocation concealment } \\
\text { (selection bias) }\end{array}$ & Unclear risk & Information not reported \\
\hline $\begin{array}{l}\text { Blinding (performance } \\
\text { bias and detection bias) }\end{array}$ & Unclear risk & Information not reported \\
\hline $\begin{array}{l}\text { Incomplete outcome da- } \\
\text { ta addressed? (Post-treat- } \\
\text { ment) }\end{array}$ & High risk & $\begin{array}{l}\text { Quote: "Four of the 13 patients in the CIMT group did not complete [the] pro- } \\
\text { gram. It seems that all 4 patients discontinued participation due to difficulties } \\
\text { in performing some ADLs such as eating, dressing, dialling the phone, opening } \\
\text { a door or operating a remote control" }\end{array}$ \\
\hline
\end{tabular}

\section{Krawczyk 2012}

$\begin{array}{ll}\text { Methods } & \text { Randomisation by computer, stratified by age, gender, affected side of the body, time between the on- } \\ \text { set of stroke and the beginning of the study and severity of the arm motor deficit } \\ \text { Blinded outcome assessor } \\ \text { Follow-up withdrawals: } 19 \% \\ \text { Single centre, inpatients }\end{array}$

Participants Poland

Recruited stroke patients consecutively admitted to the inpatient neurorehabilitation unit in the Institute of Psychiatry and Neurology Hospital

47 participants: 24 intervention, 23 control

Inclusion criteria: cerebrovascular accident more than 6 weeks before starting the study, presence of a motor deficit in the arm as assessed with the RMAAS

Exclusion criteria: permanent use of the involved arm in life situations and coexisting lack of well-defined treatment goals by the patient; excessive pain, spasticity or ataxia; presence of a severe or uncontrolled medical condition; orthopaedic or neurological limitations prior to the stroke that could affect outcome; bilateral or brainstem stroke

Mean age (SD): intervention group: 48 (14) years, control group: 46 (13) years

$\%$ women: intervention group $21 \%$, control group: $25 \%$

Stroke details: ischaemic or haemorrhagic; $46 \%$ with right hemiparesis in treatment group, $43 \%$ with right hemiparesis in control group

Time since stroke: $53 \%$ of participants were within 6 months post stroke 
Krawczyk 2012 (Continued)

Control: task-oriented training MAL activities applied with shaping

Session duration: 6 hours per day, 5 days a week for 3 weeks each group

\begin{tabular}{ll}
\hline Outcomes & Measures pre/post treatment and follow-up at 1 year \\
- Arm motor function: RMAAS \\
- Perceived arm motor function: MAL \\
\hline
\end{tabular}

Notes

\section{Risk of bias}

\begin{tabular}{lll}
\hline Bias & Authors' judgement & Support for judgement \\
\hline $\begin{array}{l}\text { Random sequence genera- } \\
\text { tion (selection bias) }\end{array}$ & Low risk & Quote: "patients were randomly allocated by a computer program" \\
\hline $\begin{array}{l}\text { Allocation concealment } \\
\text { (selection bias) }\end{array}$ & Unclear risk & Information not reported \\
\hline $\begin{array}{l}\text { Blinding (performance } \\
\text { bias and detection bias) } \\
\text { All outcomes }\end{array}$ & Low risk & $\begin{array}{l}\text { Quote: "A trained investigator who was blinded to the study group ... carried } \\
\text { out all three clinical assessments" }\end{array}$ \\
\hline $\begin{array}{l}\text { Incomplete outcome da- } \\
\text { ta addressed? (Post-treat- } \\
\text { ment) }\end{array}$ & Low risk & $\begin{array}{l}\text { At } 1 \text { year follow-up 3/24 in CIMT group (1 died, } 1 \text { changed address, } 1 \text { refused } \\
\text { to participate) and 6/23 participants in voluntary-constraint group (1 died, } 3 \\
\text { changed address, 2 refused to participate) did not participate }\end{array}$ \\
\hline
\end{tabular}

Lin 2007

$\begin{array}{ll}\text { Methods } & \text { Randomisation by random number table stratified by side of stroke, allocation by sealed envelopes } \\ & \text { Blinded outcome assessor } \\ & \text { Post-treatment withdrawals: } 6 \% \\ & \text { Multicentre, outpatients }\end{array}$

Participants Taiwan

Recruited from rehabilitation departments of 3 medical centres

32 participants: 17 intervention, 15 control

Inclusion criteria: cerebrovascular accident $>12$ months; Brunnstrom Stage $>3$ on arm section; amount of use $<2.5$ on the MAL, no serious cognitive deficits, no excessive spasticity in any joints of the affected upper limb

Exclusion criteria: history of stroke or other neurological, neuromuscular or orthopaedic disease

Mean age (SD): intervention group: 57.11 (18.3) years, control group: 58.77 (15.5) years

$\%$ women: intervention group $35 \%$, control group: $33 \%$

Stroke details: ischaemic or haemorrhagic; $53 \%$ with right hemiparesis in treatment group, $60 \%$ with right hemiparesis in control group

Time since stroke, mean (SD): intervention group 15.97 (3.46) months, control group 16.61 (2.89) months 
Lin 2007 (Continued)

mCIMT: ADL activity with the affected arm

Amount of restraint: 6 hours per day

Anatomical region restraint: hand

Control: strength, balance, fine motor dexterity training, functional task practice, stretching/weightbearing by the affected arm

Session duration: 2 hours per day, 5 days per week, 3 weeks for each group

\begin{tabular}{ll}
\hline Outcomes & Measures pre/post treatment \\
- Perceived arm motor function: MAL \\
- Global function measure: FIM2 \\
- Kinematic variables
\end{tabular}

\section{Notes}

\section{Risk of bias}

\begin{tabular}{lll}
\hline Bias & Authors' judgement & Support for judgement \\
\hline $\begin{array}{ll}\text { Random sequence genera- } \\
\text { tion (selection bias) }\end{array}$ & Low risk & $\begin{array}{l}\text { Quote: "Using a table of random numbers, 10 randomly selected numbers } \\
\text { in the range from } 1 \text { to } 20 \text { were assigned to [the] modified constraint-induced } \\
\text { movement therapy group and the remaining } 10 \text { numbers to [the] traditional } \\
\text { rehabilitation group" }\end{array}$ \\
& &
\end{tabular}

Allocation concealment Unclear risk
(selection bias)

Quote: "Patients with left stroke were randomized using two sets of sealed envelopes and those with right stroke using another two sets of sealed envelopes. For each two sets of envelopes, one unmarked set of 20 envelopes were presented to a patient to choose one. The unmarked envelopes contained a single sheet of paper with a number ranging from 1 to 20 . In the second set of envelopes, which were marked with numbers from 1 to 20 , modified constraint-induced movement therapy or traditional rehabilitation sheets were sealed"

Comment: insufficient information to permit judgment

\begin{tabular}{|c|c|c|}
\hline $\begin{array}{l}\text { Blinding (performance } \\
\text { bias and detection bias) } \\
\text { All outcomes }\end{array}$ & Low risk & $\begin{array}{l}\text { Quote: "Two occupational therapists blind to group allocation provided the } \\
\text { evaluations" }\end{array}$ \\
\hline
\end{tabular}

\begin{tabular}{|c|c|c|}
\hline $\begin{array}{l}\text { Incomplete outcome da- } \\
\text { ta addressed? (Post-treat- }\end{array}$ & Low risk & $\begin{array}{l}2 / 17 \text { missing participants from the control group (due to unstable medical } \\
\text { condition) }\end{array}$ \\
\hline
\end{tabular}
ment)

\begin{tabular}{ll} 
Lin 2009a & \\
\hline Methods & Randomisation by computer stratified according to participating hospital \\
& Blinded outcome assessor \\
& No information about withdrawals \\
Multicentre, outpatients
\end{tabular}

\begin{tabular}{ll}
\hline Participants & Taiwan \\
Recruited on the basis of brain imaging identifying unilateral stroke in 3 medical centres
\end{tabular}


Lin 2009a (Continued)

60 participants: 20 intervention, 20 control, 20 bilateral arm training group

Inclusion criteria:cerebrovascular accident $>12$ months; Brunnstrom Stage $>3$ on arm section; amount of use $<2.5$ on the MAL, no serious cognitive deficits, no excessive spasticity in any joints of the affected upper limb

Exclusion criteria: not reported

Mean age (SD): intervention group: 55.28 (9.34) years, control group: 58.77 (15.5) years, bilateral arm training group $51.58(8.67)$ years

$\%$ women: intervention group 45\%, control group: $45 \%$, bilateral arm training group $40 \%$

Stroke details: ischaemic or haemorrhagic; $40 \%$ with right hemiparesis in treatment group, $60 \%$ with right hemiparesis in control group; 55\% with right hemiparesis in bilateral arm training group

Time since stroke, mean (SD): intervention group 21.25 (21.59) months, control group 21.9 (20.51) months, bilateral arm training group 18.5 (17.4) months

Interventions

This trial had 3 arms: the intervention group performed mCIMT; a comparison group that performed bilateral arm training; and the control group

mCIMT versus bilateral arm training versus control

mCIMT: functional tasks by shaping techniques with the affected arm

Amount of restraint: 6 hours per day

Anatomical region restraint: hand

Control: training for hand function, co-ordination, balance and compensatory practice on functional tasks

Bilateral arm training: simultaneous movements of both upper extremities in functional tasks

Session duration: 2 hours per day, 5 days per week, 3 weeks for each group

\begin{tabular}{ll}
\hline Outcomes & Measures pre/post treatment: \\
- Arm motor impairment: FMA \\
- Activities of daily living measure: FIM \\
- Perceived arm motor function: MAL \\
\hline
\end{tabular}

Notes

\section{Risk of bias}

Bias Authors' judgement Support for judgement

Random sequence genera- Low risk tion (selection bias)

Allocation concealment Low risk
(selection bias)

(n)

Quote: "... participants were individually randomized into the distributed CIT, BAT, or control intervention groups, with the computerized (block) randomizations scheme, including pre stratification according to participating hospital"

Quote: "One set of opaque, numbered envelopes was prepared for each site containing cards indicating the allocated group. When a new patient was registered, a card was extracted and the relevant occupational therapist informed of the group allocation"

Blinding (performance Low risk bias and detection bias)

Quote: "... raters were blinded to the participant group and trained to properly All outcomes administer the outcome measures" 
Lin 2009a (Continued)
Incomplete outcome da-
Unclear risk
The study provided no information about withdrawals ta addressed? (Post-treatment)

Lin 2010

$\begin{array}{ll}\text { Methods } & \text { Randomisation details were not reported } \\ & \text { Blinding of outcome assessor not reported } \\ & \text { No information about withdrawals } \\ & \text { Multicentre, outpatients }\end{array}$

Participants

Taiwan

Recruited from 2 medical centres

13 participants: 5 intervention, 8 control

Inclusion criteria: cerebrovascular accident > 3 months; ability to extend actively at least $20^{\circ}$ at the wrist and $10^{\circ}$ at the metacarpophalangeal and interphalangeal joints on the last 4 fingers of the affected hand; sufficient cognitive ability

Exclusion criteria: not reported

Mean age (SD): intervention group: 46.04 (26) years, control group: 51.06 (12.4) years

$\%$ women: intervention group $40 \%$, control group: $0 \%$

Stroke details: ischaemic or haemorrhagic; $20 \%$ with right hemiparesis in treatment group, $62 \%$ with right hemiparesis in control group

Time since stroke, mean (SD): intervention group 21.5 (12.3) months, control group 16.3 (18.3) months

Interventions mCIMT versus control

mCIMT: functional tasks delivered through shaping approach

Amount of restraint: 6 hours per day

Anatomical region restraint: hand

Control: neurodevelopmental treatments focusing on balance training, stretching and weight-bearing with the affected limb, fine-motor tasks and practice of compensatory activities of daily living

Session duration: 2 hours per day, 5 days per week, 3 weeks for each group

$\begin{array}{ll}\text { Outcomes } & \text { Measures pre/post treatment } \\ & \text { - Arm motor impairment: FMA } \\ \text { - Perceived arm motor function: MAL } \\ \text { - Functional magnetic resonance (fMRI) measures }\end{array}$

Notes

\section{Risk of bias}

\section{Bias}

Random sequence genera- Unclear risk tion (selection bias)

\section{Authors' judgement Support for judgement}

Quote: "Participants were randomized to the dCIT [distributed Constraint-induced therapy] or the $\mathrm{Cl}$ [control intervention] group" 
Lin 2010 (Continued)

Allocation concealment $\quad$ Unclear risk
(selection bias)

Blinding (performance Unclear risk Information not provided
bias and detection bias)
All outcomes

Incomplete outcome da- Unclear risk Information not provided
ta addressed? (Post-treat-
ment)

\section{Myint 2008}

$\begin{array}{ll}\text { Methods } & \text { Randomisation by drawing sealed envelopes, other details were not provided } \\ & \text { Blinded of outcome assessor } \\ \text { Post-treatment withdrawals: } 10 \% \text {; follow-up withdrawals: } 7.5 \% \\ \text { Single centre, outpatients }\end{array}$

Participants China

Recruited from 3 hospitals with rehabilitation facilities

43 participants: 23 intervention, 20 control

Inclusion criteria: cerebrovascular accident between 2 to 16 weeks; $10^{\circ}$ of active extension to the metacarpophalangeal and interphalangeal joints $20^{\circ}$ at wrist

Exclusion criteria: severe aphasia, high risk of fall, cerebellar stroke and severe shoulder pain affecting therapy

Mean age (SD): intervention group: 63.4 (13.6) years, control group: 63.9 (12.2) years

$\%$ women: intervention group $56 \%$, control group: $60 \%$

Stroke details: ischaemic or haemorrhagic; $48 \%$ with right hemiparesis in treatment group, $70 \%$ with right hemiparesis in control group

Time since stroke, mean (SD): intervention group 1.27 (0.7) months, control group $1.5(0.95)$ months

Interventions
CIMT versus control
Amount of restraint: $90 \%$ of waking hours
Anatomical region restraint: arm and hand
Control: bimanual task, compensatory techniques for ADL strength, range of motion, positioning and
mobility training
Session duration: 4 hours per day, 5 days per week, 2 weeks for each group
Measures pre/post treatment and follow-up at 12 months
- Motor function: functional test for hemiparetic upper extremity, ARAT
- Perceived arm motor function: MAL
- Dexterity: 9 ADPT


Myint 2008 (Continued)

Notes

\section{Risk of bias}

\begin{tabular}{|c|c|c|}
\hline Bias & Authors' judgement & Support for judgement \\
\hline $\begin{array}{l}\text { Random sequence genera- } \\
\text { tion (selection bias) }\end{array}$ & Low risk & $\begin{array}{l}\text { Quote: "subjects were randomized by drawing sealed envelopes which were } \\
\text { filled at random with indication of which intervention group the patient was } \\
\text { allocated to" }\end{array}$ \\
\hline $\begin{array}{l}\text { Allocation concealment } \\
\text { (selection bias) }\end{array}$ & Unclear risk & Insufficient information to permit judgment \\
\hline $\begin{array}{l}\text { Blinding (performance } \\
\text { bias and detection bias) } \\
\text { All outcomes }\end{array}$ & Low risk & Quote: "The observer was blinded" \\
\hline $\begin{array}{l}\text { Incomplete outcome da- } \\
\text { ta addressed? (Post-treat- } \\
\text { ment) }\end{array}$ & High risk & $\begin{array}{l}5 / 28 \text { missing from intervention group (due to transport problem, inadequate } \\
\text { home support; others changed their mind about trial participation); } 0 / 20 \text { miss- } \\
\text { ing participants in the control group. Reasons for missing data outcomes pos- } \\
\text { sibly related to the true effect, with imbalance across intervention and control } \\
\text { groups }\end{array}$ \\
\hline
\end{tabular}

Page 2001

$\begin{array}{ll}\text { Methods } & \text { Randomisation details were not provided } \\ & \text { Blinded outcome assessor } \\ & \text { No information about withdrawals } \\ \text { Multicentre, outpatients }\end{array}$

Participants USA

Recruited through letters sent to people who experienced a cerebrovascular accident and were discharged from outpatients therapy provided at 4 rehabilitation hospitals

6 participants: 2 intervention, 2 control, 2 no treatment

Inclusion criteria: stroke between 4 weeks and 6 months, $10^{\circ}$ of active extension to the metacarpophalangeal and interphalangeal joints and $20^{\circ}$ at wrist

Exclusion criteria: severe cognitive impairment, excessive spasticity and pain

Mean age (SD): intervention group: 55 (4.24) years, control group: 52 (5.65) years, no intervention group 60.5 (23.33) years

$\%$ women: intervention group 50\%, control group 50\%, no treatment group 50\%

Stroke details: ischaemic or haemorrhagic; 50\% with right hemiparesis in treatment group, 50\% with right hemiparesis in control group, $100 \%$ with right hemiparesis in no treatment group

Time since stroke, mean (SD): intervention group 5.65 (0.21) months, control group 3.75 (2.47) months, no treatment group $4.5(0.7)$ months

Interventions

This trial had 3 arms: the intervention group performed mCIMT; a control group performed usual care; and the third group performed no treatment

mCIMT versus control versus no treatment

mCIMT: physical and occupational therapy focused on PNF with emphasis on ADL tasks, compensatory techniques with the unaffected side, two functional task of the WMFT with shaping techniques 
Page 2001 (Continued)

Amount of restraint: 5 waking hours per day

Anatomical region restraint: arm and hand

Control: physical and occupational therapy focused on PNF with emphasis on ADL tasks, compensatory techniques with the unaffected side

Session duration: 1 hour per day, 3 days per week, 10 weeks for each group

\begin{tabular}{ll}
\hline Outcomes & Measures pre/post treatment \\
& - Arm motor function: ARAT, WMFT2 \\
- Perceived arm motor function: MAL & Arm motor impairment: FMA
\end{tabular}

Notes

\section{Risk of bias}

\begin{tabular}{|c|c|c|}
\hline Bias & Authors' judgement & Support for judgement \\
\hline $\begin{array}{l}\text { Random sequence genera- } \\
\text { tion (selection bias) }\end{array}$ & Unclear risk & $\begin{array}{l}\text { Quote: "all subjects were randomly assigned ... with an equal probability" } \\
\text { Comment: insufficient information to permit judgment }\end{array}$ \\
\hline $\begin{array}{l}\text { Allocation concealment } \\
\text { (selection bias) }\end{array}$ & Unclear risk & No information provided \\
\hline $\begin{array}{l}\text { Blinding (performance } \\
\text { bias and detection bias) } \\
\text { All outcomes }\end{array}$ & Low risk & Quote: "A blinded examiner administered all instruments" \\
\hline $\begin{array}{l}\text { Incomplete outcome da- } \\
\text { ta addressed? (Post-treat- } \\
\text { ment) }\end{array}$ & Unclear risk & The study provided no information about withdrawals \\
\hline
\end{tabular}

\section{Page 2002b}

\begin{tabular}{ll}
\hline Methods & Randomisation details were not provided \\
& Blinded outcome assessor \\
& No information about withdrawals \\
& Multicentre, outpatients
\end{tabular}

\section{Participants}

\section{USA}

Recruited through letters sent to people who experienced a cerebrovascular accident and were discharged from outpatients therapy provided at 4 rehabilitation hospitals

14 participants: 4 intervention, 5 control, 5 no treatment

Inclusion criteria: stroke between 4 weeks and 6 months; $10^{\circ}$ of active extension to the metacarpophalangeal and interphalangeal joints and $20^{\circ}$ at wrist

Exclusion criteria: severe cognitive impairment, excessive spasticity and pain

Mean age (SD): intervention group: 73.5 (6.35) years, control group: 67.4 (13.8) years, no intervention group 68.2 (14.13) years

$\%$ women: intervention group $0 \%$, control group $20 \%$, no treatment group $80 \%$ 
Page 2002b (Continued)

Stroke details: only Ischaemic; 50\% with right hemiparesis in treatment group, $20 \%$ with right hemiparesis in control group, $60 \%$ with right hemiparesis in no treatment group

Time since stroke, mean (SD): intervention group 5 (0.8) months, control group 4.9 (0.9) months, no treatment group $4.3(0.67)$ months

This trial had 3 arms: the intervention group performed mCIMT; a control group performed usual care;
and the third group performed no treatment
mCIMT versus control versus no treatment
mCIMT: physical therapy and occupational therapy focused on functional tasks by the more affected
limb, stretching, stand/balance, gait training, shaping techniques on 2 or 3 functional tasks
Amount of restraint: 5 waking hours per day
Anatomical region restraint: arm and hand
Control: physical and occupational therapy focused on functional tasks by the more affected limb and
PNF
Session duration: 1 hour per day, 3 days per week, 10 weeks for each group
Measures pre/post treatment
- Motor function: ARAT
- Perceived arm motor function: MAL
- Arm motor impairment: FMA

Notes

\section{Risk of bias}

\begin{tabular}{lll}
\hline Bias & Authors' judgement & Support for judgement \\
\hline $\begin{array}{l}\text { Random sequence genera- } \\
\text { tion (selection bias) }\end{array}$ & Unclear risk & $\begin{array}{l}\text { Quote: "... all subjects randomly assigned ... with equal probability" } \\
\text { Comment: insufficient information to permit judgment }\end{array}$ \\
\hline $\begin{array}{l}\text { Allocation concealment } \\
\text { (selection bias) }\end{array}$ & Unclear risk & No information provided \\
\hline $\begin{array}{l}\text { Blinding (performance } \\
\text { bias and detection bias) } \\
\begin{array}{l}\text { All outcomes } \\
\text { Incomplete outcome da- }\end{array}\end{array}$ & Low risk & Quote: "...a blinded rater again administered the instruments to all subjects" \\
\hline $\begin{array}{l}\text { ta addressed? (Post-treat- } \\
\text { ment) }\end{array}$ & & \\
\hline
\end{tabular}

Page 2004

Methods Randomisation by computer random number table, other details were not provided

Blinded outcome assessor

No information about withdrawals

Multicentre, outpatients

Participants USA

Recruited thorough advertisements placed in therapy clinics and given to therapists in hospitals 
Page 2004 (Continued)

17 participants: 7 intervention, 4 control, 6 no treatment

Inclusion criteria: stroke $>1$ year; $10^{\circ}$ of active extension to the metacarpophalangeal and interphalangeal joints and $20^{\circ}$ at wrist

Exclusion criteria: severe cognitive impairment, excessive spasticity and pain

Mean age (SD): intervention group: 54.6 (12.77) years, control group: 60.75 (13.6) years, no intervention group 63.6 (9.81) years

$\%$ women: intervention group $29 \%$, control group $0 \%$, no treatment group $17 \%$

Stroke details: only ischaemic; $71 \%$ with right hemiparesis in treatment group, $50 \%$ with right hemiparesis in control group, $50 \%$ with right hemiparesis in no treatment group

Time since stroke, mean (SD): intervention group 25.42 (6.53) months, control group 38 (23.9) months, no treatment group 36.5 (26) months

Interventions

This trial had 3 arms: the intervention group performed mCIMT; a control group performed usual care; and the third group performed no treatment

mCIMT versus control versus no treatment

mCIMT: functional task with the affected arm, strengthening, stretching, compensatory techniques, shaping techniques on 2 or 3 functional tasks

Amount of restraint: 5 waking hours per day

Anatomical region restraint: arm and hand

Control: physical and occupational therapy focused on PNF, stretching and compensatory techniques

Session duration: 1 hour per day, 3 days per week, 10 weeks for both treatment groups

\begin{tabular}{ll}
\hline Outcomes & Measures pre/post treatment \\
- Arm motor function: ARAT \\
- Perceived arm motor function: MAL \\
- Arm motor impairment: FMA
\end{tabular}

Notes

\section{Risk of bias}

\begin{tabular}{lll}
\hline Bias & Authors' judgement & Support for judgement \\
\hline $\begin{array}{l}\text { Random sequence genera- } \\
\text { tion (selection bias) }\end{array}$ & Low risk & $\begin{array}{l}\text { Quote: "...patients were randomly assigned to 1 of 3 condition groups with } \\
\text { equal probability by using a computer-generated random numbers table" }\end{array}$ \\
\hline $\begin{array}{l}\text { Allocation concealment } \\
\text { selection bias) }\end{array}$ & Unclear risk & No information provided \\
\hline $\begin{array}{l}\text { Blinding (performance } \\
\text { bias and detection bias) }\end{array}$ & Low risk & $\begin{array}{l}\text { Quote: "examiner was blinded in that he was unaware of the patients' ran- } \\
\text { domized grouping" }\end{array}$ \\
\hline $\begin{array}{l}\text { Incomplete outcome da- } \\
\text { ta addressed? (Post-treat- } \\
\text { ment) }\end{array}$ & Unclear risk & $\begin{array}{l}\text { One participant had received botulinum toxin type A in the more affected limb } \\
<3 \text { months before the study and was excluded from post hoc analysis }\end{array}$ \\
\hline
\end{tabular}


Page 2005b

Methods

Randomisation by random number table, other details were not provided

Blinded outcome assessor

No information about withdrawals

Multicentre, outpatients

USA
Recruited volunteers; other details not provided
10 participants: 5 intervention, 5 control
Inclusion criteria: stroke < 14 days; $10^{\circ}$ of active extension to the metacarpophalangeal and
langeal joints and $20^{\circ}$ at wrist, more affected limb non use, defined as an amount of use scor
on the MAL
Exclusion criteria: severe cognitive impairment, excessive spasticity and pain
Mean age (SD): intervention group: 58.6 (6.35) years, control group: 62.2 (10.3) years
\% women: intervention group 20\%, control group 20\%
Stroke details: only Ischaemic; $80 \%$ with right hemiparesis in each group
Time since stroke, mean (SD): intervention group 4 (1.6) days, control group 4.8 (3.03) days

Interventions

mCIMT versus control

mCIMT: shaping techniques on 3 functional tasks, range of motion

Amount of restraint: 5 waking hours per day

Anatomical region restraint: hand

Control: stretching, weight bearing, manual dexterity exercise with the affected arm, compensatory techniques

Session duration: 1 hour per day, 3 days per week, 10 weeks for each treatment group

\begin{tabular}{ll}
\hline Outcomes & Measures pre/post treatment \\
- Arm motor function: ARAT \\
- Perceived arm motor function: MAL \\
- Arm motor impairment: FMA
\end{tabular}

Notes

\section{Risk of bias}

\begin{tabular}{|c|c|c|}
\hline Bias & Authors' judgement & Support for judgement \\
\hline $\begin{array}{l}\text { Random sequence genera- } \\
\text { tion (selection bias) }\end{array}$ & Low risk & $\begin{array}{l}\text { Quote: "Using a random numbers table, patients were then randomly assigned } \\
\text { to either } 1) \operatorname{mCIT}(n=5) \text { or } 2 \text { ) traditional rehabilitation }(T R)(n=5) "\end{array}$ \\
\hline $\begin{array}{l}\text { Allocation concealment } \\
\text { (selection bias) }\end{array}$ & Unclear risk & No information provided \\
\hline $\begin{array}{l}\text { Blinding (performance } \\
\text { bias and detection bias) } \\
\text { All outcomes }\end{array}$ & Low risk & $\begin{array}{l}\text { Quote: "The Fugl-Meyer, ARA, and MAL were administered by the same exam- } \\
\text { iner who performed pretests, blinded to group assignment" }\end{array}$ \\
\hline
\end{tabular}


Page 2005b (Continued)
Incomplete outcome da-
Unclear risk
The study provided no information about withdrawals ta addressed? (Post-treatment)

\section{Page 2008}

$\begin{array}{ll}\text { Methods } & \begin{array}{l}\text { Randomisation by computer-generated random numbers table, other details were not provided } \\ \text { Blinded outcome assessor } \\ \text { No information about withdrawals } \\ \text { Multicentre, outpatients }\end{array} \\ \text { USA } & \text { Recruited thorough advertisements placed in neurology and physical therapy clinics } \\ & 35 \text { participants: } 13 \text { intervention, } 12 \text { control, } 10 \text { no treatment } \\ \text { Inclusion criteria: stroke }>12 \text { months; } 10^{\circ} \text { of active extension to the metacarpophalangeal and inter- } & \text { phalangeal joints and } 20^{\circ} \text { at wrist; more affected limb non-use, defined as an amount of use score of }< \\ & 2.5 \text { on the MAL } \\ & \text { Exclusion criteria: severe cognitive impairment, excessive spasticity and pain } \\ & \text { Mean age (SD): } 57.9 \text { ( } 8.4) \text { years for all groups } \\ & \% \text { women: } 37 \% \text { for all groups } \\ & \text { Stroke details: only ischaemic; } 66 \% \text { with right hemiparesis } \\ & \text { Time since stroke, mean: } 39.8 \text { months }\end{array}$

Interventions

This trial had 3 arms: the intervention group performed mCIMT; a control group performed usual care; and the third group performed no treatment

mCIMT versus control versus no treatment

mCIMT: functional task by shaping techniques

Amount of restraint: 5 waking hours per day

Anatomical region restraint: arm and hand

Control: PNF, stretching

Session duration: 30 minutes per day, 3 days per week, 10 weeks for each group

$\begin{array}{ll}\text { Outcomes } & \text { Measures pre/post treatment } \\ & \text { - Arm motor function: ARAT } \\ \text { - Perceived arm motor function: MAL } & \text { Arm motor impairment: FMA }\end{array}$

Notes

\section{Risk of bias}

Bias Authors' judgement Support for judgement

Random sequence genera- Low risk tion (selection bias)

Quote: "Subjects were randomly assigned to 1 of 3 groups with equal probability of assignment to any of the groups using a computer-generated random numbers table" 
Page 2008 (Continued)

\begin{tabular}{lll}
$\begin{array}{l}\text { Allocation concealment } \\
\text { (selection bias) }\end{array}$ & Unclear risk & No information provided \\
\hline $\begin{array}{l}\text { Blinding (performance } \\
\text { bias and detection bias) }\end{array}$ & Low risk & Blinding of outcome assessor \\
All outcomes & &
\end{tabular}

\begin{tabular}{ll}
\hline Incomplete outcome da- $\quad$ Unclear risk & The study provided no information about withdrawals \\
ta addressed? (Post-treat- &
\end{tabular}
ment)

\section{Ploughman 2004}

\begin{tabular}{ll}
\hline Methods & Randomisation by random number generation, other details were not provided \\
& Blinded outcome assessor only on admission to treatment \\
& Post-treatment withdrawals: $11 \%$ \\
& Single centre, inpatients and outpatients
\end{tabular}

Participants Canada

Recruited from people admitted to multidisciplinary rehabilitation services from June 2001 to February 2003

23 participants: 10 intervention, 13 control

Inclusion criteria: no more than 16 weeks post-stroke at inclusion; > stage 2 but $\leq$ stage 6 on the CMII for the arm and hand

Exclusion criteria: evidence of cognitive impairment

Mean age (SD): intervention group: 57.8 (10.65) years, control group: 61.62 (5.68) years

$\%$ women: intervention group $30 \%$, control group $38 \%$

Stroke details: ischaemic or haemorrhagic; $60 \%$ with right hemiparesis in treatment group, $31 \%$ with right hemiparesis in control group

Time since stroke, mean (SD): intervention group 1.2 (0.75) months, control group 1.3 (0.78) months

Interventions
Usual care: facilitation of the proximal motor control progressing to skilled-task training, strength and
endurance training, functional electric stimulation, gait training
Amount of restraint: average 2.7 hours per day
Anatomical region restraint: hand (only thumb)
Session duration: mean therapy $58.9 \pm 41.45$ minutes per day control group, and $61.74 \pm 23.68$ minutes
per day intervention group, duration of study not specified

\section{Outcomes}

\section{Measures pre/post treatment}

- Arm motor function: ARAT

- Arm motor impairment: CMII for arm, hand, postural control and shoulder pain, grip strength

- ADL measure: FIM3

\section{Notes}

\section{Risk of bias}


Ploughman 2004 (Continued)

\begin{tabular}{lll} 
Bias & Authors' judgement & Support for judgement \\
\hline $\begin{array}{l}\text { Random sequence genera- } \\
\text { tion (selection bias) }\end{array}$ & Low risk & $\begin{array}{l}\text { Quote: "Subjects were randomly assigned, by using random number genera- } \\
\text { tion, to either conventional rehabilitation or conventional rehabilitation plus } \\
\text { FUT" }\end{array}$ \\
\hline $\begin{array}{l}\text { Allocation concealment } \\
\text { (selection bias) }\end{array}$ & Unclear risk & No information provided \\
\hline $\begin{array}{l}\text { Blinding (performance } \\
\text { bias and detection bias) } \\
\text { All outcomes }\end{array}$ & High risk & $\begin{array}{l}\text { Quote: "The ARAT admission and discharge assessments were performed by } \\
\text { the principal investigator who was blinded to the treatment condition only on } \\
\text { admission assessment" }\end{array}$ \\
\hline $\begin{array}{l}\text { Incomplete outcome da- } \\
\text { ta addressed? (Post-treat- } \\
\text { ment) }\end{array}$ & Low risk & $\begin{array}{l}3 / 13 \text { missing from intervention group due to assessment being too stressful; } \\
1 / 14 \text { missing from control group for same reason }\end{array}$ \\
\hline
\end{tabular}

\section{Singh 2013}

$\begin{array}{ll}\text { Methods } & \text { Randomisation through lottery method } \\ & \text { Unblinded outcome assessor } \\ & \text { No withdrawals } \\ & \text { Single centre, inpatients }\end{array}$

Participants India

Recruited via Central Referral Hospital and STNM Hospital in Sikkim

40 participants: 20 intervention, 20 control

Inclusion criteria: cerebrovascular accident between 2 and 4 weeks; $10^{\circ}$ of active extension to the metacarpophalangeal and interphalangeal joints and $10^{\circ}$ at wrist

Exclusion criteria: severe aphasia, severe shoulder pain affecting therapy or any comorbid condition that could limit upper extremity function

Mean age (SD): intervention group: 55.2 (9.27) years, control group: 21.9 (20.51) years

$\%$ women: intervention group 30\%, control group: $45 \%$

Stroke details: ischaemic or haemorrhagic

Time since stroke, mean (SD): intervention group $0.6(0.11)$ months, control group $0.65(0.13)$ months

MCIMT: shaping

Amount of restraint: 10 hours per day

Anatomical region restraint: hand

Control: standard physical therapy, compensatory technique for daily activities, strengthening, and range of motion exercises for the affected arm

Session duration: 2 hours per day, 5 days per week, 3 weeks for each group

\begin{tabular}{ll}
\hline Outcomes & Measures pre/post treatment \\
- Arm motor function: WMFT
\end{tabular}


Singh 2013 (Continued)

- Arm motor impairment: FMA

- Spasticity: MASh (only at baseline)

\section{Notes}

\section{Risk of bias}

\begin{tabular}{lll}
\hline Bias & Authors' judgement & Support for judgement \\
\hline $\begin{array}{l}\text { Random sequence genera- } \\
\text { tion (selection bias) }\end{array}$ & Low risk & $\begin{array}{l}\text { Quote: "Subjects were individually randomized into intervention and control } \\
\text { groups by using lottery method" }\end{array}$ \\
\hline $\begin{array}{l}\text { Allocation concealment } \\
\text { (selection bias) }\end{array}$ & Unclear risk & No information provided \\
\hline $\begin{array}{l}\text { Blinding (performance } \\
\text { bias and detection bias) } \\
\text { All outcomes }\end{array}$ & High risk & $\begin{array}{l}\text { Quote: "There are few limitations of our study like: Small sample size due to } \\
\text { limited stroke subjects, the rater who was not blinded to the study." }\end{array}$ \\
\hline $\begin{array}{l}\text { Incomplete outcome da- } \\
\text { ta addressed? (Post-treat- } \\
\text { ment) }\end{array}$ & Low risk & $\begin{array}{l}\text { Quote: "Since no follow-up and less time was kept for restraint of the unaffect- } \\
\text { ed upper extremity so no drop out during the study" }\end{array}$ \\
\hline
\end{tabular}

Smania 2012

\begin{tabular}{ll}
\hline Methods & Randomisation automated \\
& Blinded outcome assessor \\
& Post-treatment withdrawals 10\%, follow-up withdrawals: $35 \%$ \\
& Multicentre, outpatients
\end{tabular}

Participants Italy

Recruited from 9 clinical sites.

66 participants: 34 intervention, 32 control

Inclusion criteria: cerebrovascular accident occurred between 3 to 24 months earlier; $10^{\circ}$ of active wrist extension, at least $10^{\circ}$ of thumb abduction/extension, and at least $10^{\circ}$ of extension at the level of the metacarpophalangeal and interphalangeal joints in at least 2 digits

Exclusion criteria: severe cognitive impairment, amount of use $\geq 2.5$ on the MAL

Mean age (SD): intervention group: 63.93 (9.56) years, control group: 68.25 (12.68) years

$\%$ women: intervention group $13 \%$, control group: $21 \%$

Stroke details: ischaemic or haemorrhagic; $47 \%$ with right hemiparesis with $53 \%$ paresis of the dominant side in treatment group, $45 \%$ with right hemiparesis with $48 \%$ paresis of the dominant side in control group

Time since stroke, mean (SD): intervention group 11.1 (8.91) months, control group 9.38 (7.78) months

Interventions mCIMT versus control

mCIMT: passive mobilisation, task practise, ADL activities through shaping approach and household activities consisting in functional activities

Amount of restraint: 12 hours per day 
Smania 2012 (Continued)

Anatomical region restraint: hand

Control: passive mobilisation and stretching, active motility tasks, ADL activities and household activities consisting in functional activities

Session duration: 2 hours per day, 5 days per week, 2 weeks for each group

\begin{tabular}{|c|c|c|}
\hline Outcomes & \multicolumn{2}{|c|}{$\begin{array}{l}\text { Measures pre/post treatment and follow-up at } 3 \text { months } \\
\text { - Arm motor function: WMFT } \\
\text { - Perceived arm motor function: MAL } \\
\text { - Spasticity: MASh }\end{array}$} \\
\hline \multicolumn{3}{|l|}{ Notes } \\
\hline \multicolumn{3}{|l|}{ Risk of bias } \\
\hline Bias & Authors' judgement & Support for judgement \\
\hline $\begin{array}{l}\text { Random sequence genera- } \\
\text { tion (selection bias) }\end{array}$ & Low risk & $\begin{array}{l}\text { Quote: "If eligible, patients were allocated to the experimental group (EG) or } \\
\text { the control group (CG) by means of an automated randomizations system" }\end{array}$ \\
\hline $\begin{array}{l}\text { Allocation concealment } \\
\text { (selection bias) }\end{array}$ & Low risk & $\begin{array}{l}\text { Quote: "The group allocation was concealed using sealed numbered en- } \\
\text { velopes that were sent to the clinical hospital where the treatment was deliv- } \\
\text { ered. The randomizations list was locked in a desk drawer accessible only to } \\
\text { the main investigator" }\end{array}$ \\
\hline \multirow{2}{*}{$\begin{array}{l}\text { Blinding (performance } \\
\text { bias and detection bias) } \\
\text { All outcomes }\end{array}$} & Low risk & $\begin{array}{l}\text { Quote: "At each research centre the same examiner, who was blinded with re- } \\
\text { gard to treatment allocation, evaluated patients enrolled in the study" }\end{array}$ \\
\hline & & $\begin{array}{l}\text { Quote: "Examiners were requested to inform their research coordinator if } \\
\text { they discovered to which group a patient belonged, and they were periodically } \\
\text { questioned by the coordinator about this" }\end{array}$ \\
\hline \multirow{3}{*}{$\begin{array}{l}\text { Incomplete outcome da- } \\
\text { ta addressed? (Post-treat- } \\
\text { ment) }\end{array}$} & Low risk & $\begin{array}{l}\text { 4/30 missing participants from mCIMT ( } 1 \text { for unco-operativeness, } 3 \text { for medical } \\
\text { complications) }\end{array}$ \\
\hline & & $\begin{array}{l}3 / 32 \text { missing participants from control group ( } 1 \text { for unco-operativeness, } 2 \text { for } \\
\text { medical complications) }\end{array}$ \\
\hline & & Quote: "An intention-to-treat analysis was used" \\
\hline
\end{tabular}

Suputtitada 2004

\begin{tabular}{ll} 
Methods & $\begin{array}{l}\text { Randomisation by random-number table, other details were not provided } \\
\text { Blinded outcome assessor } \\
\text { No information about withdrawals } \\
\text { Single centre, outpatients }\end{array}$ \\
\hline Participants & Thailand \\
& Recruited from the Department of Rehabilitation Medicine of King Chulalongkorn Memorial Hospital \\
& 69 participants: 36 intervention, 33 control \\
Inclusion criteria: $20^{\circ}$ of active extension at wrist, $10^{\circ}$ at metacarpophalangeal and interphalangeal & joints \\
Exclusion criteria: balance problems; severe aphasia; sensory disorder; severe cognitive impairments
\end{tabular}


Mean age (SD): intervention group: 60.1 (4.8) years, control group: 58.7 (4.2) years

$\%$ women: intervention group $33.3 \%$, control group: $30.6 \%$

Stroke details: ischaemic or haemorrhagic; $91 \%$ with right hemiparesis in treatment group, $94 \%$ with right hemiparesis in control group

Time since stroke: $1-3$ years in both groups

\begin{tabular}{ll}
\hline Interventions & CIMT versus control \\
mCIMT: not described \\
Amount of the restraint: 6 hours per day \\
Anatomical region restraint: hand \\
Control: neurodevelopmental treatment \\
Session duration: 2 hours per day, 5 days \\
- Measures pre/post treatment \\
- Arm motor function: WMFT \\
- Perceived arm motor function: MAL \\
\hline \multirow{2}{*}{ Motor impairment: ARAT }
\end{tabular}

Notes

\section{Risk of bias}

\begin{tabular}{lll}
\hline Bias & Authors' judgement & Support for judgement \\
\hline $\begin{array}{l}\text { Random sequence genera- } \\
\text { tion (selection bias) }\end{array}$ & Low risk & $\begin{array}{l}\text { Quote: "... patients were randomized individually into 2 groups by using the } \\
\text { table of randomizations" }\end{array}$ \\
\hline $\begin{array}{l}\text { Allocation concealment } \\
\text { (selection bias) }\end{array}$ & Unclear risk & No information provided \\
\hline $\begin{array}{l}\text { Blinding (performance } \\
\text { bias and detection bias) }\end{array}$ & Low risk & Quote: "This was a[n] ... observer-blinded clinical trial" \\
$\begin{array}{l}\text { All outcomes } \\
\begin{array}{l}\text { Incomplete outcome da- } \\
\text { ta addressed? (Post-treat- } \\
\text { ment) }\end{array}\end{array}$ & Unclear risk & No information provided \\
\hline
\end{tabular}

Tariah 2010

$\begin{array}{ll}\text { Methods } & \text { Randomisation details were not reported } \\ & \text { Blinded outcome assessor } \\ & \text { No information about withdrawals } \\ & \text { Single centre, home-based treatment for experimental group and outpatients for control group }\end{array}$

Participants
Participant recruitment information not provided
18 participants: 10 intervention, 8 control


Tariah 2010 (Continued)

Inclusion criteria: $>2$ months post-stroke at inclusion, $20^{\circ}$ of active extension at wrist, $10^{\circ}$ at metacarpophalangeal and interphalangeal joints

Exclusion criteria: cognitive impairment; amount of use $\geq 2.5$ on the MAL; excessive spasticity and pain

Mean age (SD): intervention group: 54.8 (10.9) years, control group: 60.6 (4.9) years

$\%$ women: intervention group $20 \%$, control group: $50 \%$

Stroke details: only ischaemic; $70 \%$ with right hemiparesis in treatment group, $50 \%$ with right hemiparesis in control group

Time since stroke, mean (SD): intervention group 9.2 (5.79) months, control group 9.4 (4) months

\section{mCIMT versus control}

mCIMT: training activities focused on patients' ADLs, instrumental activities of daily living, and leisure activities (e.g. playing cards, chess, crafts, gardening)

Amount of restraint: 4 hours per day

Anatomical region restraint: hand

Control: weight-bearing and facilitation of arm movement based on conventional neurodevelopmental procedures

Session duration: 2 hours per day, 7 days per week, 2 months for both groups

$\begin{array}{ll}\text { Outcomes } & \text { Measures pre/post treatment } \\ & \text { - Arm motor function: WMFT } \\ \text { - Perceived arm motor function: MAL } & \text { - Arm motor impairment: FMA }\end{array}$

Notes

\section{Risk of bias}

\section{Bias}

Random sequence genera- Unclear risk
tion (selection bias)

Allocation concealment
(selection bias)

Unclear risk

(ection bias)

Blinding (performance

bias and detection bias)

Unclear risk

All outcomes

Incomplete outcome data addressed? (Post-treatment)

\section{Authors' judgement Support for judgement}

Quote: "participants ... were randomly numbered from one to twenty. Participants with odd numbers were allocated to CIMT group and those with even numbers were allocated to Neurodevelopmental Treatment NDT [control] group"

No information provided

Quote: "The investigators, who were blind to the allocation of the groups, provided the evaluation tests"

$2 / 10$ in the NDT group dropped out after randomisation. Reasons not provided.

Taub 1993

$\begin{array}{ll}\text { Methods } & \begin{array}{l}\text { Randomisation details were not reported } \\ \text { Blinded outcome assessor }\end{array}\end{array}$


Taub 1993 (Continued)

No information about withdrawals

Multicentre, outpatients

USA
Recruiticipants from the Spain Rehabilitation Center and the Departement of Neurology of the University of
Alabama
9 participants: intervention 4 , control 5
Inclusion criteria: stroke $>1$ year; $10^{\circ}$ of active extension to the metacarpophalangeal and interpha-
langeal joints and $20^{\circ}$ at wrist
Exclusion criteria: balance problems, extensive use of the affected arm, cognitive deficits, medical
problems, $>75$ years of age, left dominance or left hemiplegia
Median age: intervention group: 65 years, control group: 63 years
\% women: intervention group $75 \%$, control group: $80 \%$
Stroke details: only right side affected and right arm dominance for each group
Median time since stroke: intervention 4.1 years, control: 4.5 years

Interventions

CIMT versus usual care

CIMT: functional activity with the affected arm

Amount of restraint: $90 \%$ of waking hours per day

Anatomical region restraint: arm and hand

Usual care: exhorted to focus attention on using the affected arm; range of self-movement with the aid of the unaffected arm

Session duration:

Intervention: 6 hours per day, 5 days per week, 2 weeks

Control: 15 minutes per day, 5 days per week, 2 weeks

\begin{tabular}{ll}
\hline Outcomes & Measures pre/post treatment \\
- Motor function: AMAT, EMF \\
- Perceived arm motor function: MAL2
\end{tabular}

Notes

\section{Risk of bias}

\section{Bias}

Random sequence genera- Unclear risk

tion (selection bias)

\begin{tabular}{ll}
\hline $\begin{array}{l}\text { Allocation concealment } \\
\text { (selection bias) }\end{array}$ & Unclear risk information provided
\end{tabular}

Blinding (performance $\quad$ Low risk $\quad$ Blinding of outcome assessor
bias and detection bias)
All outcomes

Incomplete outcome da- Unclear risk The study provided no information about withdrawals
ta addressed? (Post-treat-
ment)
ment) 
Treger 2012

\begin{tabular}{|c|c|}
\hline \multirow[t]{3}{*}{ Methods } & $\begin{array}{l}\text { Randomisation by computer random numbers table, other details not provided } \\
\text { Blinded outcome assessor }\end{array}$ \\
\hline & No withdrawals \\
\hline & Single centre, inpatients \\
\hline \multirow[t]{9}{*}{ Participants } & Israel \\
\hline & $\begin{array}{l}\text { Recruited from people admitted to the Department of Neurological Rehabilitation, the Loewenstein } \\
\text { Hospital Rehabilitation Center }\end{array}$ \\
\hline & 28 participants: 9 intervention, 19 control \\
\hline & $\begin{array}{l}\text { Inclusion criterion: active movement in most joints of the affected upper limb (grade } \geq 16 \text { of the manual } \\
\text { function test) }\end{array}$ \\
\hline & $\begin{array}{l}\text { Exclusion criteria: neurological or orthopedic disorders prohibiting the use of the paretic arm, neglect, } \\
\text { apraxia, and cognitive disorders impeding collaboration }\end{array}$ \\
\hline & Mean age (SD): intervention group: 62 (28.4) years, control group: 61.5 (8.4) years \\
\hline & $\%$ women: intervention group 55\%, control group: $16 \%$ \\
\hline & Stroke details: only ischaemic \\
\hline & Time since stroke, mean (SD): intervention group 1.32 (0.94) months, control group 0.77 (0.8) months \\
\hline
\end{tabular}

mCIMT versus control

mCIMT: training of the affected upper limb based on a task-oriented approach, emphasising repetitive practice of functional activities and behavioural shaping

Amount of restraint: 4 hours per day

Anatomical region restraint: hand

Control: training of the affected upper limb based on a task-oriented approach, emphasizing repetitive practice of functional activities and behavioural shaping

Session duration: 1 hour and 45 minutes per day, 5 days per week, 2 weeks for both groups

\begin{tabular}{ll}
\hline Outcomes & Measures pre/post treatment: \\
& - ADL measures: FIM \\
& - Hand function: MFT \\
& Overall stroke severity: NIHSS
\end{tabular}

\section{Notes}

\section{Risk of bias}

\begin{tabular}{lll}
\hline Bias & Authors' judgement & Support for judgement \\
\hline $\begin{array}{l}\text { Random sequence genera- } \\
\text { tion (selection bias) }\end{array}$ & Low risk & $\begin{array}{l}\text { Quote: "Concealed allocation was performed by a computer-generated ran- } \\
\text { domized table of numbers created prior to the study" }\end{array}$ \\
\hline $\begin{array}{l}\text { Allocation concealment } \\
\text { (selection bias) }\end{array}$ & Low risk & $\begin{array}{l}\text { Quotes: "Concealed allocation was performed by a computer-generated ran- } \\
\text { domized table of numbers created prior to the study" }\end{array}$ \\
& $\begin{array}{l}\text { "Individual, sequentially numbered index cards with the random assignment } \\
\text { were prepared, folded, and placed in sealed opaque envelopes" }\end{array}$ \\
\hline
\end{tabular}


Treger 2012 (Continued)

Blinding (performance Low risk Quote: "The assessor of the upper limb function tests was blinded to the type bias and detection bias) of intervention. The same assessor performed baseline and follow-up tests" All outcomes

Incomplete outcome da- Low risk No participants lost to follow-up
ta addressed? (Post-treat-
ta addressed? (Post-treatment)

Van Delden 2013

$\begin{array}{ll}\text { Methods } & \text { Randomisation by using the minimisation method } \\ & \text { Blinding of outcome assessor not reported } \\ \text { Follow-up withdrawals: } 8 \% \\ \text { Single centre }\end{array}$

Participants

The Netherlands

Recruited from the Reade rehabilitation centre in Amsterdam

60 participants: 22 intervention, 19 control, 19 bilateral arm training with rhythmic auditory cueing

Inclusion criteria: cerebrovascular accident between 1 and 6 months; $10^{\circ}$ of active wrist extension, $10^{\circ}$ af active thumb abduction/extension and $10^{\circ}$ active extension in at least 2 additional digits; motivated to participate

Exclusion criteria: upper-limb orthopaedic limitations; cognitive impairment.

Mean age (SD): intervention group: 59.8 (13.8) years, control group: 56.9 (12.7) years, bilateral arm training with rhythmic auditory cueing $62.6(9.8)$ years

$\%$ women: intervention group $36 \%$, control group: $58 \%$, bilateral arm training with rhythmic auditory cueing $42 \%$

Stroke details: ischaemic or haemorrhagic; $45 \%$ with right hemiparesis with $50 \%$ paresis of the dominant side in treatment group, $58 \%$ with right hemiparesis with $37 \%$ paresis of the dominant side in control group, $58 \%$ with right hemiparesis with $47 \%$ paresis of the dominant side in bilateral arm training with rhythmic auditory cueing (BATRAC) group

Time since stroke, mean (SD): intervention group 2.14 (1.6) months, control group 2.6 (1.6) months, BATRAC group 1.8 (1.14) months

Interventions

This trial had 3 arms: the intervention group performed $\mathrm{mCIMT}$; a comparison group performed bilateral arm training with rhythmic auditory cueing (BATRAC); and the control group

MCIMT versus BATRAC versus control

mCIMT: functionally oriented task practice;

Amount of restraint: 6 hours per day

Anatomical region restraint: hand

Control: exercise therapy based on existing guidelines for upper extremity treatment after stroke as presented by the Dutch Society of Occupational Therapy

BATRAC: bilateral movements that targeted rhythmic flexion and extension movements about the wrist rather than movements of proximal parts of the upper limb

Session duration: 1 hour per day, 3 days per week, 6 weeks for each group 
Van Delden 2013 (Continued)

Outcomes Measures pre/post treatment and follow up at 1 months

- Arm motor function: ARAT

- Dexterity: 9HPT

- Motor impairment: FMA, MI

- Perceived arm motor function: MAL

- Sensory: EmNSA

- Quality of life: SIS

Notes

\section{Risk of bias}

\section{Bias} Authors' judgement Support for judgement

Random sequence genera- Low risk tion (selection bias)

Quoted from supplementary materials: "After stratification, participants were randomized in permuted blocks and allocated to 1 of the 3 intervention groups"

"Concealed allocation was effectuated online using the minimization method"

\begin{tabular}{lll}
\hline $\begin{array}{l}\text { Allocation concealment } \\
\text { (selection bias) }\end{array}$ & Low risk & $\begin{array}{l}\text { Quote: "Concealed allocation was effectuated online using the minimization } \\
\text { method" }\end{array}$ \\
\hline $\begin{array}{l}\text { Blinding (performance } \\
\text { bias and detection bias) }\end{array}$ & Unclear risk & Information not provided \\
All outcomes & \\
\hline
\end{tabular}

Incomplete outcome da- Low risk ta addressed? (Post-treatment)
1/22 participants lost from mCIMT (moved to another place)
1/19 participants lost from BATRAC (intervention refused after allocation)
3/19 participants lost from control (moved to another place)

\section{Wang 2011}

\begin{tabular}{|c|c|}
\hline \multirow[t]{3}{*}{ Methods } & $\begin{array}{l}\text { Randomisation by computer random-numbers table, other details were not provided } \\
\text { Blinded outcome assessor }\end{array}$ \\
\hline & No information about withdrawals \\
\hline & Single centre, outpatients \\
\hline \multirow[t]{7}{*}{ Participants } & China \\
\hline & Recruited from people admitted to the Affiliated Hospital of Medical School Qingdao University \\
\hline & 30 participants: 10 intervention, 10 control high-intensity, 10 control low-intensity \\
\hline & $\begin{array}{l}\text { Inclusion criteria: } 20^{\circ} \text { of active extension at wrist, } 10^{\circ} \text { at metacarpophalangeal and interphalangeals } \\
\text { joints }\end{array}$ \\
\hline & Exclusion criteria: excessive pain in the affected limb; aphasia; cognitive impairment \\
\hline & $\begin{array}{l}\text { Mean age (SD): intervention group: } 59.4(10.89) \text { years, control group high-intensity: } 63.5 \text { (9.63) years, } \\
\text { control group control low-intensity: } 67 \text { (7.45) years }\end{array}$ \\
\hline & $\begin{array}{l}\% \text { women: intervention group } 50 \% \text {, control group high-intensity } 60 \% \text {, control group control low-inten- } \\
\text { sity } 30 \%\end{array}$ \\
\hline
\end{tabular}


Wang 2011 (Continued)

Stroke details: ischaemic or haemorrhagic; $53 \%$ with right hemiparesis in treatment group, $60 \%$ with right hemiparesis in control group

Time since stroke, mean (SD): intervention group 2.7 (2.2) months, control group high-intensity: 2.9 (2.2), control group control low-intensity: 2.2 (1.2) months

This trial had 3 arms: the intervention group performed mCIMT; a control group performed high-inten-
sity training; and the another control group performed low-intensity training
mCIMT versus high-intensity training group versus low-intensity training group
mCIMT: functional activities through shaping approach
Amount of restraint: $90 \%$ of waking hours
Anatomical region restraint: hand
Low-intensity and high-intensity groups: strength, balance, manual dexterity exercises, functional task
practice, stretching and weight-bearing exercises
Session duration: mCIMT and high-intensity group: 3 hours per day; low-intensity group: 45 minutes
per day, all groups: 5 days a week for 4 weeks

Notes

\section{Risk of bias}

\begin{tabular}{lll}
\hline Bias & Authors' judgement & Support for judgement \\
\hline $\begin{array}{l}\text { Random sequence genera- } \\
\text { tion (selection bias) }\end{array}$ & Low risk & $\begin{array}{l}\text { Quote: "Participants ... were subsequently assessed at random (using a ran- } \\
\text { dom numbers table) into } 3 \text { groups" }\end{array}$ \\
\hline $\begin{array}{l}\text { Allocation concealment } \\
\text { (selection bias) }\end{array}$ & Unclear risk & No information provided \\
\hline $\begin{array}{l}\text { Blinding (performance } \\
\text { bias and detection bias) } \\
\text { All outcomes }\end{array}$ & Low risk & $\begin{array}{l}\text { Quote: "The Wolf Motor Function Test (WMFT) was administered before thera- } \\
\text { py, and 2 and 4 weeks after the intervention period by the same rater, who was } \\
\text { blinded to the group assignment" }\end{array}$ \\
\hline $\begin{array}{l}\text { Incomplete outcome da- } \\
\text { ta addressed? (Post-treat- } \\
\text { ment) }\end{array}$ & Unclear risk & The study provided no information about withdrawals \\
\hline
\end{tabular}

Wittenberg 2003

\begin{tabular}{ll} 
Methods & Randomisation by random-numbers table, other details were not provided \\
& Blinded outcome assessor \\
& No withdrawals \\
& Single centre, inpatients \\
\hline
\end{tabular}

Participants USA

Recruited mainly from referral by community physicians and therapists

16 participants: 9 intervention, 7 control 
Wittenberg 2003 (Continued)

Inclusion criteria: cerebrovascular accident $>12$ months, $10^{\circ}$ of active extension to the metacarpopha-

langeal and interphalangeal joints and $20^{\circ}$ at wrist

Exclusion criteria: not reported

Mean age (range): intervention group: 65 (41-81) years, control group: 63 (50-75) years

$\%$ women: intervention group $11 \%$, control group: $28 \%$

Stroke details: only ischaemic

Time since stroke, mean (SD): intervention group 34 (16-86) months, control group 28 (12-48) months

Interventions
CIMT versus control
Amount of restraint: waking hours
Anatomical region restraint: arm and hand
Control: task performance with the unaffected side, passive therapy for the affected arm
Session duration:
Intervention: 6 hours per day, 4 days per week, 4 hours on weekend days, 2 weeks
Control: 3 hours per day, 5 days per week, for 2 weeks

Outcomes Measures pre/post treatment and follow up at 6 months

- Arm motor function: WMFT

- Perceived Arm motor function: MAL

- Neurophysiologic test: AMPS, PET, TMS

Notes

\section{Risk of bias}

\begin{tabular}{lll}
\hline Bias & Authors' judgement & Support for judgement \\
\hline $\begin{array}{l}\text { Random sequence genera- } \\
\text { tion (selection bias) }\end{array}$ & Low risk & $\begin{array}{l}\text { Quote: "Using a random number table, patients were randomized into } 2 \\
\text { groups" }\end{array}$ \\
\hline $\begin{array}{l}\text { Allocation concealment } \\
\text { (selection bias) }\end{array}$ & Unclear risk & No information provided \\
\hline $\begin{array}{l}\text { Blinding (performance } \\
\text { bias and detection bias) } \\
\text { All outcomes }\end{array}$ & Low risk & Quote: "... thoroughly blinded raters" \\
\hline $\begin{array}{l}\text { Incomplete outcome da- } \\
\text { ta addressed? (Post-treat- } \\
\text { ment) }\end{array}$ & Low risk & No missing data \\
\hline
\end{tabular}

Wolf 2006

Methods Randomisation automated, balanced with respect to sex, premorbid handedness, side of stroke and level of function

Blinded outcome assessor 
Wolf 2006 (Continued)

Post-treatment withdrawals: $8 \%$; follow-up withdrawals: $17 \%$

Multicentre, outpatients

USA
Recruited from 247 facilities spanning the 7 participating sites
222 participants: 106 intervention, 116 control
Inclusion criteria: cerebrovascular accident between 3 and 9 months; $10^{\circ}$ of active extension to the
metacarpophalangeal and interphalangeal joints and $20^{\circ}$ at wrist or $10^{\circ}$ of active extension to the
metacarpophalangeal and interphalangeal joints of two digits, and at wrist, $10^{\circ}$ of thumb abduc-
tion/extension
Exclusion criteria: scored less than 24 on the MMSE; physician-determined medical problems could in-
terfere with participation; excessive pain of the paretic extremity; substantial use of the paretic arm in
daily life as determined by a score $\geq 2.5$ on the Motor Activity Log

Mean (SD) age: intervention group: 61 (13.5), control group: 63.43 (12.6) years

$\%$ women: intervention group 34.9, control group: 37.1

Stroke details: ischaemic or haemorrhagic; $47.2 \%$ with hemiparesis of the dominant side in treatment group, $51.75 \%$ with hemiparesis of the dominant side in control group

Time since stroke, mean (SD): intervention group 5.9 (2.1), control group 6.2 (2.3) months

\begin{tabular}{l} 
Interventions \\
CIMT versus control \\
Amount of restraint: $90 \%$ of waking hours \\
Anatomical region restraint: hand \\
Control: usual and customary care ranged from no treatment to the application of mechanical inter- \\
ventions or various occupational and physical therapy approaches in the home \\
Session duration: CIMT: 6 hours per day, 7 days per week, 2 weeks; control: not provided. \\
\hline Measures pre/post treatment and follow up at 4,8 , and 12 months \\
- Motor function: WMFT \\
- Perceived arm motor function: MAL \\
\hline
\end{tabular}

Notes

\section{Risk of bias}

\begin{tabular}{lll}
\hline Bias & Authors' judgement & Support for judgement \\
\hline $\begin{array}{l}\text { Random sequence genera- } \\
\text { tion (selection bias) }\end{array}$ & Low risk & $\begin{array}{l}\text { Quote: "Participants were randomly assigned to the experimental (CIMT) or } \\
\text { control condition using an automated, centralized system administered by the } \\
\text { data management centre" }\end{array}$ \\
\hline $\begin{array}{l}\text { Allocation concealment } \\
\text { (selection bias) }\end{array}$ & Low risk & Centralised \\
\hline $\begin{array}{l}\text { Blinding (performance } \\
\text { bias and detection bias) } \\
\text { All outcomes }\end{array}$ & Low risk & Blinding of outcome assessor \\
\hline
\end{tabular}




\section{Wolf 2006 (Continued)}

Incomplete outcome da- Low risk $\quad$ 8/106 missing from intervention group (5 withdrew, 1 moved, 1 stroke, 1 poor ta addressed? (Post-treatment) health), 15/116 missing from control group (7 withdrew, 2 moved, 2 died)

Wu 2007a

$\begin{array}{ll}\text { Methods } & \text { Randomisation details were not reported } \\ & \text { Blinded outcome assessor } \\ & \text { No withdrawals } \\ & \text { Multicentre, inpatients/outpatients }\end{array}$

Participants Taiwan

Recruited from the rehabilitation departments of 2 medical centres (Chang Gung Memorial Hospital and National Taiwan University Hospital)

30 participants: 15 intervention, 15 control

Inclusion criteria: cerebrovascular accident between 12 and 36 months; $10^{\circ}$ of active extension to the finger and $20^{\circ}$ at wrist; non-use of the more affected upper extremity (AoU score $<2.5$ on the MAL); no serious cognitive deficits

Exclusion criteria: balance problems sufficient to compromise safety when wearing the study's constraint device; excessive spasticity in any joint of the affected upper extremity

Mean age (SD): intervention group: 54.66 (8.63) years, control group: 53.31 (6.29) years $\%$ women: intervention group $47 \%$, control group: $40 \%$

Stroke details: $40 \%$ with right hemiparesis in treatment group, 33\% with right hemiparesis in control group

Time since stroke, mean (SD): intervention group 18.53 (6.92) months, control group 17.61 (7.55) months

Interventions $\quad$ mCIMT versus control

mCIMT: functional tasks by shaping techniques with the affected arm, normalisation of muscle tone Amount of restraint: 6 hours per day

Anatomical region restraint: hand

Control: neurodevelopmental therapy emphasising balance training, stretching/weight bearing of the affected arm, fine-motor dexterity training in addition to practice on ADL with the less affected side

Session duration: 2 hours per day, 5 days per week, 3 weeks for each group

$\begin{array}{ll}\text { Outcomes } & \text { Measures pre/post treatment } \\ \text { - } & \text { Perceived arm motor function: MAL } \\ \text { - ADL measure: FIM } \\ \text { - Kineatic variables }\end{array}$

Notes

\section{Risk of bias}


Wu 2007a (Continued)

$\begin{array}{ll}\begin{array}{l}\text { Random sequence genera- } \\ \text { tion (selection bias) }\end{array} & \begin{array}{l}\text { Quote: "... subjects were randomized with equal probability" } \\ \text { Comment: insufficient information to permit judgment }\end{array}\end{array}$

\begin{tabular}{lll}
\hline $\begin{array}{l}\text { Allocation concealment } \\
\text { (selection bias) }\end{array}$ & Unclear risk & No information provided
\end{tabular}

\begin{tabular}{lll}
\hline $\begin{array}{l}\text { Blinding (performance } \\
\text { bias and detection bias) }\end{array}$ & Low risk & $\begin{array}{l}\text { Quote: "A certified } \\
\text { ject allocation was }\end{array}$ \\
\hline $\begin{array}{l}\text { Incomplete outcome da- } \\
\text { ta addressed? (Post-treat- } \\
\text { ment) }\end{array}$ & Low risk & No missing data \\
\end{tabular}

\section{Wu 2007b}

$\begin{array}{ll}\text { Methods } & \text { Randomisation by random-numbers table, other details were not provided } \\ \text { Blinded outcome assessor } \\ \text { No withdrawals } \\ \text { Multicentre, outpatients }\end{array}$

Participants Taiwan

Recruited from 2 stroke rehabilitation units

47 participants: 24 intervention, 23 control

Inclusion criteria: cerebrovascular accident between 3 weeks and 37 months; Brunnstrom stage $>3$ on arm section; non-use of the more affected upper extremity (amount-of-use score $<2.5$ on the MAL); no serious cognitive deficits

Exclusion criteria: balance problems sufficient to compromise safety when wearing the study's constraint device

Mean age (SD): intervention group: 53.93 (11.2) years, control group: 56.77 (12.9) years

$\%$ women: intervention group 33\%, control group: $30 \%$

Stroke details: ischaemic or haemorrhagic; $46 \%$ with right hemiparesis in treatment group, $48 \%$ with right hemiparesis in control group, all participants had right-hand dominance

Time since stroke, mean (SD): intervention group 12.51 (9.64) months, control group 11.98 (11.72) months

Interventions mCIMT versus control

mCIMT: ADL training with the affected arm

Amount of restraint: 6 hours per day

Anatomical region restraint: hand

Control: neurodevelopmental therapy emphasising functional task practice, stretching/weight-bear-

ing, fine-motor dexterity training

Session duration: 2 hours per day, 5 days per week, 3 weeks for each group

$\begin{array}{ll}\text { Outcomes } & \text { Measures pre/post treatment } \\ \text { - Arm motor impairment: FMA } \\ \text { - Perceived arm motor function: MAL }\end{array}$


Wu 2007b (Continued)

- ADL measure: FIM

- Kinematic variables

\section{Notes}

\section{Risk of bias}

\begin{tabular}{lll}
\hline Bias & Authors' judgement & Support for judgement \\
\hline $\begin{array}{l}\text { Random sequence genera- } \\
\text { tion (selection bias) }\end{array}$ & Low risk & $\begin{array}{l}\text { Quote: "Subjects were randomly assigned to the CIMT or traditional interven- } \\
\text { tion group by using a random numbers table" }\end{array}$ \\
\hline $\begin{array}{l}\text { Allocation concealment } \\
\text { (selection bias) }\end{array}$ & Unclear risk & No information provided \\
\hline $\begin{array}{l}\text { Blinding (performance } \\
\text { bias and detection bias) } \\
\begin{array}{l}\text { All outcomes } \\
\text { Incomplete outcome da- }\end{array}\end{array}$ & Low risk & $\begin{array}{l}\text { Quote: "Clinical evaluation were administered in random order by a blinded } \\
\text { rater" }\end{array}$ \\
\hline $\begin{array}{l}\text { ta addressed? (Post-treat- } \\
\text { ment) }\end{array}$ & & No missing data \\
\hline
\end{tabular}

\section{Wu 2007c}

Methods

Randomisation by random-numbers table, other details were not provided

Blinded outcome assessor

No withdrawals

Multicentre, inpatients/outpatients

Participants Taiwan

Recruited from the rehabilitation departments of 3 medical centres

26 participants: 13 intervention, 13 control

Inclusion criteria: cerebrovascular accident between 0.5 and 31 months; Brunnstrom stage $>3$ on arm section; non use of the more affected upper extremity (amount-of-use score $<2.5$ on the MAL); no serious cognitive deficits

Exclusion criteria: balance problems sufficient to compromise safety when wearing the study's constraint device

Mean age (SD): intervention group: 71.44 (6.42) years, control group: 71.94 (16.79) years

$\%$ women: intervention group 38\%, control group: $46 \%$

Stroke details: ischaemic or haemorrhagic; $46 \%$ with right hemiparesis in treatment group, 54\% with right hemiparesis in control group, all participants had right hand dominance

Time since stroke, mean (SD): intervention group 6.70 (8.99) months, control group 8.32 (7.97) months

Interventions

mCIMT versus usual care

mCIMT: functional tasks by shaping techniques with the affected arm, normalisation of muscle tone Amount of restraint: 6 hours per day

Anatomical region restraint: hand

Usual care: neurodevelopmental therapy emphasising functional task practice, stretching/weightbearing, fine-motor dexterity training 
Wu 2007c (Continued)

Session duration: 2 hours per day, 5 days per week, 3 weeks for each group

Measures pre/post treatment
- Perceived arm motor function: MAL
- Arm motor impairment: FMA
- ADL measure: FIM
- Quality of life: SIS

Notes

\section{Risk of bias}

\begin{tabular}{lll}
\hline Bias & Authors' judgement & Support for judgement \\
\hline $\begin{array}{l}\text { Random sequence genera- } \\
\text { tion (selection bias) }\end{array}$ & Low risk & $\begin{array}{l}\text { Quote: "Subjects were individually randomized into the mCIMT or the tradi- } \\
\text { tional rehabilitation group by using a table of random numbers" }\end{array}$ \\
\hline $\begin{array}{l}\text { Allocation concealment } \\
\text { (selection bias) }\end{array}$ & Unclear risk & No information provided \\
\hline $\begin{array}{l}\text { Blinding (performance } \\
\text { bias and detection bias) } \\
\text { All outcomes }\end{array}$ & Low risk & $\begin{array}{l}\text { Quote: "Before and after the 3-week intervention period, the tests were admin- } \\
\text { istered in random order by a blinded rater" }\end{array}$ \\
\hline $\begin{array}{l}\text { Incomplete outcome da- } \\
\text { ta addressed? (Post-treat- } \\
\text { ment) }\end{array}$ & Low risk & No missing data \\
\hline
\end{tabular}

Wu 2011

\begin{tabular}{|c|c|}
\hline \multirow[t]{4}{*}{ Methods } & Randomisation by computer \\
\hline & Blinded outcome assessor \\
\hline & No information about withdrawals \\
\hline & Multicentre, outpatients \\
\hline
\end{tabular}

Participants

Taiwan

Recruited from 4 stroke rehabilitation units

66 participants: 22 intervention, 22 control, 22 BAT group

Inclusion criteria: cerebrovascular accident $>12$ months; Brunnstrom Stage $>3$ on arm section; amount of use $<2.5$ on the MAL, no serious cognitive deficits, no excessive spasticity in any joints of the affected upper limb

Exclusion criteria: not reported

Mean age (SD): intervention group: 51.91 (11.93) years, control group: 55.19 (2.5) years, bilateral arm training group $52.22(10.72)$ years

$\%$ women: intervention group $32 \%$, control group: $72 \%$, BAT group $18 \%$

Stroke details: ischaemic or haemorrhagic; $64 \%$ with right hemiparesis in treatment group, 54\% with right hemiparesis in control group; $45 \%$ with right hemiparesis in BAT group 
Wu 2011 (Continued)

Time since stroke, mean (SD): intervention group 14.91 (12.04) months, control group 17.77 (12.45) months, BAT group 15.92 (13.74) months

Interventions

This trial had 3 arms: the intervention group performed $\mathrm{mCIMT}$; a comparison group performed bilateral arm training; and the control group

mCIMT versus bilateral arm training versus control

mCIMT: functional tasks by shaping techniques with the affected arm Amount of restraint: 6 hours per day

Anatomical region restraint: hand

Control: neurodevelopmental therapy emphasising functional task practice, stretching/weight bear-

ing, fine-motor dexterity training

BAT: simultaneous movements of both upper extremities in functional tasks

Session duration: 2 hours per day, 5 days per week, 3 weeks for each group

\begin{tabular}{ll}
\hline Outcomes & Measures pre/post treatment \\
& - Arm motor function: WMFT \\
- Perceived arm motor function: MAL \\
- Kinematic variables
\end{tabular}

Notes

\section{Risk of bias}

\begin{tabular}{lll}
\hline Bias & Authors' judgement & Support for judgement \\
\hline $\begin{array}{l}\text { Random sequence genera- } \\
\text { tion (selection bias) }\end{array}$ & Low risk & $\begin{array}{l}\text { Quote. "Eligible participants were randomized to ... treatment groups using } \\
\text { the computerized (block) randomizations scheme" }\end{array}$ \\
\hline $\begin{array}{l}\text { Allocation concealment } \\
\text { (selection bias) }\end{array}$ & Unclear risk & No information provided \\
\hline $\begin{array}{l}\text { Blinding (performance } \\
\text { bias and detection bias) } \\
\text { All outcomes }\end{array}$ & Low risk & $\begin{array}{l}\text { Quote: "Before and after the 3-week intervention period, ... outcome measures } \\
\text { were administered by } 2 \text { certified, trained occupational therapists blinded to } \\
\text { the participant group" }\end{array}$ \\
\hline $\begin{array}{l}\text { Incomplete outcome da- } \\
\text { ta addressed? (Post-treat- } \\
\text { ment) }\end{array}$ & Unclear risk & $\begin{array}{l}\text { The study provided no information about withdrawals } \\
\text { Analyses were performed on 21/22 participants for kinematics in BAT group, } \\
21 / 22 \text { participants for WMFT in mCIMT and control groups }\end{array}$ \\
\hline
\end{tabular}

Wu 2012a

Methods

Randomisation prestratified on the basis of participating hospital

Blinded outcome assessor

No withdrawals

Multicentre, outpatients

Participants Taiwan

Recruited from the rehabilitation departments of 4 hospitals 
Wu 2012a (Continued)

57 participants: 19 intervention, 18 control, 20 arm plus trunk restraint

Inclusion criteria: cerebrovascular accident > 12 months; residual motor ability of the affected upper extremity (score on the arm motor subscale of the FMA of $\geq 15$ ); amount of use $<2.5$ on the MAL, no serious cognitive deficits, no excessive spasticity in any joints of the affected upper limb

Exclusion criteria: not reported

Mean age (SD): intervention group: 56.3 (12.2) years, control group: 58.6 (11.6) years, arm plus trunk restraint group 54 (9.7) years

$\%$ women: intervention group $26 \%$, control group: $22 \%$, arm plus trunk restraint group $20 \%$

Stroke details: ischaemic or haemorrhagic; $37 \%$ with right hemiparesis in treatment group, $28 \%$ with right hemiparesis in control group; $60 \%$ with right hemiparesis in arm plus trunk restraint group

Time since stroke, mean (SD): intervention group 13.7 (7.3) months, control group 17.7 (13.4) months, arm plus trunk restraint 15.7 (13.5) months

Interventions

This trial had 3 arms: the intervention group performed mCIMT; a comparison group performed arm plus trunk restraint; and the control group

mCIMT versus arm plus trunk restraint versus control

mCIMT: functional tasks by shaping techniques with the affected arm

Amount of restraint: 6 hours per day

Anatomical region restraint: hand

Control: neurodevelopmental therapy emphasising functional task practice, stretching/weight bearing, fine-motor dexterity training, arm plus trunk restraint: functional tasks by shaping techniques with the affected arm with restraining of trunk anterior and rotation movements

Session duration: 2 hours per day, 5 days per week, 3 weeks for each group

\begin{tabular}{ll}
\hline Outcomes & Measures pre/post treatment \\
- Arm motor function: ARAT \\
- Perceived arm motor function: MAL \\
- Perceived instrumental ADL participation: FAI
\end{tabular}

Notes

\section{Risk of bias}

Bias Authors' judgement Support for judgement

Random sequence genera- Unclear risk Quote: "All participants were unaware of the study hypotheses and were rantion (selection bias) domized to the dCIT-TR [distribuited constraint-induced therapy combined with trunk restraint], dCIT [distribuited constraint-induced therapy], or control group by a pre stratification strategy based on the participating site"

\begin{tabular}{lll}
\hline $\begin{array}{l}\text { Allocation concealment } \\
\text { (selection bias) }\end{array}$ & Unclear risk & No information provided \\
\hline $\begin{array}{l}\text { Blinding (performance } \\
\text { bias and detection bias) }\end{array}$ & Low risk & $\begin{array}{l}\text { Quote: "The outcome measures were administered before and after a 3-week } \\
\text { intervention by 3 certified occupational therapists who were unaware of group } \\
\text { allocation" }\end{array}$ \\
\hline
\end{tabular}


Wu 2012a (Continued)

Incomplete outcome da- Low risk No missing data ta addressed? (Post-treatment)

Yoon 2014

Methods

Randomisation by random card

Blinded outcome assessor

No information about withdrawals

Single centre, inpatients

Participants Korea

Recruited from the Department of Rehabilitation Medicine at Pusan National University Yangsan Hospital

26 participants: 9 intervention, 9 control, 8 arm restraint plus mirror therapy

Inclusion criteria: $10^{\circ}$ of active wrist extension, $10^{\circ}$ of active thumb abduction/extension and $10^{\circ}$ active extension in at least 2 additional digits; possibility of simple communication; patients who could maintain a sitting position for more than 30 minutes

Exclusion criteria: depression; inability to co-operate in the treatment; inability to perform the active task training for musculoskeletal problems; spasticity; complex regional pain syndrome or secondary adhesive capsulitis

Mean age (SD): intervention group: 64.33 (8.54) years, control group: 60.56 (16.94) years, arm restraint plus mirror therapy group $47.36(14.4)$ years

$\%$ women: intervention group 33\%, control group: 55\%, arm restraint plus mirror therapy group 25\%

Stroke details: ischaemic or haemorrhagic; $67 \%$ with right hemiparesis in treatment group, $44 \%$ with right hemiparesis in control group; $62 \%$ with right hemiparesis in arm restraint plus mirror therapy group

Time since stroke, mean (SD): intervention group 0.6 (0.3) months, control group $0.8(0.4)$ months, arm restraint plus mirror therapy group 0.8 (0.38) months

Interventions

This trial had 3 arms: the intervention group performed CIMT; a comparison group performed CIMT plus mirror therapy; and the control group

CIMT versus CIMT plus mirror therapy versus control

CIMT: fine motor exercise under the supervision of occupational therapist plus conventional physiotherapy plus self exercise

Amount of restraint: 6 hours per day

Anatomical region restraint: arm plus hand

CIMT plus mirror therapy: fine motor exercise under the supervision of occupational therapist plus conventional physiotherapy plus mirror therapy with flexion/extension of the shoulder, elbow, wrist, finger, and pronation/supination of the forearm

Control: self-exercise program

Session duration:

CIMT: 6 hours of exercise, plus 40 minutes of conventional physiotherapy plus 30 minutes of self exercise daily; 
Yoon 2014 (Continued)

CIMT plus mirror therapy: 6 hours of exercise, plus 40 minutes of conventional physiotherapy, plus 30 minutes of mirror therapy daily;

Control group: 60 minutes of self exercise, plus 40 minutes of conventional physiotherapy

All for 5 days a week for 2 weeks

\begin{tabular}{ll}
\hline Outcomes & Measures pre/post treatment \\
- Arm motor function: WMFT \\
- Dexterity: 9HPT, Box and Block Test \\
- Motor impairment: grip force \\
- Activities of daily living measure: BI (Korean version) \\
- Arm motor impairment: FMA \\
- Brunnstrom stage
\end{tabular}

Notes

\section{Risk of bias}

\begin{tabular}{lll}
\hline Bias & Authors' judgement & Support for judgement \\
\hline $\begin{array}{l}\text { Random sequence genera- } \\
\text { tion (selection bias) }\end{array}$ & Low risk & $\begin{array}{l}\text { Quote: "they were assigned into three groups by picking a random card with } \\
\text { numbers on them" }\end{array}$ \\
\hline $\begin{array}{l}\text { Allocation concealment } \\
\text { (selection bias) }\end{array}$ & Unclear risk & No information provided \\
\hline $\begin{array}{l}\text { Blinding (performance } \\
\text { bias and detection bias) } \\
\text { All outcomes }\end{array}$ & Low risk & $\begin{array}{l}\text { Quote: "... the results were compared between the three groups by the blinded } \\
\text { observers" }\end{array}$ \\
\hline
\end{tabular}

Incomplete outcome da-

Unclear risk

The study provided no information about withdrawals

ta addressed? (Post-treat-

ment)

9HPT: Nine-Hole Peg Test, a test measuring finger-hand co-ordination in terms of the time it takes a patient to place nine pegs in a 5-in by 5 -in board then remove them

16HPT: Sixteen-Hole Peg Test: the time needed to place 16 pegs $(2.15 .9 \mathrm{~cm})$ in a pegboard with 16 holes determined with a stopwatch

ADL: activities of daily living

AMAT: Arm Motor Activity Test, 16 timed items

AMPS: Assessment of Motor and Process Skills, a real-time test in which patients do prescribed functional tasks that are videotaped and scored by a viewer

AoU: amount of use

ARAT: Action Research Arm Test, 19 items, 57-point test divided into four categories (grasp, grip, pinch and gross movement), each item graded on a 4-point ordinal scale (anchored $0=$ can perform no part of the test, $3=$ performs the test normally)

BAT: Bilateral arm training

BATRAC: Bilateral arm training with rhythmic auditory cueing

BI: Barthel Index

BLMA: Birgitta Lindmarks Motor Assessment

Box and Block Test: assesses unilateral gross manual dexterity

$\mathrm{Cl}$ : control intervention

CIMT: constraint-induced movement therapy

CIT: constraint-induced therapy

CMII: Chedoke-McMaster Impairment Inventory, a 7-point scale ranging from 1 to 7 that presents 7 stages of motor recovery for arm, hand, postural control and shoulder pain, assessed with a severity scale

COPM: Canadian Occupational Performance Measure, a structured clinical assessment that allows participants to self-rate goals of therapy in the categories of self-care, productivity, and leisure 
CVA: Cerebrovascular accident

$\mathrm{dCIT}$ : distributed constraint-induced therapy

EMF: Emory Motor Function test, 16 timed items (2 strength items and 1 quality of movement item)

EmNSA: Erasmus modification of the Nottingham Sensory Assessment to measure the sense of touch, pressure, proprioception, and sharpblunt discrimination in the upper limb

FAl: Frenchay Activities Index, a self-report scale, measures a person's perception of instrumental ADL participation at 3 or 6 months. It contains 15 items that can be separated into 3 factors: domestic chores, leisure/work, and outdoor activities. Each item is scored on a 0 to 3 point scale. Higher scores indicate better performance.

FIM: Functional Independence Measure, 5 items that specifically assess upper extremity function. Each item is scored on a 7-point ordinal scale

FIM2: Functional Independence Measure, 18 items grouped into six sub scales. Each item is scored on a 7-point ordinal scale

FIM3: Functional Independence Measure, 6 items that specifically assess upper extremity function. Each item is scored on a 7-point ordinal scale

FMA: Fugl-Meyer Assessment, a 66-point upper extremity section of the Fugl-Meyer Assessment of Motor Recovery After Stroke which assesses impairment using a 3-point ordinal scale ( 0 = cannot perform to $2=$ can perform fully)

FMA2: Fugl-Meyer Assessment, a 33-point upper extremity section of the Fugl-Meyer Assessment of Motor Recovery After Stroke Assessment, which assesses impairment using a 3-point ordinal scale $(0=$ cannot perform to $2=$ can perform fully)

FU: Forced use

GPT: Grooved Pegboard Test, a test of dexterity that evaluates the speed with which the patient grasps and inserts 25 pegs $(3 \mathrm{~cm}$ long, 5 $\mathrm{mm}$ diameter) into a grid of vertical holes in a horizontal $10 \mathrm{~cm}^{2}$ surface. It indicates the number of pegs placed per second for each hand MAL: Motor Activity Log, a semi-structured interview comprising $30 \mathrm{ADL}$ tasks graded on a 6-point AoU scale and a 6-point Quality of Movement (QoM) scale

MAL2: Motor Activity Log, a semi-structured interview comprising 14 ADL tasks graded on a 6-point AoU scale and a 6-point Quality of Movement (QoM) scale

MAL3: Motor Activity Log, a semi-structured interview comprising 28 ADL tasks graded on a 6-point AoU scale and a 6-point Quality of Movement (QoM) scale

MAS: Motor Assessment Scale, a performance-based scale developed for assessing everyday motor function in patients with stroke. Eight areas of motor function are assessed using a 7-point scale (0 to 6)

MAS2: Modified Motor Assessment Scale, items used for upper extremity only; both arms were tested, consisting of 15 tasks from gross arm to fine finger movements in a $0-5$ point scale

MASh: Modified Ashworth Scale, grades spasticity on the International Classification of Functioning level of body functions (muscle tone functions)

mCIMT: modified constraint-induced movement therapy

MESUPES: Motor Evaluation Scale for Arm in Stroke Patients, a scale that takes the quality of upper limb movement into account during the evaluation of arm performance after stroke

MFT: Manual Function Test, assess various functions of the paralysed upper limb in hemiplegic patients post stroke in performing simple tasks

MI: Motricity Index, to measure strength in the upper limbs

MMSE: Mini Mental State Examination

NIHSS: The National Institute of Health Stroke Scale. assesses cognitive, sensory, and motor impairments as an indicator of overall stroke severity

PET: positron emission tomography

PNF: proprioceptive neuromuscular facilitation

RMAAS: Rivermead Motor Assessment Arm Scale: motor performance test

SD: standard deviation

SHFT: Sollerman Hand Function Test, consisting of 20 sub-tests reflecting daily hand activities (type of grasp, quality of movement and speed of performance assessed in a 0-4 point scale)

SIS: Stroke Impact Scale

TC: Therapeutic climbing

TF: Traditional physiotherapy

TMS: transcranical magnetic stimulation

UE: upper extremity

WMFT: Wolf Motor Function Test, 17 simple limb movements and tasks with the affected arm. 15 items are timed and two assess strength WMFT2: Wolf Motor Function Test, 19 simple limb movements and tasks with the affected arm. 17 items are timed and two assess strength

\section{Characteristics of excluded studies [ordered by study ID]}

\begin{tabular}{ll}
\hline Study & Reason for exclusion \\
\hline Brogårdh 2006 & RCT; the study authors explored the extended mitt used alone after CIMT and 4-years follow-up
\end{tabular}

Constraint-induced movement therapy for upper extremities in people with stroke (Review) 


\begin{tabular}{ll}
\hline Study & Reason for exclusion \\
\hline Fuzaro 2012 & RCT; the study authors compare mCIMT and a modified FU \\
\hline Gautier 2008 & RCT; the study authors compare 2 different forms of CIMT \\
\hline Lin 2008 & RCT; the study authors compare mCIMT and a modified FU \\
\hline Lin $2009 \mathrm{~b}$ & RCT; the study authors compare mCIMT and a modified FU \\
\hline Sawaki 2014 & RCT; some participants were also included in another study (Wolf 2006) \\
\hline Tan 2012 & Not an RCT, controls were matched to subject receiving CIMT \\
\hline Van der Lee 1999 & $\begin{array}{l}\text { Not an RCT; computer-generated randomisation, but with 21 aberrations (11 participants who } \\
\text { should have received the experimental treatment were allocated to the reference group and 10 } \\
\text { vice versa) }\end{array}$ \\
\hline Wu 2012b & RCT; it included participants from the included study of Wu 2012a \\
\hline
\end{tabular}

CIMT: constraint-induced movement therapy

FU: forced use

mCIMT: modified constraint-induced movement therapy

$\mathrm{RCT}$ : randomised controlled trial

Characteristics of studies awaiting assessment [ordered by study ID]

Barzel 2015

\begin{tabular}{ll}
\hline Methods & RCT \\
\hline Participants & People with stroke \\
\hline Interventions & mCIMT \\
\hline Outcomes & MAL-QOM and WMFT \\
\hline Notes & Protocol for a completed study (clinicaltrials.gov) \\
\hline
\end{tabular}

Boe 2014

\begin{tabular}{ll}
\hline Methods & RCT \\
\hline Participants & People with stroke \\
\hline Interventions & mCIMT \\
\hline Outcomes & ARAT, MAL, Satisfaction with Stroke Care Questionnaire, Re-integration to Normal Living Index \\
\hline Notes & \\
\hline
\end{tabular}


Dos Santos 2012

\begin{tabular}{ll}
\hline Methods & RCT \\
\hline Participants & People with stroke \\
\hline Interventions & Restraint of the less affected upper limb \\
\hline Outcomes & Fugl-Meyer Scale, FIM \\
\hline Notes & \\
\hline
\end{tabular}

Jansa 2007

\begin{tabular}{ll}
\hline Methods & RCT \\
\hline Participants & People with stroke \\
\hline Interventions & CIMT \\
\hline Outcomes & Assesment of motor and process skills \\
\hline Notes & Presented as a poster at 11th Congress of the EFNS, Brussels, Belgium, 2007 \\
\hline
\end{tabular}

Olivier 2012

\begin{tabular}{ll}
\hline Methods & RCT \\
\hline Participants & People with stroke \\
\hline Interventions & Light constraint-induced therapy \\
\hline Outcomes & MAL-QOM and WMFT \\
\hline Notes & This study has been terminated (departure of the investigator co-ordinator to another country) \\
\hline
\end{tabular}

\section{Uswatte 2014}

\begin{tabular}{ll}
\hline Methods & RCT \\
\hline Participants & People with stroke \\
\hline Interventions & Expanded Constraint Induced therapy \\
\hline Outcomes & MAL \\
\hline Notes & \\
\hline
\end{tabular}

ARAT: Action Research Arm Test

CIMT: constraint-induced movement therapy

FIM: Functional Independence Measure

MAL: Motor Activity Log

Constraint-induced movement therapy for upper extremities in people with stroke (Review)

Copyright ๑ 2017 The Cochrane Collaboration. Published by John Wiley \& Sons, Ltd. 
MAL-QOM: Motor Activity Log - Quality Of Movement mCIMT: modified constraint-induced movement therapy

$\mathrm{RCT}$ : randomised controlled trial

WMFT: Wolf Motor Function Test

\section{Characteristics of ongoing studies [ordered by study ID]}

Gautier 2015

\begin{tabular}{ll} 
Trial name or title & $\begin{array}{l}\text { Examining mechanisms of neuroplasticity following motor rehabilitation in stroke - examining how } \\
\text { motor rehabilitation promotes brain reorganization following stroke, an MRI Study }\end{array}$ \\
\hline Methods & RCT \\
\hline Participants & People with stroke \\
\hline Interventions & Constraint-induced therapy \\
\hline Outcomes & Brain structure, WMFT, ARAT, MAL \\
\hline Starting date & Galy 2012 \\
\hline Contact information &
\end{tabular}

Notes

Padovani Do Santos 2015

Trial name or title Checking a security protocol of modified forced use therapy and efficacy reducing the constriction of the movement time in 12 hours

\begin{tabular}{ll}
\hline Methods & RCT \\
\hline Participants & People with stroke \\
\hline Interventions & FU therapy \\
\hline Outcomes & Root mean square activity through surface electromyography and strength handgrip \\
\hline Starting date & May 2015 \\
\hline Contact information & Tamyris Padovani dos Santos, University of Sao Paulo \\
\hline Notes & \\
\hline
\end{tabular}

\section{Pereira 2015}

Trial name or title

Effects of constraint-induced therapy for the scapular kinematics and related to the quality of movement in patients with severe chronic hemiparesis

\begin{tabular}{ll}
\hline Methods & RCT \\
\hline Participants & People with stroke \\
\hline
\end{tabular}


Pereira 2015 (Continued)

\begin{tabular}{ll} 
Interventions & Constraint-induced therapy \\
\hline Outcomes & Movement of the scapula and trunk through kinematic, WMFT, MAL \\
\hline Starting date & January 2015 \\
\hline Contact information & nat_duarte@yahoo.com.br \\
\hline Notes &
\end{tabular}

Notes

ARAT: Action Research Arm Test

FU: forced use

MAL: Motor Activity Log

RCT: randomised controlled trial

WMFT: Wolf Motor Function Test

\section{DATA AND ANALYSES}

Comparison 1. Constraint versus control: primary outcome

\begin{tabular}{lllll}
\hline Outcome or subgroup title & No. of studies & $\begin{array}{l}\text { No. of partici- } \\
\text { pants }\end{array}$ & Statistical method & Effect size \\
\hline 1 Disability postintervention & 11 & 344 & $\begin{array}{l}\text { Std. Mean Difference (IV, Random, } \\
95 \% \mathrm{Cl})\end{array}$ & $0.24[-0.05,0.52]$ \\
\hline $\begin{array}{l}\text { 2 Disability: } 3 \text { to 6-month fol- } \\
\text { low-up }\end{array}$ & 3 & 125 & $\begin{array}{l}\text { Std. Mean Difference (IV, Random, } \\
95 \% \mathrm{Cl})\end{array}$ & $-0.21[-0.57,0.16]$ \\
\hline
\end{tabular}

\section{Analysis 1.1. Comparison 1 Constraint versus control: primary outcome, Outcome 1 Disability postintervention.}

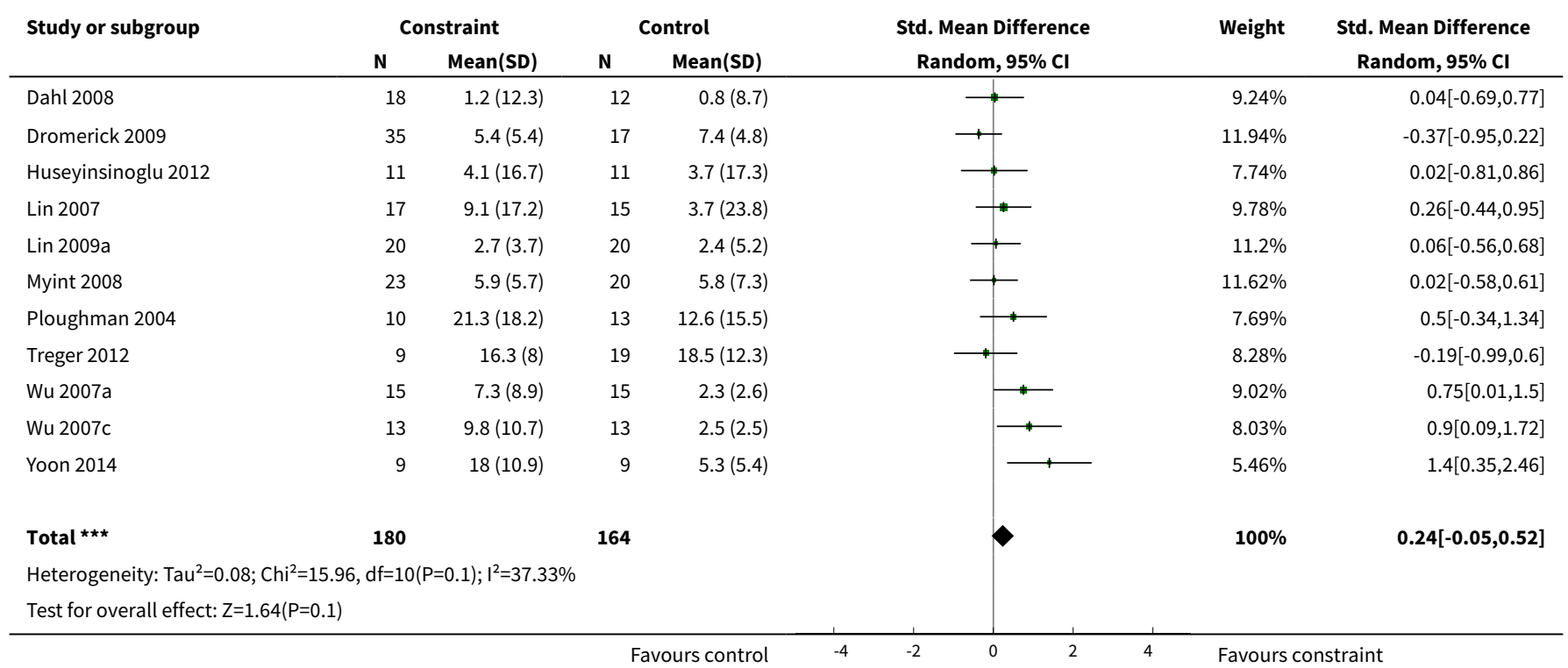




\section{Analysis 1.2. Comparison 1 Constraint versus control: primary outcome, Outcome 2 Disability: 3 to 6-month follow-up.}

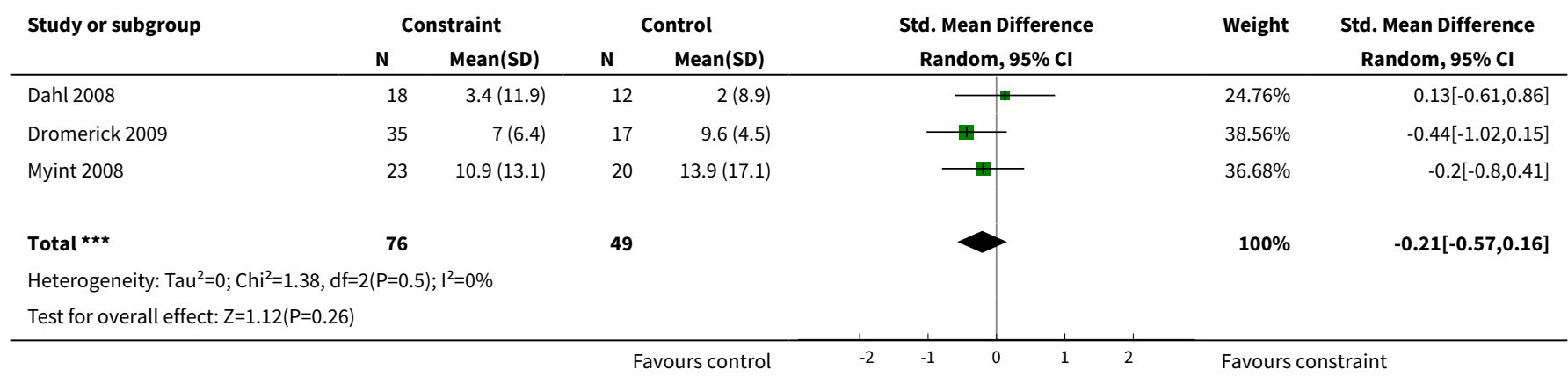

Comparison 2. Constraint versus control: subgroup analysis on primary outcome

\begin{tabular}{|c|c|c|c|c|}
\hline $\begin{array}{l}\text { Outcome or subgroup } \\
\text { title }\end{array}$ & No. of studies & $\begin{array}{l}\text { No. of partici- } \\
\text { pants }\end{array}$ & Statistical method & Effect size \\
\hline $\begin{array}{l}1 \text { Amount of task prac- } \\
\text { tice }\end{array}$ & 11 & & Std. Mean Difference (IV, Fixed, 95\% CI) & Subtotals only \\
\hline $1.1 \leq 30$ hours & 8 & 253 & Std. Mean Difference (IV, Fixed, 95\% CI) & $0.18[-0.07,0.44]$ \\
\hline $1.2>30$ hours & 3 & 91 & Std. Mean Difference (IV, Fixed, 95\% CI) & $0.25[-0.18,0.67]$ \\
\hline $\begin{array}{l}2 \text { Anatomical region re- } \\
\text { straint }\end{array}$ & 11 & & Std. Mean Difference (IV, Fixed, 95\% CI) & Subtotals only \\
\hline 2.1 Arm plus hand & 2 & 61 & Std. Mean Difference (IV, Fixed, 95\% CI) & $0.35[-0.17,0.87]$ \\
\hline 2.2 Hand only & 9 & 283 & Std. Mean Difference (IV, Fixed, 95\% CI) & $0.17[-0.08,0.41]$ \\
\hline 3 Time since stroke & 7 & & Std. Mean Difference (IV, Fixed, 95\% CI) & Subtotals only \\
\hline 3.10 to 3 months & 5 & 164 & Std. Mean Difference (IV, Fixed, 95\% CI) & $0.07[-0.26,0.39]$ \\
\hline 3.23 to 9 months & 0 & 0 & Std. Mean Difference (IV, Fixed, 95\% CI) & $0.0[0.0,0.0]$ \\
\hline 3.3 More than 9 months & 2 & 62 & Std. Mean Difference (IV, Fixed, 95\% CI) & $0.49[-0.02,1.00]$ \\
\hline
\end{tabular}

Analysis 2.1. Comparison 2 Constraint versus control: subgroup analysis on primary outcome, Outcome 1 Amount of task practice.

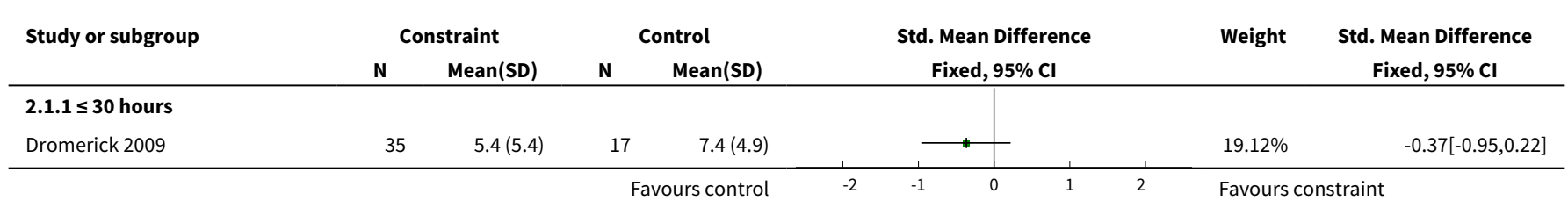




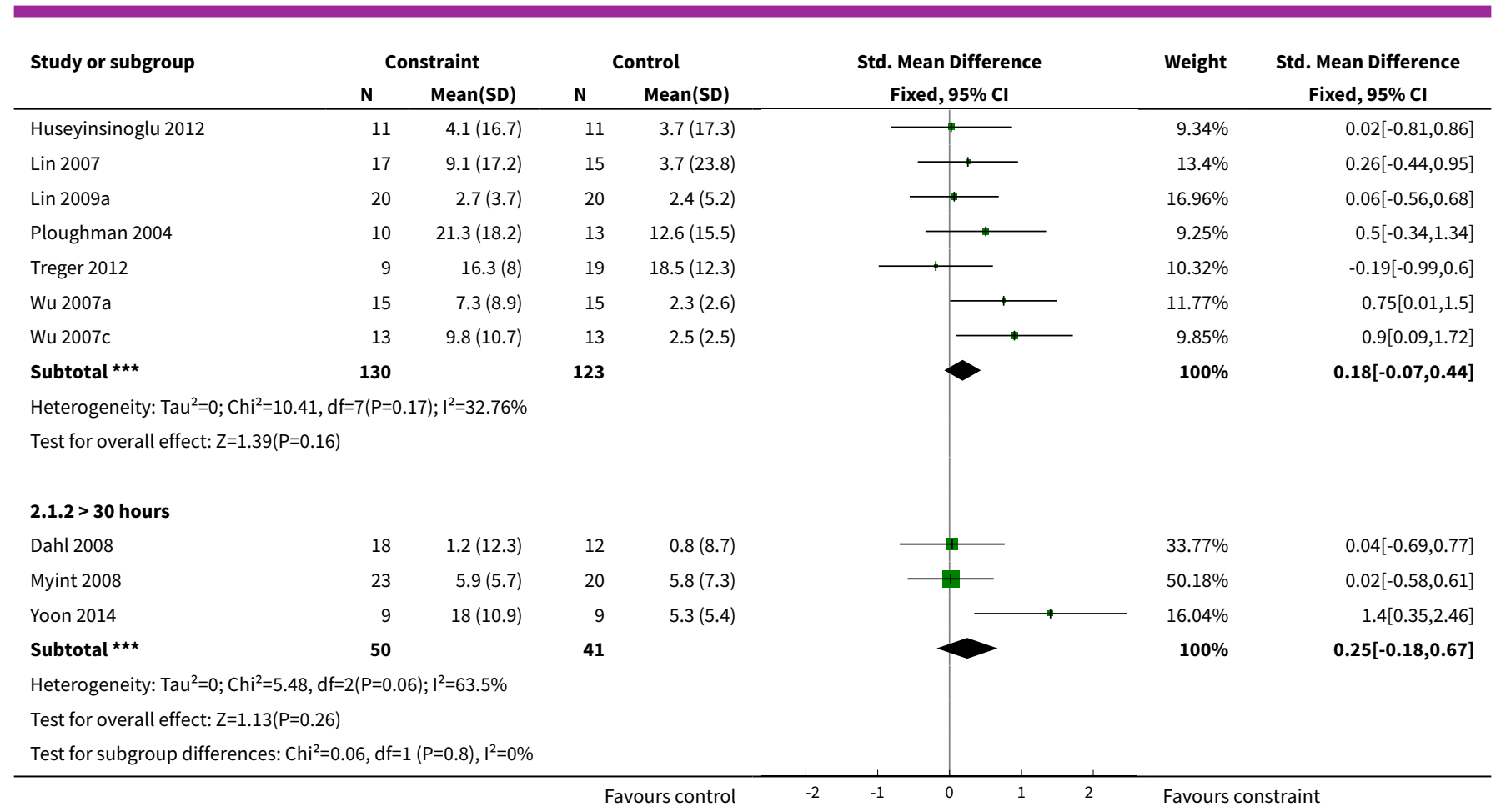

Analysis 2.2. Comparison 2 Constraint versus control: subgroup analysis on primary outcome, Outcome 2 Anatomical region restraint.

\begin{tabular}{|c|c|c|c|c|c|c|c|}
\hline \multirow{3}{*}{$\begin{array}{l}\text { Study or subgroup } \\
\text { 2.2.1 Arm plus hand }\end{array}$} & \multicolumn{2}{|c|}{ Constraint } & \multicolumn{2}{|c|}{ Control } & \multirow{2}{*}{$\begin{array}{l}\text { Std. Mean Difference } \\
\text { Fixed, } 95 \% \mathrm{Cl}\end{array}$} & \multirow[t]{2}{*}{ Weight } & \multirow{2}{*}{$\begin{array}{l}\text { Std. Mean Difference } \\
\text { Fixed, } 95 \% \mathrm{Cl}\end{array}$} \\
\hline & \multirow[t]{2}{*}{$\mathbf{N}$} & \multirow[t]{2}{*}{$\operatorname{Mean}(\mathrm{SD})$} & \multirow[t]{2}{*}{$\mathbf{N}$} & \multirow[t]{2}{*}{ Mean(SD) } & & & \\
\hline & & & & & & & \\
\hline Myint 2008 & 23 & $5.9(5.7)$ & 20 & $5.8(7.3)$ & & $75.78 \%$ & $0.02[-0.58,0.61]$ \\
\hline Yoon 2014 & 9 & $18(10.9)$ & 9 & $5.3(5.4)$ & & $24.22 \%$ & $1.4[0.35,2.46]$ \\
\hline Subtotal $* \star \star$ & 32 & & 29 & & & $100 \%$ & $0.35[-0.17,0.87]$ \\
\hline \multicolumn{8}{|c|}{ Heterogeneity: $\mathrm{Tau}^{2}=0 ; \mathrm{Chi}^{2}=5.01, \mathrm{df}=1(\mathrm{P}=0.03) ; \mathrm{I}^{2}=80.02 \%$} \\
\hline \multicolumn{8}{|c|}{ Test for overall effect: $Z=1.32(P=0.19)$} \\
\hline \multicolumn{8}{|l|}{ 2.2.2 Hand only } \\
\hline Dahl 2008 & 18 & $1.2(12.3)$ & 12 & $0.8(8.7)$ & & $10.89 \%$ & $0.04[-0.69,0.77]$ \\
\hline Dromerick 2009 & 35 & $5.4(5.4)$ & 17 & $7.4(4.9)$ & & $17.03 \%$ & $-0.37[-0.95,0.22]$ \\
\hline Huseyinsinoglu 2012 & 11 & $4.1(16.7)$ & 11 & $3.7(17.3)$ & & $8.32 \%$ & $0.02[-0.81,0.86]$ \\
\hline $\operatorname{Lin} 2007$ & 17 & $9.1(17.2)$ & 15 & $3.7(23.8)$ & & $11.94 \%$ & $0.26[-0.44,0.95]$ \\
\hline Lin 2009a & 20 & $2.7(3.7)$ & 20 & $2.4(5.2)$ & & $15.12 \%$ & $0.06[-0.56,0.68]$ \\
\hline Ploughman 2004 & 10 & $21.3(18.2)$ & 13 & $12.6(15.5)$ & & $8.24 \%$ & $0.5[-0.34,1.34]$ \\
\hline Treger 2012 & 9 & $16.3(8)$ & 19 & $18.5(12.3)$ & & $9.19 \%$ & $-0.19[-0.99,0.6]$ \\
\hline Wu 2007a & 15 & $7.3(8.9)$ & 15 & $2.3(2.6)$ & + & $10.49 \%$ & $0.75[0.01,1.5]$ \\
\hline Wu 2007c & 13 & $9.8(10.7)$ & 13 & $2.5(2.5)$ & & $8.78 \%$ & $0.9[0.09,1.72]$ \\
\hline Subtotal $\star \star \star$ & 148 & & 135 & & & $100 \%$ & $0.17[-0.08,0.41]$ \\
\hline \multicolumn{8}{|c|}{ Heterogeneity: $\mathrm{Tau}^{2}=0 ; \mathrm{Chi}^{2}=10.55, \mathrm{df}=8(\mathrm{P}=0.23) ; \mathrm{I}^{2}=24.14 \%$} \\
\hline \multicolumn{8}{|c|}{ Test for overall effect: $Z=1.35(P=0.18)$} \\
\hline \multicolumn{8}{|c|}{ Test for subgroup differences: $\mathrm{Chi}^{2}=0.4, \mathrm{df}=1(\mathrm{P}=0.53), \mathrm{I}^{2}=0 \%$} \\
\hline
\end{tabular}




\section{Analysis 2.3. Comparison 2 Constraint versus control: subgroup analysis on primary outcome, Outcome 3 Time since stroke.}

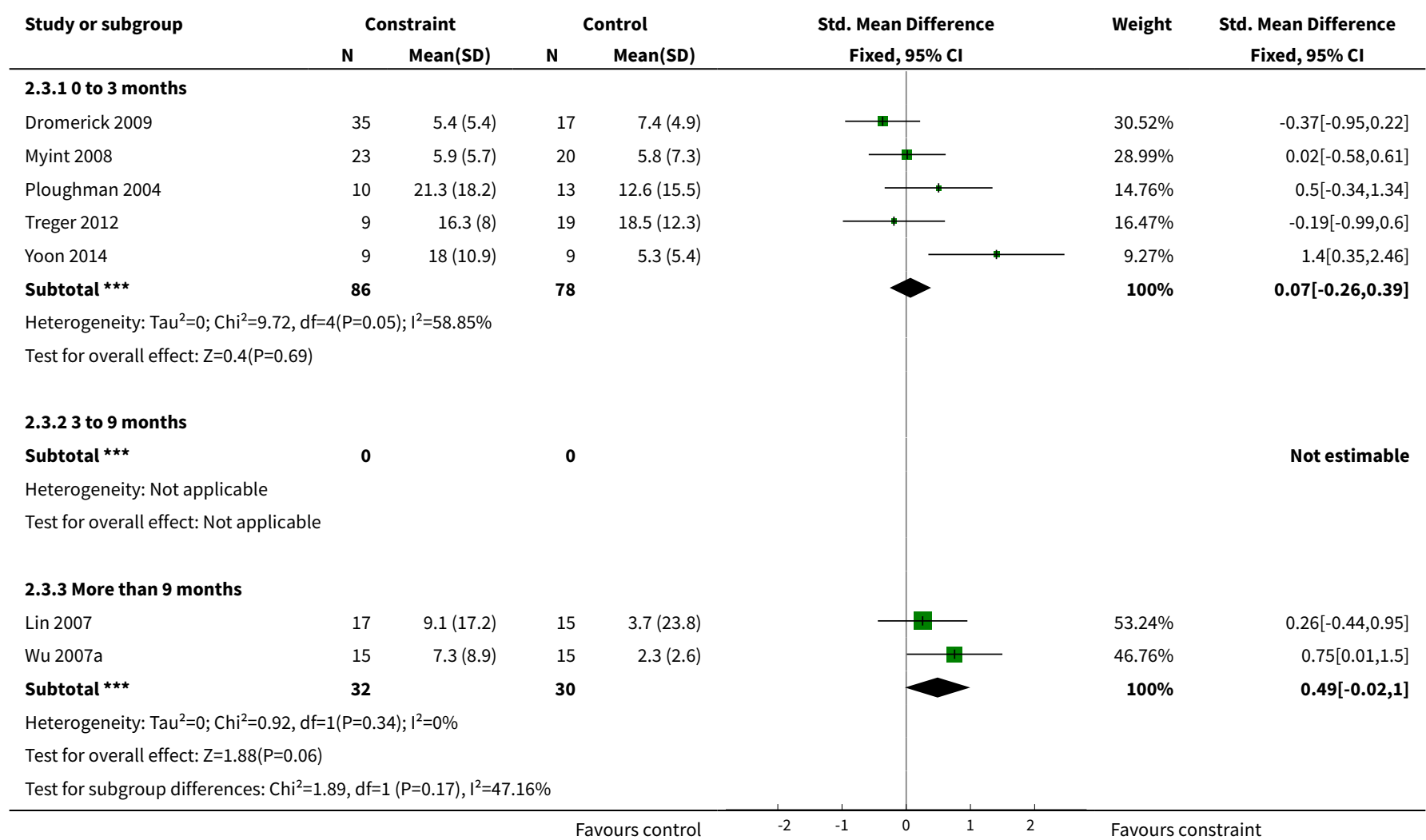

\section{Comparison 3. Constraint versus control: secondary outcomes}

\begin{tabular}{|c|c|c|c|c|}
\hline Outcome or subgroup title & No. of studies & $\begin{array}{l}\text { No. of partici- } \\
\text { pants }\end{array}$ & Statistical method & Effect size \\
\hline 1 Arm Motor Function & 28 & 858 & $\begin{array}{l}\text { Std. Mean Difference (IV, Random, } \\
95 \% \mathrm{CI})\end{array}$ & $0.34[0.12,0.55]$ \\
\hline $\begin{array}{l}1.1 \text { Constraint therapy versus } \\
\text { usual care }\end{array}$ & 25 & 816 & $\begin{array}{l}\text { Std. Mean Difference (IV, Random, } \\
95 \% \mathrm{CI} \text { ) }\end{array}$ & $0.31[0.09,0.52]$ \\
\hline $\begin{array}{l}1.2 \text { Constraint therapy versus } \\
\text { no treatment }\end{array}$ & 3 & 42 & $\begin{array}{l}\text { Std. Mean Difference (IV, Random, } \\
95 \% \mathrm{CI})\end{array}$ & $1.04[-0.31,2.40]$ \\
\hline $\begin{array}{l}2 \text { Perceived Arm Motor Func- } \\
\text { tion (Quality of Use) }\end{array}$ & 24 & 891 & $\begin{array}{l}\text { Mean Difference (IV, Random, 95\% } \\
\mathrm{CI})\end{array}$ & $0.68[0.47,0.88]$ \\
\hline 2.1 CIMT versus usual care & 22 & 865 & $\begin{array}{l}\text { Mean Difference (IV, Random, 95\% } \\
\mathrm{Cl} \text { ) }\end{array}$ & $0.65[0.44,0.86]$ \\
\hline 2.2 CIMT versus no treatment & 2 & 26 & $\begin{array}{l}\text { Mean Difference (IV, Random, 95\% } \\
\mathrm{Cl} \text { ) }\end{array}$ & $0.94[-0.32,2.20]$ \\
\hline
\end{tabular}




\begin{tabular}{|c|c|c|c|c|}
\hline Outcome or subgroup title & No. of studies & $\begin{array}{l}\text { No. of partici- } \\
\text { pants }\end{array}$ & Statistical method & Effect size \\
\hline $\begin{array}{l}3 \text { Perceived Arm Motor Func- } \\
\text { tion (Amount of Use) }\end{array}$ & 23 & 851 & $\begin{array}{l}\text { Mean Difference (IV, Random, 95\% } \\
\mathrm{CI} \text { ) }\end{array}$ & $0.79[0.50,1.08]$ \\
\hline 3.1 CIMT versus usual care & 21 & 818 & $\begin{array}{l}\text { Mean Difference (IV, Random, 95\% } \\
\mathrm{CI} \text { ) }\end{array}$ & $0.75[0.44,1.05]$ \\
\hline 3.2 CIMT versus no treatment & 2 & 33 & $\begin{array}{l}\text { Mean Difference (IV, Random, 95\% } \\
\mathrm{CI} \text { ) }\end{array}$ & $1.20[0.78,1.62]$ \\
\hline 4 Arm Motor Impairment & 16 & 372 & $\begin{array}{l}\text { Std. Mean Difference (IV, Random, } \\
95 \% \mathrm{CI})\end{array}$ & $0.82[0.31,1.34]$ \\
\hline $\begin{array}{l}4.1 \text { Constraint therapy versus } \\
\text { usual care }\end{array}$ & 15 & 355 & $\begin{array}{l}\text { Std. Mean Difference (IV, Random, } \\
95 \% \mathrm{CI})\end{array}$ & $0.88[0.33,1.42]$ \\
\hline $\begin{array}{l}4.2 \text { Constraint therapy versus } \\
\text { no treatment }\end{array}$ & 1 & 17 & $\begin{array}{l}\text { Std. Mean Difference (IV, Random, } \\
95 \% \mathrm{CI})\end{array}$ & $0.25[-0.70,1.21]$ \\
\hline 5 Quality of life & 3 & 96 & $\begin{array}{l}\text { Mean Difference (IV, Random, 95\% } \\
\mathrm{CI})\end{array}$ & $6.54[-1.20,14.28]$ \\
\hline $\begin{array}{l}5.1 \text { Constraint therapy versus } \\
\text { usual care }\end{array}$ & 3 & 96 & $\begin{array}{l}\text { Mean Difference (IV, Random, 95\% } \\
\mathrm{Cl} \text { ) }\end{array}$ & $6.54[-1.20,14.28]$ \\
\hline 6 Dexterity & 4 & 113 & $\begin{array}{l}\text { Std. Mean Difference (IV, Random, } \\
95 \% \mathrm{CI})\end{array}$ & $0.42[0.04,0.79]$ \\
\hline $\begin{array}{l}6.1 \text { Constraint therapy versus } \\
\text { usual care }\end{array}$ & 4 & 113 & $\begin{array}{l}\text { Std. Mean Difference (IV, Random, } \\
95 \% \mathrm{CI})\end{array}$ & $0.42[0.04,0.79]$ \\
\hline
\end{tabular}

\section{Analysis 3.1. Comparison 3 Constraint versus control: secondary outcomes, Outcome 1 Arm Motor Function.}

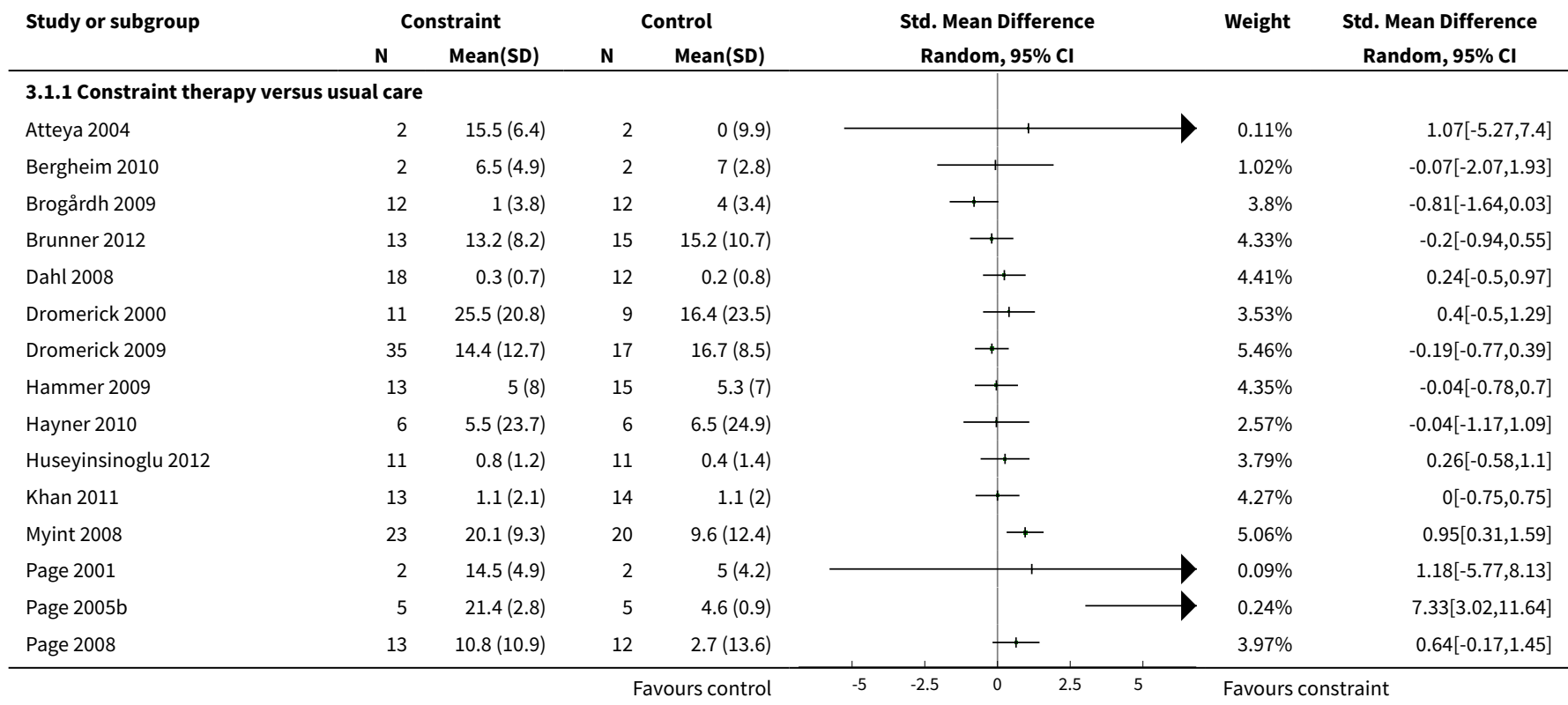




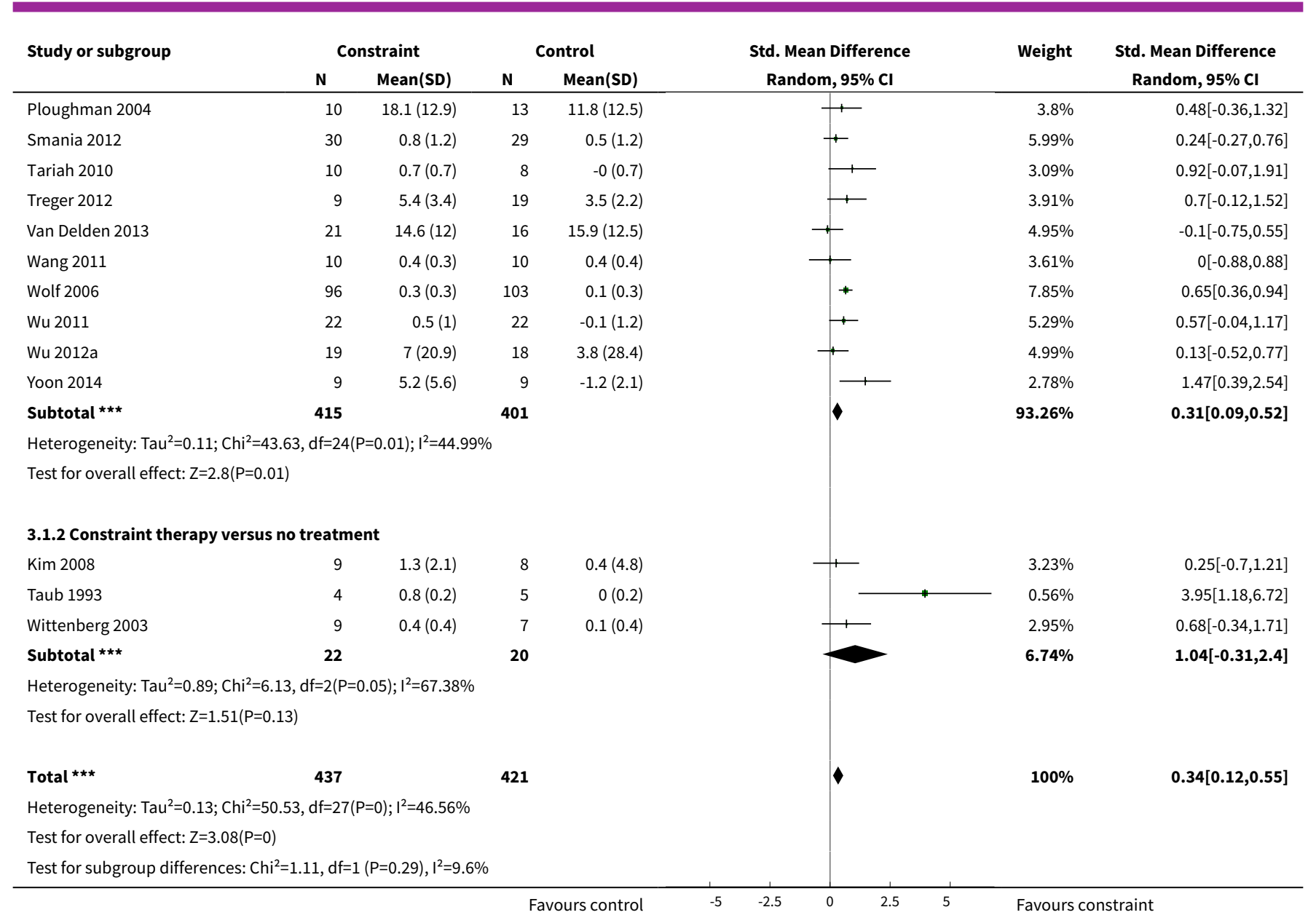

Analysis 3.2. Comparison 3 Constraint versus control: secondary outcomes, Outcome 2 Perceived Arm Motor Function (Quality of Use).

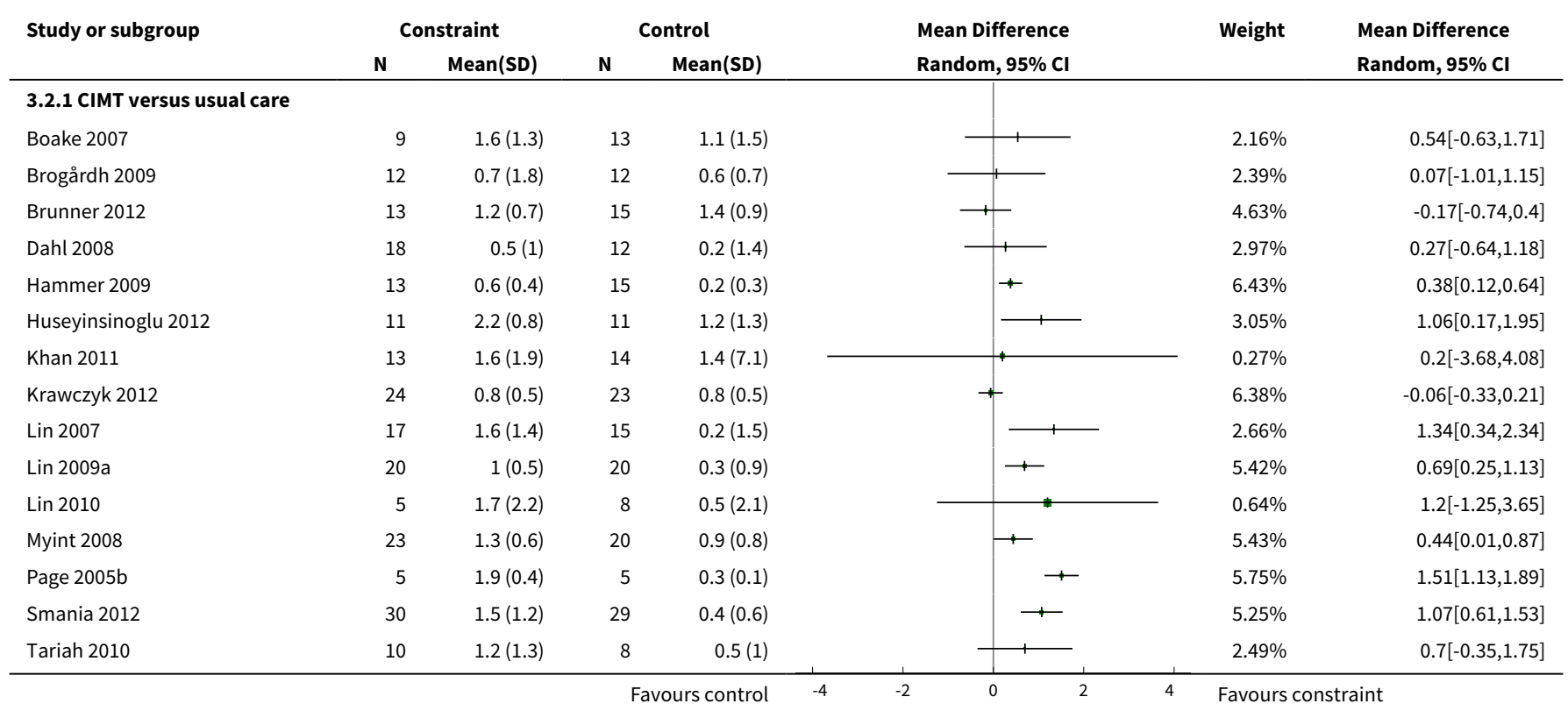




\begin{tabular}{|c|c|c|c|c|c|c|c|}
\hline \multirow[t]{2}{*}{ Study or subgroup } & \multicolumn{2}{|c|}{ Constraint } & \multicolumn{2}{|c|}{ Control } & \multirow{2}{*}{$\begin{array}{l}\text { Mean Difference } \\
\text { Random, } 95 \% \mathrm{CI}\end{array}$} & \multirow[t]{2}{*}{ Weight } & \multirow{2}{*}{$\begin{array}{l}\text { Mean Difference } \\
\text { Random, } 95 \% \mathrm{Cl}\end{array}$} \\
\hline & $\mathbf{N}$ & Mean(SD) & $\mathbf{N}$ & Mean(SD) & & & \\
\hline Van Delden 2013 & 21 & $1.3(1)$ & 16 & $1(0.8)$ & 1 & $4.56 \%$ & $0.3[-0.28,0.88]$ \\
\hline Wolf 2006 & 98 & $1(0.6)$ & 103 & $0.3(0.5)$ & + & $6.88 \%$ & $0.73[0.57,0.89]$ \\
\hline Wu 2007a & 15 & $1.1(0.8)$ & 15 & $0.3(0.8)$ & 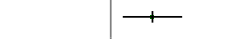 & $4.58 \%$ & $0.81[0.23,1.39]$ \\
\hline Wu 2007b & 24 & $1.1(0.7)$ & 23 & $0.1(0.5)$ & $\rightarrow$ & $5.88 \%$ & $0.99[0.63,1.35]$ \\
\hline Wu 2007c & 13 & $1.2(0.9)$ & 13 & $0.1(0.4)$ & $\multimap$ & $5 \%$ & $1.06[0.56,1.56]$ \\
\hline Wu 2011 & 22 & $1.2(1.3)$ & 22 & $0.7(1.5)$ & 1 & $3.24 \%$ & $0.57[-0.27,1.41]$ \\
\hline Wu 2012a & 19 & $1(1.1)$ & 18 & $0.4(1.1)$ & 1 & $3.8 \%$ & $0.6[-0.12,1.32]$ \\
\hline Subtotal $\star \star \star$ & 435 & & 430 & & $>$ & $89.84 \%$ & $0.65[0.44,0.86]$ \\
\hline \multicolumn{8}{|c|}{ Heterogeneity: $\mathrm{Tau}^{2}=0.14 ; \mathrm{Chi}^{2}=76.1, \mathrm{df}=21(\mathrm{P}<0.0001) ; \mathrm{I}^{2}=72.41 \%$} \\
\hline \multicolumn{8}{|c|}{ Test for overall effect: $Z=6.1(P<0.0001)$} \\
\hline \multicolumn{8}{|c|}{ 3.2.2 CIMT versus no treatment } \\
\hline Kim 2008 & 9 & $0.5(0.3)$ & 8 & $0.2(0.6)$ & + & $5.51 \%$ & $0.31[-0.11,0.73]$ \\
\hline Taub 1993 & 4 & $2(0.4)$ & 5 & $0.4(0.4)$ & 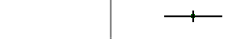 & $4.65 \%$ & $1.6[1.04,2.16]$ \\
\hline Subtotal $\star \star \star$ & 13 & & 13 & & & $10.16 \%$ & $0.94[-0.32,2.2]$ \\
\hline \multicolumn{8}{|c|}{ Heterogeneity: $\mathrm{Tau}^{2}=0.77 ; \mathrm{Chi}^{2}=12.93, \mathrm{df}=1(\mathrm{P}=0) ; \mathrm{I}^{2}=92.26 \%$} \\
\hline \multicolumn{8}{|c|}{ Test for overall effect: $Z=1.46(P=0.14)$} \\
\hline 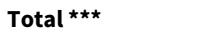 & 448 & & 443 & & $\diamond$ & $100 \%$ & $0.68[0.47,0.88]$ \\
\hline \multicolumn{8}{|c|}{ Heterogeneity: $\operatorname{Tau}^{2}=0.15 ; \mathrm{Chi}^{2}=89.64, \mathrm{df}=23(\mathrm{P}<0.0001) ; \mathrm{I}^{2}=74.34 \%$} \\
\hline \multicolumn{8}{|c|}{ Test for overall effect: $Z=6.46(P<0.0001)$} \\
\hline Test for subgroup dif & 2, $d f=1$ & $=0.66), I^{2}=0 \%$ & & & & & \\
\hline
\end{tabular}

Analysis 3.3. Comparison 3 Constraint versus control: secondary outcomes, Outcome 3 Perceived Arm Motor Function (Amount of Use).

\begin{tabular}{|c|c|c|c|c|c|c|c|c|}
\hline \multirow[t]{2}{*}{ Study or subgroup } & \multicolumn{2}{|c|}{ Constraint } & \multicolumn{2}{|c|}{ Control } & \multirow{2}{*}{\multicolumn{2}{|c|}{$\begin{array}{l}\text { Mean Difference } \\
\text { Random, } 95 \% \mathrm{Cl}\end{array}$}} & \multirow[t]{2}{*}{ Weight } & \multirow{2}{*}{$\begin{array}{l}\text { Mean Difference } \\
\text { Random, } 95 \% \mathrm{Cl}\end{array}$} \\
\hline & $\mathbf{N}$ & $\operatorname{Mean}(S D)$ & $\mathbf{N}$ & $\operatorname{Mean}(S D)$ & & & & \\
\hline \multicolumn{9}{|c|}{ 3.3.1 CIMT versus usual care } \\
\hline Boake 2007 & 9 & $1.7(1.5)$ & 13 & $1.3(1.7)$ & 1 & & $2.65 \%$ & $0.48[-0.84,1.8]$ \\
\hline Brogårdh 2009 & 12 & $0.8(1)$ & 12 & $0.4(1)$ & 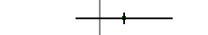 & & $4.21 \%$ & $0.39[-0.39,1.17]$ \\
\hline Brunner 2012 & 13 & $1.3(0.7)$ & 15 & $1.5(1)$ & $1-$ & & $4.75 \%$ & $-0.2[-0.82,0.42]$ \\
\hline Dahl 2008 & 18 & $0.6(1.7)$ & 12 & $0.8(1.7)$ & & & $2.9 \%$ & $-0.22[-1.44,1]$ \\
\hline Hammer 2009 & 13 & $0.6(0.4)$ & 15 & $0.4(0.3)$ & + & & $5.8 \%$ & $0.23[-0.04,0.5]$ \\
\hline Huseyinsinoglu 2012 & 11 & $2.3(0.8)$ & 11 & $1.2(1.9)$ & & & $2.87 \%$ & $1.15[-0.08,2.38]$ \\
\hline Khan 2011 & 13 & $1.7(2)$ & 14 & $1.6(1.6)$ & & & $2.56 \%$ & $0.1[-1.26,1.46]$ \\
\hline Lin 2007 & 17 & $1.4(1.3)$ & 15 & $0.2(1.4)$ & $\longrightarrow$ & & $3.76 \%$ & $1.16[0.25,2.07]$ \\
\hline Lin 2009a & 20 & $0.7(0.5)$ & 20 & $0.1(0.4)$ & $\rightarrow$ & & $5.75 \%$ & $0.59[0.3,0.88]$ \\
\hline Lin 2010 & 5 & $1.5(2.4)$ & 8 & $0.6(2.1)$ & & & $1.03 \%$ & $0.9[-1.67,3.47]$ \\
\hline Myint 2008 & 23 & $1.5(0.7)$ & 20 & $0.5(0.4)$ & 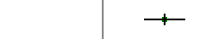 & & $5.64 \%$ & $0.99[0.66,1.32]$ \\
\hline Smania 2012 & 30 & $1.4(1.2)$ & 29 & $0.3(0.6)$ & 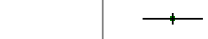 & & $5.2 \%$ & $1.12[0.64,1.6]$ \\
\hline Tariah 2010 & 10 & $1.4(1.5)$ & 8 & $0.7(1.1)$ & + & & $2.95 \%$ & $0.69[-0.51,1.89]$ \\
\hline Van Delden 2013 & 21 & $1.3(1.3)$ & 16 & $1(0.8)$ & \begin{tabular}{l|l}
1 \\
\end{tabular} & & $4.53 \%$ & $0.3[-0.38,0.98]$ \\
\hline Wolf 2006 & 98 & $1.2(0.7)$ & 103 & $0.3(0.6)$ & + & & $5.97 \%$ & $0.86[0.69,1.03]$ \\
\hline Wu 2007a & 15 & $1.4(0.9)$ & 15 & $0.3(0.6)$ & 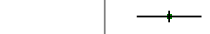 & & $5.08 \%$ & $1.03[0.51,1.55]$ \\
\hline Wu 2007b & 24 & $1.2(0.7)$ & 23 & $0.2(0.4)$ & $\rightarrow$ & & $5.63 \%$ & $1.04[0.71,1.37]$ \\
\hline Wu 2007c & 13 & $1(0.8)$ & 13 & $0.2(0.4)$ & $\longrightarrow$ & & $5.26 \%$ & $0.78[0.32,1.24]$ \\
\hline
\end{tabular}




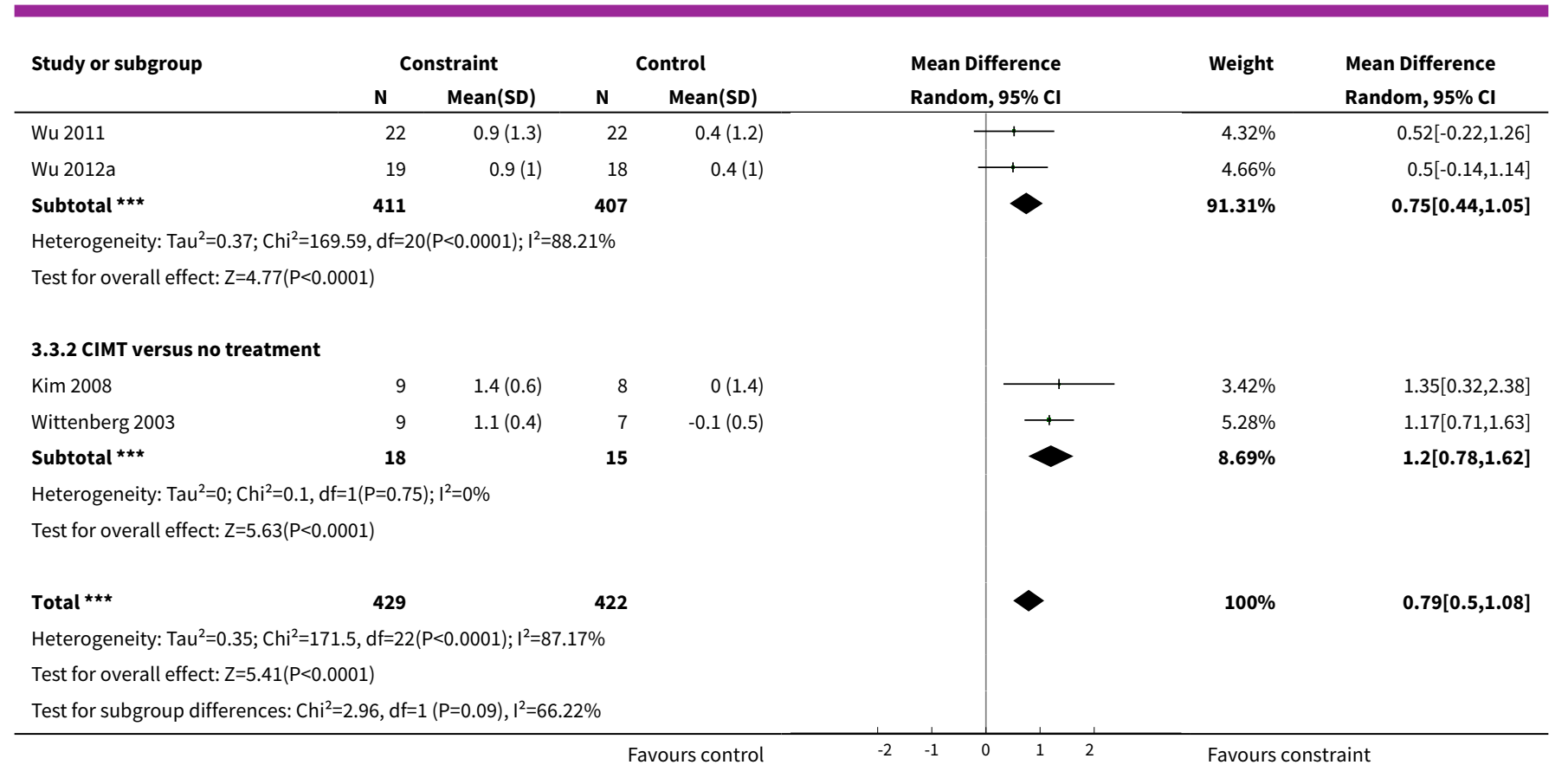

Analysis 3.4. Comparison 3 Constraint versus control: secondary outcomes, Outcome 4 Arm Motor Impairment.

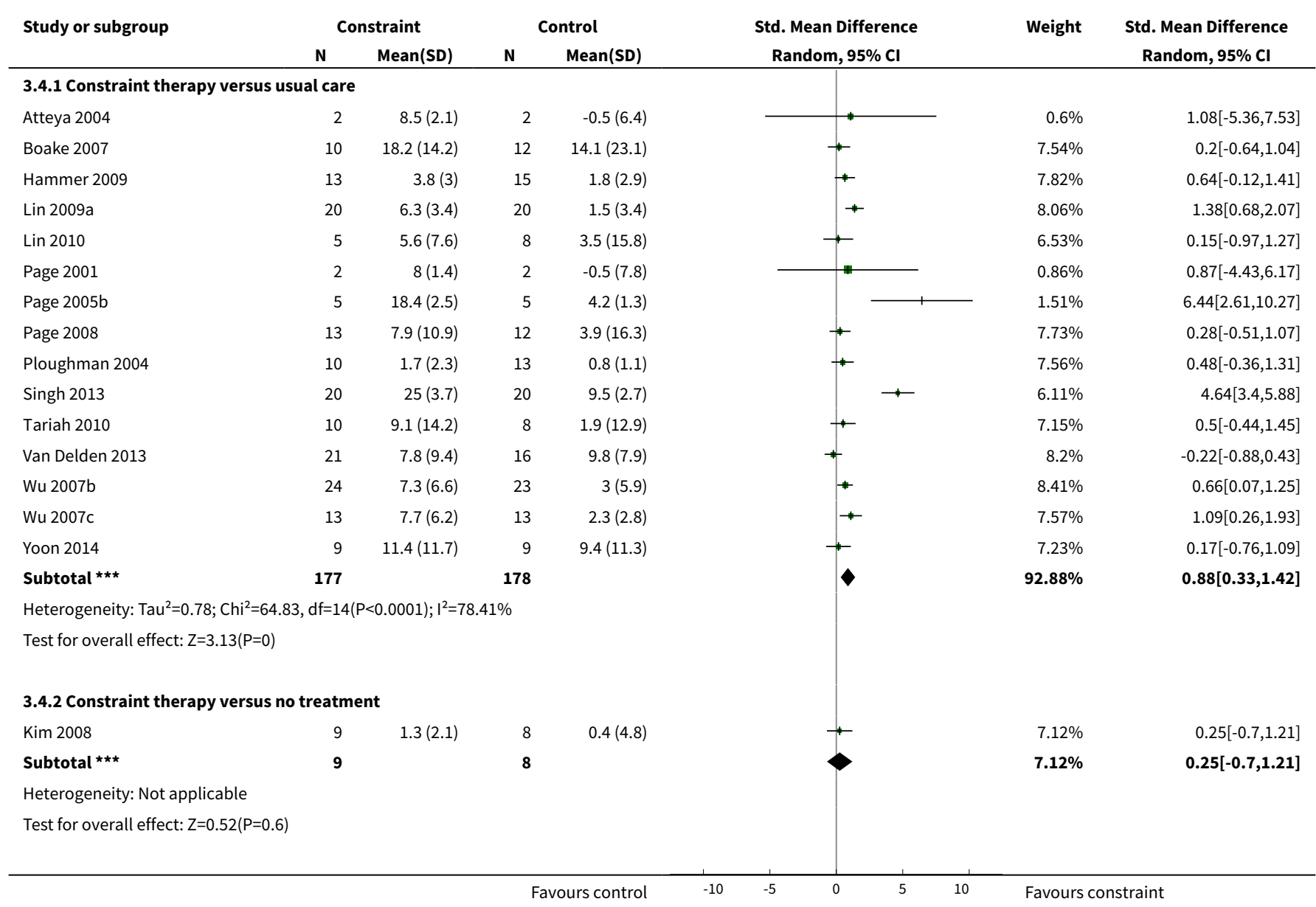




\begin{tabular}{|c|c|c|c|c|c|c|c|c|}
\hline \multirow{3}{*}{ 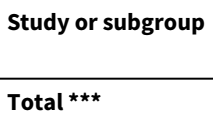 } & \multicolumn{2}{|c|}{ Constraint } & \multicolumn{2}{|c|}{ Control } & \multirow{2}{*}{\multicolumn{2}{|c|}{$\begin{array}{c}\text { Std. Mean Difference } \\
\text { Random, } 95 \% \mathrm{Cl}\end{array}$}} & \multirow[t]{2}{*}{ Weight } & \multirow{3}{*}{$\begin{array}{c}\begin{array}{c}\text { Std. Mean Difference } \\
\text { Random, } 95 \% \mathrm{Cl}\end{array} \\
0.82[0.31,1.34]\end{array}$} \\
\hline & \multirow{2}{*}{$\begin{array}{l}\mathrm{N} \\
186\end{array}$} & \multirow[t]{2}{*}{ Mean(SD) } & & \multirow[t]{2}{*}{$\operatorname{Mean}(S D)$} & & & & \\
\hline & & & & & & 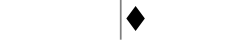 & $100 \%$ & \\
\hline \multicolumn{9}{|c|}{ Heterogeneity: Tau $^{2}=0.73 ; \mathrm{Chi}^{2}=65.55, \mathrm{df}=15(\mathrm{P}<0.0001) ; \mathrm{I}^{2}=77.12 \%$} \\
\hline \multicolumn{9}{|c|}{ Test for overall effect: $Z=3.14(P=0)$} \\
\hline \multicolumn{9}{|c|}{ Test for subgroup differences: $\mathrm{Chi}^{2}=1.22, \mathrm{df}=1(\mathrm{P}=0.27), \mathrm{I}^{2}=18.15 \%$} \\
\hline
\end{tabular}

\section{Analysis 3.5. Comparison 3 Constraint versus control: secondary outcomes, Outcome 5 Quality of life.}

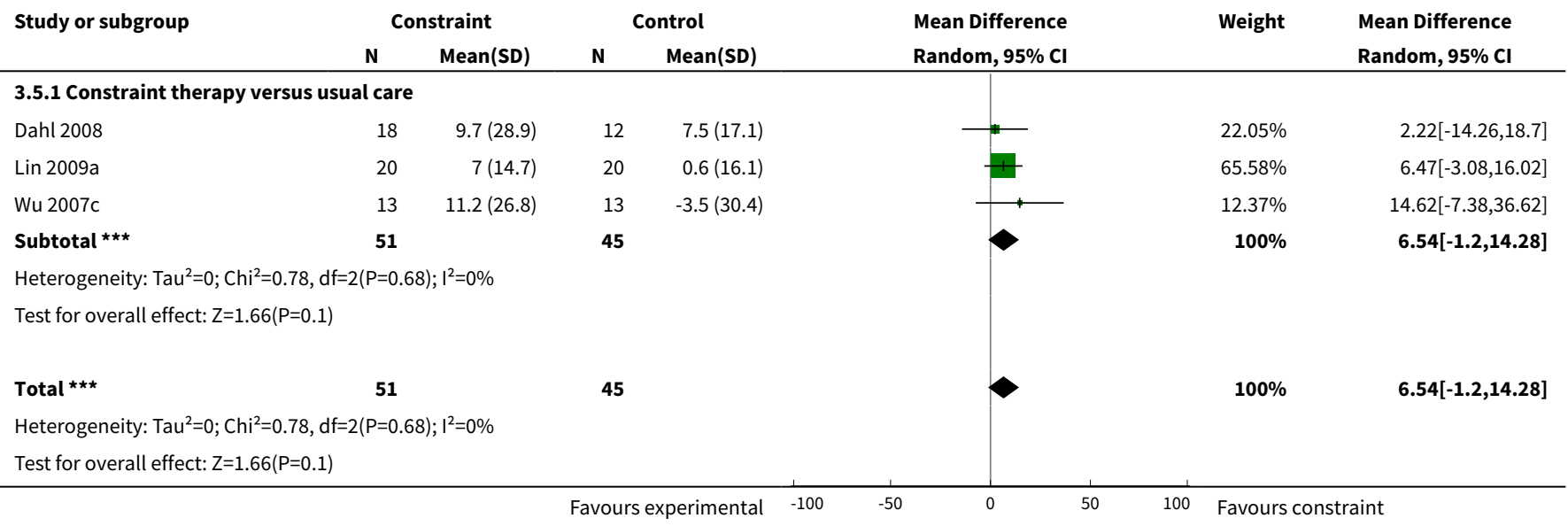

Analysis 3.6. Comparison 3 Constraint versus control: secondary outcomes, Outcome 6 Dexterity.

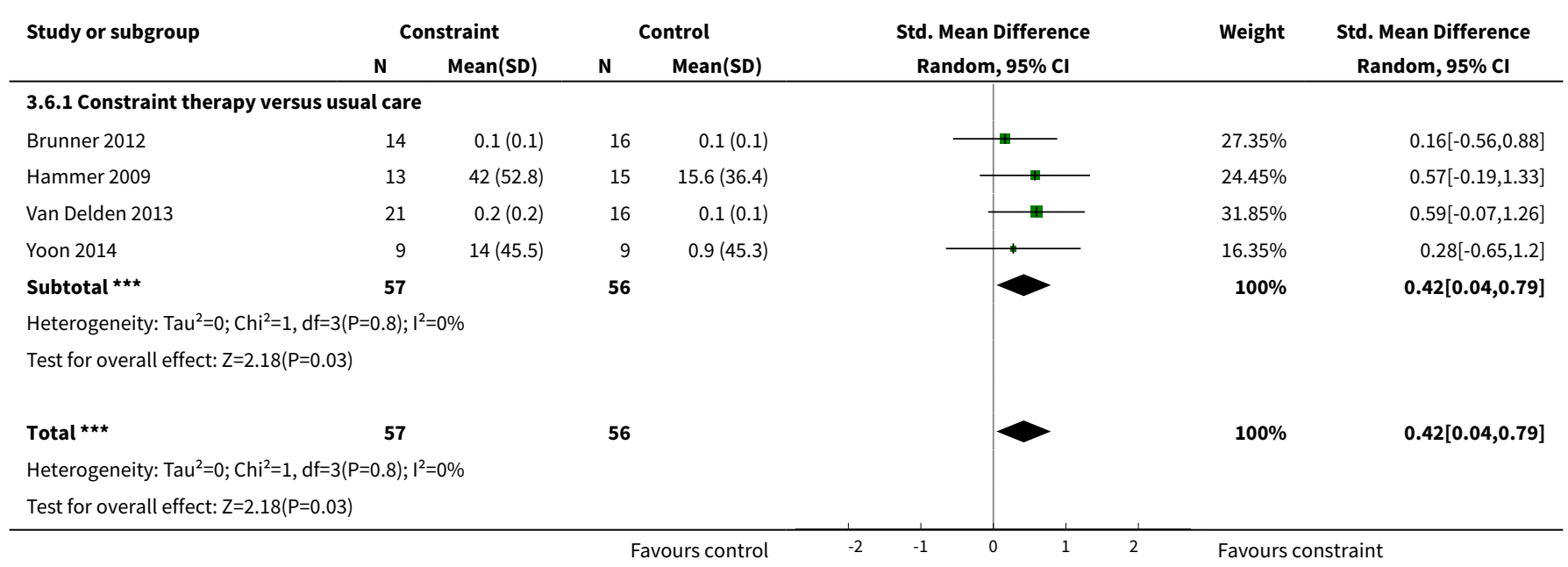

\section{ADDITIONAL TABLES}


Table 1. Criteria for subgroup analysis

\begin{tabular}{|c|c|c|c|c|}
\hline Study ID & $\begin{array}{l}\text { Dosage of prac- } \\
\text { tice }\end{array}$ & $\begin{array}{l}\text { Anatomical re- } \\
\text { straint }\end{array}$ & $\begin{array}{l}\text { Constraint ef- } \\
\text { fect }\end{array}$ & Time since stroke \\
\hline & $\begin{array}{l}1=3 \text { hour or less; } \\
2=\text { more than } 3 \\
\text { hours }\end{array}$ & $\begin{array}{l}1=\text { only hand; } 2 \\
=\text { both arm and } \\
\text { hand }\end{array}$ & $\begin{array}{l}1=\text { restraint; } 2= \\
\text { restraint plus ex- } \\
\text { ercise }\end{array}$ & $\begin{array}{l}1=0 \text { to } 3 \text { months; } \\
2=3 \text { to } 9 \text { months; } \\
3=\text { more than } 9 \\
\text { months; } 4=\text { wide } \\
\text { range (from } 0.5 \text { to } \\
37 \text { months) }\end{array}$ \\
\hline Alberts 2004 & 2 & 1 & 2 & 2 \\
\hline Atteya 2004 & 1 & 2 & 2 & 2 \\
\hline Azab 2009 & 1 & 1 & 2 & 1 \\
\hline Bergheim 2010 & 1 & 1 & 2 & 1 \\
\hline Boake 2007 & 2 & 1 & 2 & 1 \\
\hline Brogårdh 2009 & 1 & 1 & 2 & 1 \\
\hline Brunner 2012 & 1 & 1 & 2 & 1 \\
\hline Dahl 2008 & 2 & 1 & 2 & 4 \\
\hline Dromerick 2000 & 1 & 1 & 2 & 1 \\
\hline Dromerick 2009 & 1 & 1 & 2 & 1 \\
\hline Hammer 2009 & 1 & 2 & 1 & 1 \\
\hline Hayner 2010 & 2 & 1 & 2 & 3 \\
\hline Huseyinsinoglu 2012 & 1 & 1 & 2 & 2 \\
\hline Khan 2011 & 2 & 1 & 2 & 4 \\
\hline Kim 2008 & 1 & 1 & 1 & 3 \\
\hline Krawczyk 2012 & 2 & 2 & 2 & 3 \\
\hline Lin 2007 & 1 & 1 & 2 & 3 \\
\hline $\operatorname{Lin} 2009 a$ & 1 & 1 & 2 & 4 \\
\hline Lin 2010 & 1 & 1 & 2 & 4 \\
\hline Myint 2008 & 2 & 2 & 2 & 1 \\
\hline Page 2001 & 1 & 2 & 2 & 2 \\
\hline Page $2002 b$ & 1 & 2 & 2 & 2 \\
\hline Page 2004 & 1 & 2 & 2 & 3 \\
\hline
\end{tabular}


Table 1. Criteria for subgroup analysis (Continued)

\begin{tabular}{|c|c|c|c|c|}
\hline Page 2005b & 1 & 1 & 2 & 1 \\
\hline Page 2008 & 1 & 2 & 2 & 3 \\
\hline Ploughman 2004 & 1 & 1 & 2 & 1 \\
\hline Singh 2013 & 1 & 1 & 2 & 1 \\
\hline Smania 2012 & 1 & 1 & 2 & 2 \\
\hline Tariah 2010 & 1 & 1 & 2 & 2 \\
\hline Taub 1993 & 2 & 2 & 2 & 3 \\
\hline Treger 2012 & 1 & 1 & 2 & 1 \\
\hline Van Delden 2013 & 1 & 1 & 2 & 2 \\
\hline Wang 2011 & 1 & 1 & 2 & 1 \\
\hline Wittenberg 2003 & 2 & 2 & 2 & 3 \\
\hline Wolf 2006 & 2 & 1 & 2 & 2 \\
\hline Wu 2007a & 1 & 1 & 2 & 4 \\
\hline Wu 2007b & 1 & 1 & 2 & 4 \\
\hline Wu 2007c & 1 & 1 & 2 & 4 \\
\hline Wu 2011 & 1 & 1 & 2 & 4 \\
\hline Wu 2012a & 1 & 1 & 2 & 4 \\
\hline Yoon 2014 & 2 & 2 & 2 & 1 \\
\hline
\end{tabular}




\begin{tabular}{|c|c|c|c|c|c|c|c|c|c|}
\hline Study ID & Arm motor function & $\begin{array}{l}\text { Perceived motor } \\
\text { function }\end{array}$ & Dexterity & $\begin{array}{l}\text { Arm motor } \\
\text { impairment }\end{array}$ & $\begin{array}{l}\text { Activities of } \\
\text { daily living } \\
\text { measures }\end{array}$ & $\begin{array}{l}\text { Quality of } \\
\text { life }\end{array}$ & $\begin{array}{l}\text { Kinemat- } \\
\text { ics }\end{array}$ & $\begin{array}{l}\text { Neuro- } \\
\text { physio- } \\
\text { logics }\end{array}$ & Strength \\
\hline Alberts 2004 & Wolf Motor Function Test & & & $\begin{array}{l}\text { Fugl Meyer As- } \\
\text { sessment }\end{array}$ & & & & & $\begin{array}{l}\text { Hand dy- } \\
\text { namome- } \\
\text { ter }\end{array}$ \\
\hline Atteya 2004 & $\begin{array}{l}\text { Action Research Arm Test, } \\
\text { Wolf Motor Function Test }\end{array}$ & $\begin{array}{l}\text { Motor Activity } \\
\text { Log }\end{array}$ & & $\begin{array}{l}\text { Fugl Meyer As- } \\
\text { sessment }\end{array}$ & & & & & \\
\hline Azab 2009 & & & & & Bartel Index & & & & \\
\hline $\begin{array}{l}\text { Bergheim } \\
2010\end{array}$ & $\begin{array}{l}\text { Wolf Motor Function Test, } \\
\text { Motor Assessment Scale }\end{array}$ & & & & & & & & \\
\hline Boake 2007 & & $\begin{array}{l}\text { Motor Activity } \\
\text { Log }\end{array}$ & $\begin{array}{l}\text { Grooved } \\
\text { Pegboard } \\
\text { Test }\end{array}$ & $\begin{array}{l}\text { Fugl Meyer As- } \\
\text { sessment }\end{array}$ & & & & $\begin{array}{l}\text { Transcra- } \\
\text { nial mag- } \\
\text { netic stim- } \\
\text { ulation }\end{array}$ & \\
\hline $\begin{array}{l}\text { Brogårdh } \\
2009\end{array}$ & $\begin{array}{l}\text { Motor Assessment Scale, } \\
\text { Sollerman Hand Function } \\
\text { Scale }\end{array}$ & $\begin{array}{l}\text { Motor Activity } \\
\text { Log }\end{array}$ & & & & & & & \\
\hline Brunner 2012 & Action Research Arm Test & & $\begin{array}{l}\text { Nine-Hole } \\
\text { Peg Test }\end{array}$ & & & & & & \\
\hline Dahl 2008 & Wolf Motor Function Test & $\begin{array}{l}\text { Motor Activity } \\
\text { Log }\end{array}$ & & & $\begin{array}{l}\text { Function- } \\
\text { al Indepen- } \\
\text { dence Mea- } \\
\text { sure }\end{array}$ & $\begin{array}{l}\text { Stroke Im- } \\
\text { pact Scale }\end{array}$ & & & \\
\hline $\begin{array}{l}\text { Dromerick } \\
2000\end{array}$ & Action Research Arm Test & & & & & & & & \\
\hline $\begin{array}{l}\text { Dromerick } \\
2009\end{array}$ & Action Research Arm Test & & & & $\begin{array}{l}\text { Function- } \\
\text { al Indepen- } \\
\text { dence Mea- } \\
\text { sure }\end{array}$ & $\begin{array}{l}\text { Stroke Im- } \\
\text { pact Scale }\end{array}$ & & & \\
\hline
\end{tabular}




\begin{tabular}{|c|c|c|c|c|c|c|c|}
\hline Hammer 2009 & $\begin{array}{l}\text { Action Research Arm Test, } \\
\text { Motor Assessment Scale }\end{array}$ & $\begin{array}{l}\text { Motor Activity } \\
\text { Log }\end{array}$ & $\begin{array}{l}\text { Six- } \\
\text { teen-Hole } \\
\text { Peg Test }\end{array}$ & $\begin{array}{l}\text { Fugl Meyer As- } \\
\text { sessment }\end{array}$ & & & Grippit \\
\hline Hayner 2010 & Wolf Motor Function Test & & & & & & \\
\hline $\begin{array}{l}\text { Huseyinsinoglu } \\
2012\end{array}$ & Wolf Motor Function Test & $\begin{array}{l}\text { Motor Activity } \\
\text { Log }\end{array}$ & & & $\begin{array}{l}\text { Function- } \\
\text { al Indepen- } \\
\text { dence Mea- } \\
\text { sure }\end{array}$ & & \\
\hline Khan 2011 & Wolf Motor Function Test & $\begin{array}{l}\text { Motor Activity } \\
\text { Log }\end{array}$ & & & & & \\
\hline Kim 2008 & Manual Function Test & $\begin{array}{l}\text { Motor Activity } \\
\text { Log }\end{array}$ & $\begin{array}{l}\text { Perdue } \\
\text { Pegboard } \\
\text { Test }\end{array}$ & & & & \\
\hline $\begin{array}{l}\text { Krawczyk } \\
2012\end{array}$ & $\begin{array}{l}\text { Rivermead motor assessment } \\
\text { arm scale }\end{array}$ & $\begin{array}{l}\text { Motor Activity } \\
\text { Log }\end{array}$ & & & & & \\
\hline Lin 2007 & & $\begin{array}{l}\text { Motor Activity } \\
\text { Log }\end{array}$ & & & $\begin{array}{l}\text { Function- } \\
\text { al Indepen- } \\
\text { dence Mea- } \\
\text { sure }\end{array}$ & Yes & \\
\hline Lin 2009a & & $\begin{array}{l}\text { Motor Activity } \\
\text { Log }\end{array}$ & & $\begin{array}{l}\text { Fugl Meyer As- } \\
\text { sessment }\end{array}$ & $\begin{array}{l}\text { Function- } \\
\text { al Indepen- } \\
\text { dence Mea- } \\
\text { sure }\end{array}$ & $\begin{array}{l}\text { Stroke Im- } \\
\text { pact Scale }\end{array}$ & \\
\hline Lin 2010 & & $\begin{array}{l}\text { Motor Activity } \\
\text { Log }\end{array}$ & & $\begin{array}{l}\text { Fugl Meyer As- } \\
\text { sessment }\end{array}$ & & & $\begin{array}{l}\text { Functional } \\
\text { magnetic } \\
\text { resonance }\end{array}$ \\
\hline Myint 2008 & Action Research Arm Test & $\begin{array}{l}\text { Motor Activity } \\
\text { Log }\end{array}$ & $\begin{array}{l}\text { Nine-Hole } \\
\text { Peg Test }\end{array}$ & & Bartel Index & & \\
\hline Page 2001 & $\begin{array}{l}\text { Action Research Arm Test, } \\
\text { Wolf Motor Function Test }\end{array}$ & $\begin{array}{l}\text { Motor Activity } \\
\text { Log }\end{array}$ & & $\begin{array}{l}\text { Fugl Meyer As- } \\
\text { sessment }\end{array}$ & & & \\
\hline Page 2002b & Action Research Arm Test & $\begin{array}{l}\text { Motor Activity } \\
\text { Log }\end{array}$ & & $\begin{array}{l}\text { Fugl Meyer As- } \\
\text { sessment }\end{array}$ & & & \\
\hline
\end{tabular}




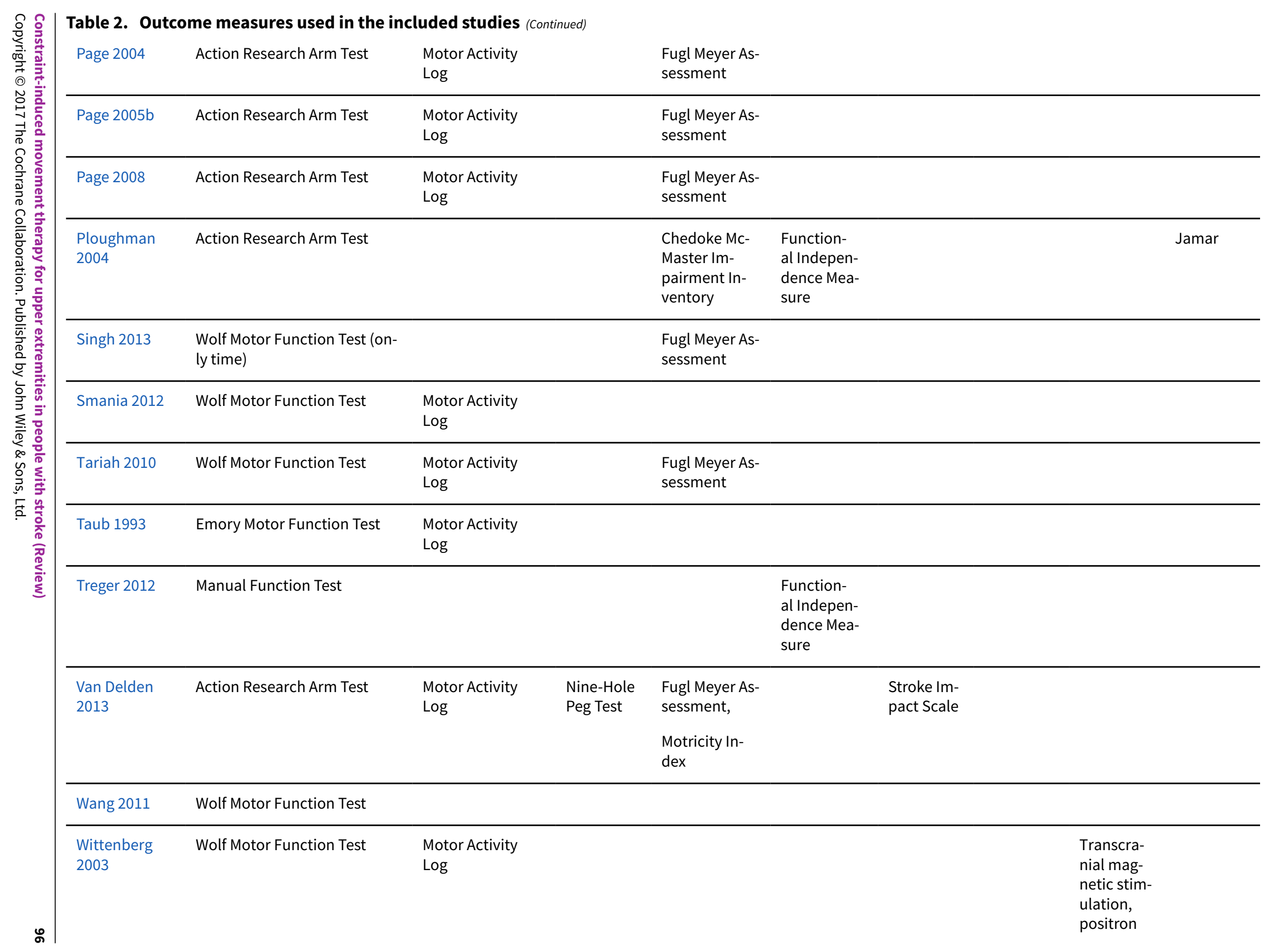




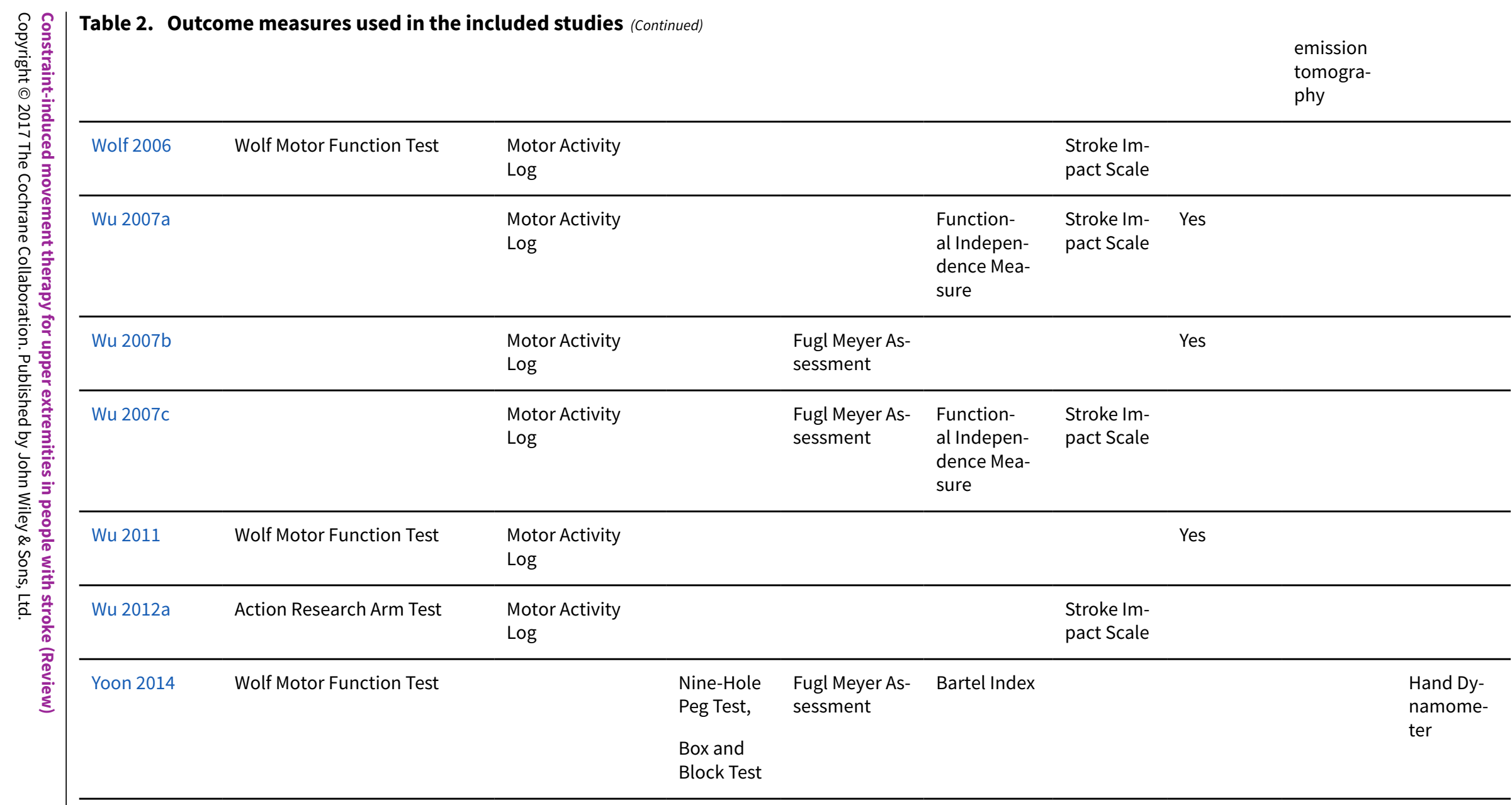




\section{AP PEN DICES}

\section{Appendix 1. CENTRAL search strategy}

The Cochrane Central Register of Controlled Trials (CENTRAL) (onlinelibrary.wiley.com)

\#1 MeSH descriptor: [Cerebrovascular Disorders] explode all trees

\#2 MeSH descriptor: [Brain Injuries] this term only

\#3 MeSH descriptor: [Brain Injury, Chronic] this term only

$\# 4$ \#1 or \#2 or \#3

\#5 stroke* or cva or poststroke or post-stroke (Word variations have been searched)

\#6 cerebrovasc* or "cerebral vascular" (Word variations have been searched)

\#7 cerebral or cerebellar or brain* or vertebrobasilar (Word variations have been searched)

\#8 infarct ${ }^{\star}$ or isch?emi* or thrombo* or emboli* or apoplexy (Word variations have been searched)

$\# 9$ \#7 and \#8

\#10 cerebral or brain or subarachnoid (Word variations have been searched)

\#11 hamorrhage or hemorrhage or haematoma or hematoma or bleed ${ }^{*}$ (Word variations have been searched)

$\# 12 \# 10$ and \#11

\#13 MeSH descriptor: [Hemiplegia] this term only

\#14 MeSH descriptor: [Paresis] explode all trees

$\# 15 \# 13$ or \#14

\#16 hempar* or hemipleg* or paresis or paretic or "brain injur*" (Word variations have been searched)

$\# 17$ \#4 or \#5 or \#6 or \#9 or \#12 or \#15 or \#16

\#18 MeSH descriptor: [Upper Extremity] explode all trees

\#19 "upper limb*" or "upper extremit*" or "arm" or "shoulder" or "hand" or "axilla" or "elbow*" or "forearm*" or "finger*" or "wrist*" (Word variations have been searched)

$\# 20 \# 18$ or 19

\#21 MeSH descriptor: [Restraint, Physical] this term only

\#22 MeSH descriptor: [Exercise Movement Techniques] this term only

\#23 MeSH descriptor: [Exercise] this term only

\#24 MeSH descriptor: [Exercise Therapy] this term only

\#25 MeSH descriptor: [Immobilization] this term only

\#26 MeSH descriptor: [Physical Therapy Modalities] this term only

\#27 "constrain*" or "restrain*" or "immobili*" (Word variations have been searched)

\#28 "mCIMT" or "CIT" or "Cl therapy" or "forced use" (Word variations have been searched)

\#29 MeSH descriptor: [Recovery of Function] this term only

\#30 MeSH descriptor: [Splints] this term only

\#31 MeSH descriptor: [Casts, Surgical] this term only

Constraint-induced movement therapy for upper extremities in people with stroke (Review) 
\#32 \#21 or \#22 or \#23 or \#24 or \#25 or \#26 or \#27 or \#28 or \#29 or \#30 or \#31

\#33 \#17 and \#20 and \#32 in Trials

\section{Appendix 2. MEDLINE (Ovid) search strategy}

The following search strategy, which was developed by the Cochrane Stroke Group Trials Search Coordinator, was used for MEDLINE (Ovid) and was adapted for the Cochrane Central Register of Controlled Trials (CENTRAL).

1. exp cerebrovascular disorders/ or brain injuries/ or brain injury, chronic/

2. (stroke\$ or cva or poststroke or post-stroke).tw.

3. (cerebrovasc $\$$ or cerebral vascular).tw.

4. (cerebral or cerebellar or brain $\$$ or vertebrobasilar).tw.

5. (infarct\$ or isch?emi\$ or thrombo\$ or emboli\$ or apoplexy).tw.

6. 4 and 5

7. (cerebral or brain or subarachnoid).tw.

8. (haemorrhage or hemorrhage or haematoma or hematoma or bleed\$).tw.

9. 7 and 8

10. hemiplegia/ or exp paresis/

11. (hempar\$ or hemipleg\$ or paresis or paretic or brain injur\$).tw.

12. 1 or 2 or 3 or 6 or 9 or 10 or 11

13. exp upper extremity/

14. (upper limb\$ or upper extremit\$ or arm or shoulder or hand or axilla or elbow\$ or forearm\$ or finger\$ or wrist\$).tw.

15. 13 or 14

16. restraint, physical/

17. exercise movement techniques/ or exercise/ or exercise therapy/

18. immobilization/

19. physical therapy techniques/

20. (constrain\$ or restrain\$ or immobili\$).tw.

21. (mCIMT or CIT or "Cl therapy" or "forced use").tw.

22. recovery of function/

23. splints/ or casts, surgical/

24. 16 or 17 or 18 or 19 or 20 or 21 or 22 or 23

25. 12 and 15 and 24

\section{Appendix 3. EMBASE search strategy}

\section{EMBASE (Ovid)}

1. cerebrovascular disease/ or exp basal ganglion hemorrhage/ or cerebral artery disease/ or exp cerebrovascular accident/ or stroke/ or exp carotid artery disease/ or exp brain hematoma/ or exp brain hemorrhage/ or exp brain infarction/ or exp brain ischemia/ or exp intracranial aneurysm/ or exp occlusive cerebrovascular disease/ or exp brain injury/ or stroke patient/ or stroke unit/

2. (stroke\$ or cva or poststroke or post-stroke).tw.

3. (cerebrovasc $\$$ or cerebral vasc\$).tw.

4. (cerebral or cerebellar or brain $\$$ or vertebrobasilar).tw.

5. (infarct\$ or isch?emi\$ or thrombo $\$$ or emboli\$ or apoplexy).tw.

6. 4 and 5

7. (cerebral or brain or subarachnoid).tw.

8. (haemorrhage or hemorrhage or haematoma or hematoma or bleed\$).tw.

9. 7 and 8

10. hemiplegia/ or hemiparesis/ or paresis/

11. (hemipleg\$ or hemipar\$ or paresis or paretic or brain injur\$).tw.

12. 1 or 2 or 3 or 6 or 9 or 10 or 11

13. exp arm/

14. (upper limb\$ or upper extremit\$ or arm or shoulder or hand or axilla or elbow\$ or forearm\$ or finger\$ or wrist\$).tw.

15. 13 or 14

16. constraint induced therapy/ or exp exercise/ or exp kinesiotherapy/ or physiotherapy/ or immobilization/

17. (restrain\$ or constrain\$ or immobili\$).tw.

18. (mCIMT or CIT or Cl therapy or "forced use").tw.

19. dynamic splint/ or plaster cast/ or splint/

20. (splint\$ or cast or casts).tw.

21. or/16-20

22. 12 and 15 and 21 


\section{Appendix 4. CINAHL search strategy}

CINAHL (EbSCO)

S1 .(MH "Cerebrovascular Disorders+") or (MH "stroke patients") or (MH "stroke units")

S2 .TI ( stroke or poststroke or post-stroke or cerebrovasc* or brain vasc* or cerebral vasc or cva or apoplex or SAH ) or AB ( stroke or poststroke or post-stroke or cerebrovasc* or brain vasc* or cerebral vasc or cva or apoplex or SAH )

S3 .TI ( brain* or cerebr* or cerebell* or intracran* or intracerebral) or AB ( brain* or cerebr* or cerebell* or intracran* or intracerebral )

S4 .TI (ischemi ${ }^{\star}$ or ischaemi ${ }^{\star}$ or infarct ${ }^{\star}$ or thrombo ${ }^{\star}$ or emboli* or occlus $^{\star}$ ) or AB (ischemi ${ }^{\star}$ or ischaemi ${ }^{\star}$ or infarct $^{\star}$ or thrombo* $^{\star}$ or emboli $^{\star}$ or occlus* )

S5.S3 and S4

S6 .TI ( brain* or cerebr* or cerebell* or intracerebral or intracranial or subarachnoid ) or AB ( brain* or cerebr ${ }^{\star}$ or cerebell* or intracerebral or intracranial or subarachnoid)

S7 .TI ( haemorrhage* or hemorrhage* or haematoma* or hematoma* or bleed ${ }^{\star}$ ) or AB ( haemorrhage* or hemorrhage* or haematoma* or hematoma* or bleed*)

S8.S6 and S7

S9.(MH "Hemiplegia")

S10 .TI ( hemipleg* or hemipar* or paresis or paretic) or AB ( hemipleg* or hemipar* or paresis or paretic)

S11 .(MH "Left Hemisphere Injuries") OR (MH "Right Hemisphere Injuries") OR (MH "Brain Injuries")

S12.(MH "Upper Extremity+")

S13 .TI ( upper limb* or upper extremit* or arm or shoulder or hand or axilla or elbow* or forearm* or finger* or wrist ${ }^{\star}$ ) or AB ( upper limb* or upper extremit* or arm or shoulder or hand or axilla or elbow* or forearm* or finger ${ }^{\star}$ or wrist $^{\star}$ )

S14.(MH "Constraint-Induced Therapy")

S15.(MH "Restraint, Physical")

S16.(MH "Immobilization")

S17.(MH "Taping and Strapping")

S18.(MH "Exercise+")

S19.(MH "Therapeutic Exercise+")

S20.(MH "Physical Therapy/MT")

S21.(MH "Slings") OR (MH "Splints")

S22.(MH "Casts")

S23.(MH "Task Performance and Analysis")

S24 .TI ( constrain* or restrain* or immobil*) or AB ( constrain* or restrain* or immobil* )

S25 .TI ( $\mathrm{mCIT}$ or CIT or "Cl therapy" or "forced use" or splint* or cast or casts ) or AB ( mCIT or CIT or "Cl therapy" or "forced use" or splint* or cast or casts )

$\mathrm{S} 26 . \mathrm{S} 1$ or $\mathrm{S} 2$ or $\mathrm{S} 5$ or $\mathrm{S} 8$ or $\mathrm{S} 9$ or $\mathrm{S} 10$ or $\mathrm{S} 11$

$\mathrm{S} 27 . \mathrm{S} 12$ or $\mathrm{S} 13$

$\mathrm{S} 28 . \mathrm{S} 14$ or $\mathrm{S} 15$ or $\mathrm{S} 16$ or $\mathrm{S} 17$ or S18 or S19 or S20 or S21 or S22 or S23 or S24 or S25

S29.S26 and S27 and S28

\section{Appendix 5. AMED (Ovid) search strategy}

AMED (Ovid)

1. cerebrovascular disorders/ or cerebral hemorrhage/ or cerebral infarction/or cerebral ischemia/ or cerebrovascular accident/ or stroke/

2. brain injuries/ or hemiplegia/

3. (stroke\$ or cva or poststroke or post-stroke).tw.

4. (cerebrovasc\$ or cerebral vascular).tw.

5. (cerebral or cerebellar or brain\$ or vertebrobasilar).tw.

6. (infarct\$ or isch?emi\$ or thrombo or emboli\$ or apoplexy).tw.

7. 5 and 6

8. (cerebral or brain or subarachnoid).tw.

9. (haemorrhage or hemorrhage or haematoma or hematoma or bleed\$).tw.

10. 8 and 9

11. (hempar\$ or hemipleg\$ or brain injur\$).tw. 
12. 1 or 2 or 3 or 4 or 7 or 10 or 11

13. exp arm/

14. (upper limb\$ or upper extremit\$ or arm or shoulder or hand or axilla or elbow\$ or forearm\$ or finger\$ or wrist\$).tw.

15. 13 or 14

16. restraint physical/

17. exercise/ or exercise movement techniques/ or exercise therapy/

18. immobilization/ or casting/ or splinting/

19. physical therapy modalities/

20. splints/

21. "recovery of function"/

22. (constrain\$ or restrain\$ or immobili\$).tw.

23. (mCIT or CIT or "Cl therapy" or "forced use" or splint\$ or cast or casts).tw.

24. 16 or 17 or 18 or 19 or 20 or 21 or 22 or 23

25. 12 and 15 and 24

\section{Appendix 6. PEDro search strategy}

PEDro is a web-based database of randomised controlled trials and systematic reviews relevant to physiotherapy. The following search strategy was used.

Abstract and Title: constraint, stroke, cva, poststroke, hemi, brain injur, ${ }^{\star}$ matoma, bleed, cerebrovasc, cerebral, brain, infarct, thrombo. Body part: upper arm, shoulder or shoulder girdle / forearm or elbow / hand or wrist.

All search terms in the title or abstract were combined with body part descriptors using the AND operator.

\section{FEE D B A C K}

\section{Risk of bias, 25 May 2017}

\section{Summary}

Date of Submission: 25-May-2017

Name: Martin Vuillème

Email Address: martin.vuilleme@gmail.com

Role: Volunteer translator

Comment: (Singh 2013) is assessed by the authors as being at low risk of bias in the "performance bias and detection bias" domain. The support for this judgement is [Quote: "the rater ... was not blinded to the study"]. This is not coherent with the assessment of the authors, as their methods explicitly say that studies with no blinding will be scored as high risk. The full quote from Singh is: "There are few limitations of our study like: Small sample size due to limited stroke subjects, the rater who was not blinded to the study.".

Singh P, Pradhan B (2013). Study to assess the effectiveness of modified constraint-induced movement therapy in stroke subjects: a randomized controlled trial. Annals of Indian Academy of Neurology, 16(2),180. doi:10.4103/0972-2327.112461

\section{Reply}

Dear Martin Vuillème

Thank you for reporting back to us the incoherent evaluation of the risk of bias of the study by Singh et al (1) in the text of our review. The judgment of the "Performance bias and detection bias" domain in the Risk of bias table for this study has been corrected to "high risk". The text of the review on risk of bias has also been corrected.

The overall quality of evidence or the conclusions of the review have not changed (2).

Best regards, 
Valeria Sirtori, Davide Corbetta, Greta Castellini, Lorenzo Moja, Roberto Gatti

References:

1. Singh P, Pradhan B. Study to assess the effectiveness of modified constraint-induced movement therapy in stroke subjects: A randomized controlled trial. Annals of Indian Academy of Neurology. 2013; 16(2): 180.

2. Corbetta D, Sirtori V, Castellini G, Moja L, Gatti R. Constraint-induced movement therapy for upper extremities in people with stroke. Cochrane Database of Systematic Reviews 2015, Issue 10. Art.No.:CD004433. DOI: 10.1002/14651858.CD004433.pub3."

\section{Contributors}

Martin Vuillème: commentator

Valeria Sirtori, Davide Corbetta, Greta Castellini, Lorenzo Moja, Roberto Gatti: review authors

WHAT'S NEW

\begin{tabular}{lll}
\hline Date & Event & Description \\
\hline 1 September 2017 & Feedback has been incorporated & $\begin{array}{l}\text { A correction has been made to the 'Risk of bias' table for Singh } \\
2013 \text { and the text of the review amended accordingly. }\end{array}$ \\
\hline
\end{tabular}

\section{H IST O R Y}

Protocol first published: Issue 4, 2003

Review first published: Issue 4, 2009

\begin{tabular}{lll}
\hline Date & Event & Description \\
\hline 31 May 2015 & New search has been performed & $\begin{array}{l}\text { We updated the searches to January 2015 and have included } \\
\text { several new trials in the review; the previous review included 19 } \\
\text { trials while the current version includes 42 trials involving 1453 } \\
\text { participants }\end{array}$ \\
\hline 31 May 2015 & $\begin{array}{l}\text { New citation required and conclusions } \\
\text { have changed }\end{array}$ & $\begin{array}{l}\text { New trials included in the review led to changes of the estimated } \\
\text { effects of treatment. Statistical significance and meaningful dif- } \\
\text { ferences were lost for clinically relevant outcomes, changing our } \\
\text { interpretation of results. Our conclusions are now more conserv- } \\
\text { ative }\end{array}$ \\
\hline 24 April 2008 & Amended & Converted to new review format. \\
\hline
\end{tabular}

\section{CONTRIBUTIONS OF AUTHORS}

This systematic review has been written on the basis of the review authors' clinical experience (VS, DC and RG). All review authors contributed to all stages of the review. Three review authors (VS, DC and GC) independently assessed study selection, data extraction and methodological quality. We resolved disagreements by consensus, and consulted a fourth review author (RG) if disagreement persisted. LM provided insight into epidemiological and statistical methods. VS, DC, RG and LM drafted different parts of the manuscript.

\section{DECLARATIONS OF INTEREST}

Davide Corbetta: none known.

Valeria Sirtori: none known.

Greta Castellini: none known.

Lorenzo Moja: none known.

Roberto Gatti: none known. 


\section{SOURCESOF SUPPORT}

\section{Internal sources}

- None, Other.

\section{External sources}

- None, Other.

- National Institute for Health Research (NIHR), UK.

This project was supported by the National Institute for Health Research, via Cochrane Incentive Award funding to the Cochrane Stroke Group. The views and opinions expressed therein are those of the authors and do not necessarily reflect those of the Systematic Reviews Programme, NIHR, NHS or the Department of Health.

\section{DIFFERENCES BETWEEN PROTOCOL AND REVIEW}

In 2003, based on the-then existing evidence about CIMT, the protocol for this review was published in The Cochrane Library (Sirtori 2003); subsequently, the same authors found that the protocol did not reflect the increasing variability among potentially relevant primary studies and the review was out of date in terms of systematic review methodology. The main shortcomings in the protocol related to:

- the inclusion criteria in terms of participants, interventions and outcome measures, as they were too restrictive and narrowly focused, being de facto a subgroup analysis (Higgins 2011). Outcome measures added during the systematic review process were not present in the original protocol of this review. These items were perceived as being of importance for physiotherapists and people with stroke, and offer a more complete picture about the efficacy of this technique;

- the Methods section, which did not provide enough detail to ensure replicability.

We have now revised these sections extensively, with the following main amendments.

- Background: to reflect what is known in 2015.

- Objectives: to include studies investigating not only CIMT but also modified CIMT (mCIMT) and Forced Use (FU) therapy, which are closely related and belong to one specific class of intervention.

- Types of interventions: to include interventions that differ widely in duration and intensity.

- Types of outcome measures: new secondary outcomes were added in order to offer physiotherapists and people with stroke a more complete picture of the efficacy of this technique.

- Methods of the review: to provide enough detail to allow repetition of the review by other researchers.

We considered these legitimate reasons to modify the original protocol.

I N DEX TERMS

\section{Medical Subject Headings (MeSH)}

*Stroke Rehabilitation; *Upper Extremity; Exercise Movement Techniques [ ${ }^{\star}$ methods]; Immobilization [*methods]; Paresis [etiology] [*rehabilitation]; Randomized Controlled Trials as Topic; Stroke [complications]; Time Factors

\section{MeSH check words}

Humans 